Research Report 259/Finland Research Report 2011:15/Sweden
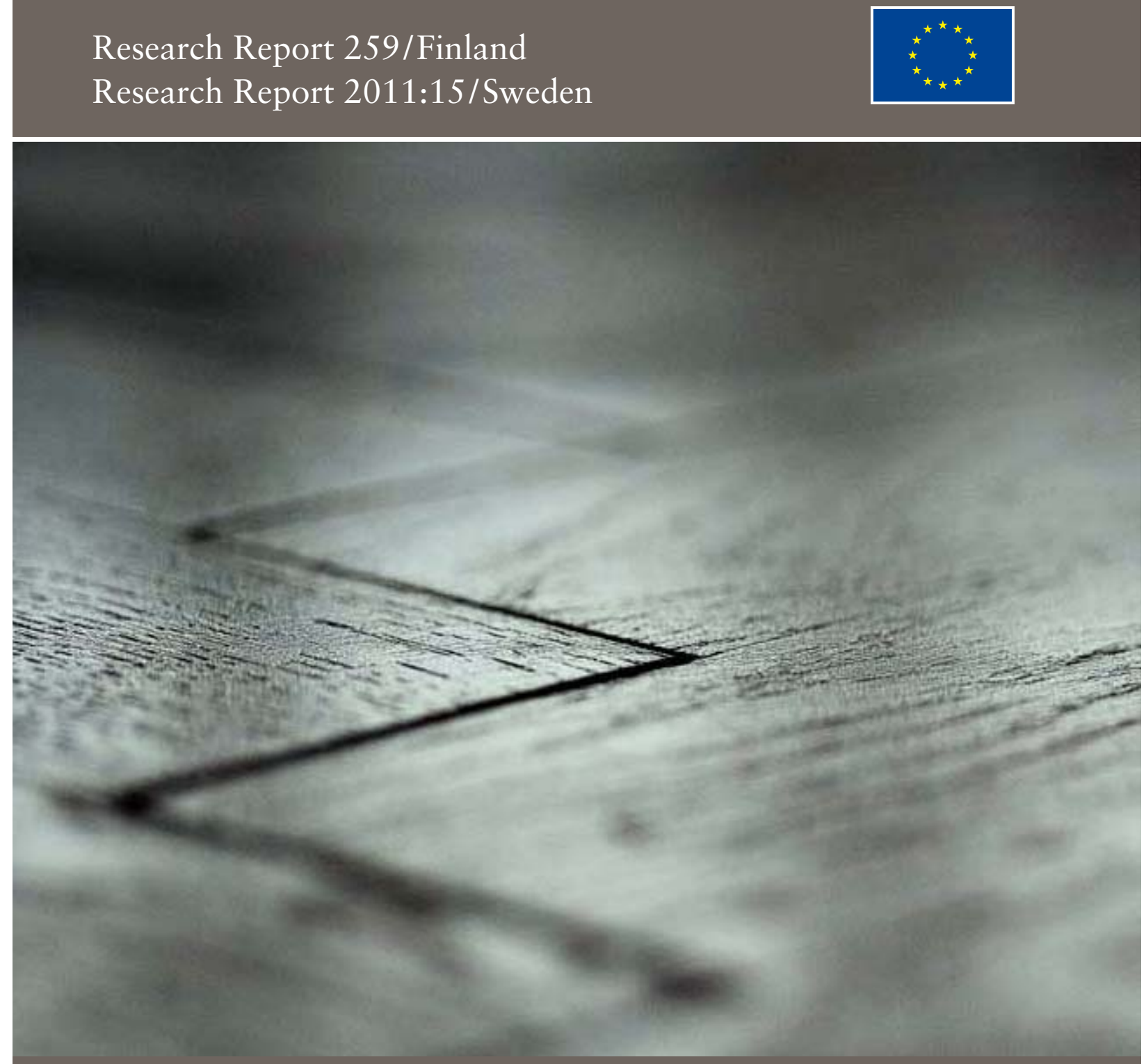

Homicide in Finland, the Netherlands and Sweden

A First Study on the European

Homicide Monitor Data

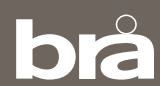

National Council for Crime Prevention (a)

National Research Institute of Legal Policy
Fis

Universiteit Leiden 


\title{
Homicide in Finland, the Netherlands and Sweden
}

\author{
A First Study on the European \\ Homicide Monitor Data
}

\author{
Sven Granath \\ Johanna Hagstedt \\ The National Council for Crime Prevention, Sweden
}

Janne Kivivuori

Martti Lehti

The National Research Institute of Legal Policy, Finland

\section{Soenita Ganpat \\ Marieke Liem \\ Paul Nieuwbeerta}

The Institute for Criminal Law and Criminology

at Leiden University, The Netherlands

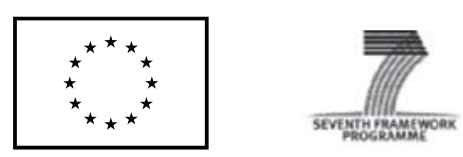

Co-financed by the European Union, European Commission, Directorate - General Home Affairs, Funding programme on Prevention of and Fight against Crime (ISEC), under grant agreement $\mathrm{nr}$ JLS/2007/ISEC/434, and the Seventh Framework Programme.

This publication reflects the views only of the authors, and the European Commission cannot be held responsible for any use which may be made of the information contained therein. 
The Swedish National Council for Crime Prevention - a centre of knowledge on crime and measures to combat crime

The Swedish National Council for Crime Prevention (Brottsförebyggande rådet - Brå) works to reduce crime and improve levels of safety by producing data and disseminating knowledge on crime, crime prevention work and the justice system's response to crime.

\section{The National Research Institute of Legal Policy}

The NRILP (Oikeuspoliittinen tutkimuslaitos) is a research institute operating in connection with the Finnish Ministry of Justice. The institute practices independent research on legal policy and crime; monitors and analyses policy and crime trends; promotes national and international cooperation in the research of its field; and takes part in researcher training in cooperation with universities.

The Institute for Criminal Law and Criminology at Leiden University Leiden University is the oldest university in the Netherlands (founded in 1575 ) and is one of Europe's foremost research universities. The Institute for Criminal Law and Criminology conducts education and research in the field of criminal law and criminology. One of its main research areas is the study of national and international patterns of homicide. This research takes place within the context of the research programme Criminal Justice: Legitimacy, Accountability, and Effectivity.

Production:

Brottsförebyggande rådet/The Swedish National Council for Crime Prevention

Box 1386, Tegnérgatan 23, SE-11193 Stockholm, Sweden

Phone +46 (0)8 40187 00, fax +46 (0)8 41190 75, e-mail info@bra.se, www.bra.se

Authors: Soenita Ganpat, Sven Granath, Johanna Hagstedt, Janne Kivivuori,

Martti Lehti, Marieke Liem and Paul Nieuwbeerta.

Cover and layout: Anna Gunneström

Figures and maps: Helena Halvarsson

Cover photo: Cecilia Bergman

Print: Edita Norstedts Västerås 2011

CThe Swedish National Council for Crime Prevention, The National Research Institute of Legal Policy and

The Institute for Criminal Law and Criminology at Leiden University

The Swedish National Council for Crime Prevention

Research Report 2011:15

ISBN 978-91-86027-77-3

URN:NBN:SE:BRA-441

ISSN 1100-6676
National Research Institute of Legal Policy

Research Report 259

ISBN 978-951-704-404-2

ISSN 1797-562X 


\section{Contents}

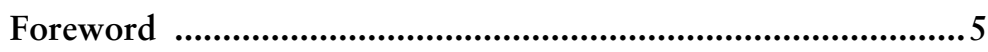

Acknowledgments ......................................................................

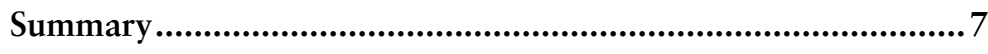

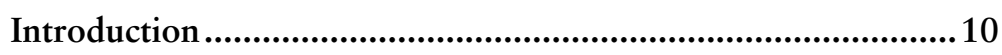

Aim and research questions...................................................11

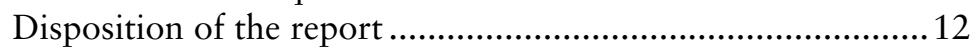

Global, EU and national perspectives on homicide...................12

Socio-demographic variables...................................................... 25

Data and methods ...........................................................................

The European Homicide Monitor data ...................................... 31

The dark figure of homicide ...................................................... 36

The impact of differences in health care resources................... 37

Additional data used in the study .............................................. 38

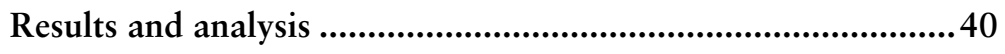

Homicide rates and regional variations ....................................40

Incident characteristics .............................................................. 44

Victim characteristics .............................................................. 70

Perpetrator characteristics ....................................................... 79

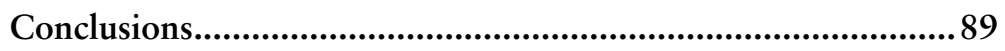

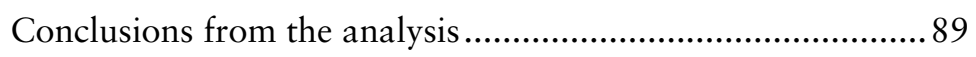

Possible explanations …………………................................ 92

Methodological conclusions, limitations and

suggested improvements............................................................93

Recommendations for future research ..................................... 95

The future of the European Homicide Monitor........................99

Appendix A. Description of national homicide

data in Finland, the Netherlands and Sweden.........................109

Appendix B. The European Homicide Monitor

Guidebook and Coding Manual 2011. 



\section{Foreword}

Crimes that lead to homicide through murder, manslaughter or aggravated assault involve the most severe types of violence. Within the EU there is no Union-wide systematic collection of data regarding lethal violence. Therefore, questions about the incidence and characteristics of homicides within EU member states as well as comparisons between countries regarding trends, levels and structural similarities and differences have remained unanswered.

In order to enable comparisons of lethal violence within the EU and other European countries, The National Council for Crime Prevention in Sweden, The National Research Institute of Legal Policy in Finland and the department of Criminal Law and Criminology of Leiden University in the Netherlands received funding from the EU for a three-year project between the years 2009 and 2011. The Project has been coordinated by the lead partner, the National Council for Crime Prevention in Sweden.

The project is unique in that one of its main goals has been to lay the foundations for a joint database on lethal violence among EU member states, providing new opportunities for detailed comparisons and analyses. Another goal has been to undertake a first comparative analysis of lethal violence in the three member states. The results of this analysis will be presented in this report.

It is the hope and expectation of the three project members that the project will lead to the establishment of the foundations of a European Homicide Monitor (EHM) and that the database can and will be used by other European states by adding national data to the international dataset as well as using the data for analyses on lethal violence in Europe.

Stockholm in August 2011

Jan Andersson

Director-General 


\section{Acknowledgments}

The project members would like to thank Professor Martin Killias at the University of Lausanne in Zurich, Switzerland, and Professor William Alex Pridemore of Indiana University in Bloomington, Indiana, USA, for reviewing our manuscript and Jakub Boratynski, Head of Unit 'Fight against Organized Crime', European Commission Directorate-General for Home Affairs for participating in the European Homicide Monitor session at the Stockholm Criminology Symposium.

We would also like to thank our project steering group: $\mathrm{Di}$ rector-General Jan Andersson, at the National Council for Crime Prevention, Director-General Tapio Lappi-Seppälä at the National Research Institute of Legal Policy and Professor Paul Nieuwbeerta at the Institute for Criminal Law and Criminology at Leiden University. Thank you also, to Annika Eriksson, Head of the Department for Research and Development at the National Council for Crime Prevention, Senior Research Analyst Juha Kääriäinen at the Finnish Police College, in Finland and Director Kauko Aromaa at the European Institute for Crime Prevention and Control.

We would also like to recognize the efforts of both national and local institutions for their aid in collecting the data used in the study.

Lastly we would like to extend our gratitude to the European Commission, Director General for Justice, Freedom and Security, and the Prevention of and Fight Against Crime programme for funding this project and to Research Director Janne Kivivuori at the National Research Institute of Legal Policy, again to Professor Paul Nieuwbeerta at the Institute for Criminal Law and Criminology at Leiden University, to Erik Grevholm at the National Council for Crime Prevention, to Mikael Rying at Mid Sweden University for their visionary ideas that led to the realization of this project. 


\section{Summary}

\section{Major findings}

- With regard to many of the homicide characteristics examined, the results indicate a pattern where Finland and Netherlands are at the two "extremes", with Sweden usually placed in the middle. One important exception is the homicide rate, where Sweden has the lowest and Finland has the highest homicide rate per 100,000 population.

- When it comes to homicide structure, the two Nordic countries are in many ways more similar to one another than they are to the Netherlands. Although all the identified homicide types exist in all three countries, homicides committed in Finland and Sweden are often characterized by acquainted men killing each other in situations where alcohol is an important factor. In the Netherlands a larger proportion of homicides were associated with a criminal milieu, with slightly younger perpetrators, a higher proportion of homicides committed outdoors with firearms and a lower clearance rate.

- Expressive motives were most often found in Finland and instrumental motives were most often found in the Netherlands.

- The difference in overall homicide rates between the Netherlands and Sweden was mainly consisted of organized crimerelated homicides outdoors, while the difference in homicide rates between Finland and Sweden on the one hand and the Netherlands on the other consisted mainly of homicides between intoxicated acquaintances.

- Similarities between the three countries include the time of the homicides (predominantly at night-time) and what day of the week they occur (mainly during weekends).

- In all three countries the victims and perpetrators are largely characterized by being males born in the same country that the crime took place in. A large proportion of these men are between the ages of 25 and 64 . 


\section{The importance of the EHM}

- The study shows that building a homicide database on a European level is feasible.

- Research of the kind carried out in this project has not previously been carried out. The data in the study are unique and have been compiled for the specific purpose of creating directly comparable data between Finland, the Netherlands and Sweden.

- The EHM offers standardized comparability for countries and regions to compare homicide characteristics, patterns and trends.

- Since homicide is not randomly distributed in physical and social space, the EHM could help governments and agencies to target homicide prevention efforts. The database offers a data source for the evaluation of homicide prevention policies.

\section{Key limitations}

- National homicide data from the three countries have been combined to form the database. In its current state the contents are to a large extent based on existing data in the national databases, which causes a substantial number of unknown values for some variables and variable values.

- There are definition problems for some variables and, although the effects are judged to be minor, cases legally defined as assault leading to death are not included in the Dutch data.

\section{Suggested improvements}

- The primary goal is to reduce the number of unknown values for variables where the results are distorted or difficult to interpret due to missing cases.

- Before encouraging other countries to join the EHM, the variable list and coding manual must be modified so that it contains a set of ideal variables and values and presents strict definitions to some problematic variables.

\section{Future research}

- The EHM offers numerous possibilities for future research, including looking at any of the variables not explored in the report, studying small homicide types, individual characteristics of victims and perpetrators or analysing the data from a 
law-oriented perspective concerning judicial definitions and sentencing practices.

- The data can also be studied from a more theoretical or policyoriented perspective, testing hypotheses, measuring impacts of health care resources, changes in alcohol policy etc.

- Valuable lessons can be learned by comparing the EHM data to mortality statistics or data from other homicide monitors in order to ensure high data quality and identify what characterizes homicides in Europe from homicides in other parts of the world.

- When data are available for a longer set of years, additional research can be conducted on the trends and developments in homicide rates and characteristics.

\section{The future of the EHM}

- All of the project partners are committed to continuing the work on the EHM by gathering data nationally and combining data at regular intervals.

- The project partners hope that other research institutions will find an interest in the results and the data used in this study.

- The project partners hope that other member states will compile national data in the format used in the project, laying the foundations for a European Homicide Monitor that includes as many European countries as possible.

- It is suggested that the EU takes an active role in the expansion of the monitor, because it provides a unique data source for research and could be an important part of European research infrastructure, helping both policy targeting and evaluating what works in homicide prevention. 


\section{Introduction}

Homicides are crimes involving the most severe types of violence. Homicides lead to high social costs due to loss of life and human suffering, which is why they are assigned substantial resources in connection to criminal investigations, court cases and the implementation of penal sanctions. Few countries have comprehensively studied the costs of interpersonal violence, but the existing studies indicate that they are significant. For example, in Scotland estimates suggest that violent crime results in annual economic losses of about 3.5 billion Euros (Sethi et al. 2010, 24). Homicides also have a great effect on perceptions of insecurity in society, leading to the erosion of human and social capital and negative effects on community development. Systematic knowledge about lethal violence is necessary for assessing factors that foster lethal violence, preventive measures, sentencing policy and the punishment and treatment of perpetrators. Homicides in the European Union member countries constitute a crime type with a relatively small dark figure. This makes them particularly suitable for international comparisons and a relatively good indicator of the development in violent crime in general (Eisner 2008).

Currently, the European Union does not have any homogenous comparable data regarding lethal violence. Cause-of-death statistics as well as national criminal statistics can be used to assess the frequency of homicides in different countries, but their comparability is not without problems (Smit et al. 2011). More detailed national data on the characteristics of homicides are even less comparable due to legal and definitional differences.

In order to improve this situation and enable more reliable comparisons of the characteristics of lethal violence within the European Union, the National Council for Crime Prevention in Sweden, the National Research Institute of Legal Policy in Finland and the Institute for Criminal Law and Criminology of Leiden University in the Netherlands received funding from the European Union to conduct a three-year project between the years 2009 and 2011. The main aim of the project is to lay the foundations for a joint database on lethal violence among the member countries in order to provide new opportunities for detailed comparisons and analyses of homicide. The database has been termed the European Homicide Monitor (EHM). This report is a pilot study on the epidemiology of homicides in Finland, the Netherlands and Sweden, 
based on the dataset created during the project. This report is the first to give a complete and reliable overview of the incidence and patterns of homicide in these three countries.

\section{Aim and research questions}

This research report has two main goals. Since it is the first analysis to be made based on the EHM data, the purpose has been to explore the data regarding content and results as well as to examine them methodologically.

Our first aim has been to conduct a comparative analysis of lethal violence in Finland, the Netherlands and Sweden. The analysis is mainly descriptive and will focus on the similarities and differences in the characteristics and rates of homicidal crime. This aim can be broken down into the following specific research questions:

- How many homicides are committed and what are the homicide rates in each country?

- Which situational characteristics are there?

- Are there any different homicide patterns?

- Who are the victims and perpetrators of these crimes?

- What are the similarities and differences in the three project countries?

- Are there any future research topics that can be explored with the help of the EHM data?

The second aim has been to explore the EHM data from a methodological perspective. Again, as the report contains the first analysis conducted based on the EHM data, it is necessary to pay attention to the strengths and weaknesses of the data. Suggestions can then be made with regard to how we can improve the database in the future and make it as good a tool for comparative homicide research as possible. This aim can be specified into the following research questions:

- Are there any methodological weaknesses and problems associated with the presented variables?

- Are there any possible improvements?

- What are the future methodological prospects? 


\section{Disposition of the report}

In the first part of the report we review earlier homicide research from Sweden, Finland and the Netherlands as well as previous comparative studies on European homicidal crime. After that, homicide trends of recent decades and basic socio-demographic background variables are presented for the three countries. In chapter 2 we discuss the methodology of the study and in chapter 3 we present the results of the analysis, on both case and individual level. In chapter 4, conclusions are drawn and future suggestions and recommendations are made regarding research topics and the future of the EHM.

\section{Global, EU and national perspectives on homicide}

\section{Earlier research}

Current homicide research in Finland, the Netherlands and Sweden can be divided into three major approaches: sociological, historical, and forensic (i.e., psychiatric and psychological). In this chapter we focus on the sociological studies on homicides in these countries over the last couple of decades. They form only a small part of all homicide research published in Finland, the Netherlands and Sweden during this period. Information about the other fields of research can be found in Liem \& Pridemore (2011), among others.

\section{Sweden}

By and large, Sweden's current homicide research is based on the multiple factor approach. In the last decade, some of the most comprehensive works of this kind has been carried out by Rying (2000; 2001; 2007; 2008), who has studied the epidemiology of homicides in Sweden in general and intimate-partner homicides against women in particular during the 1990s and the early 2000s. Rying finds the frequency and characteristics of homicides in Sweden to have remained largely unchanged over the last three decades, although the numbers of women killed by their partners was slightly lower in the beginning of the 2000s than it was in the 1970s (Rying 2007; 2008). The homicides of the last ten years have been studied by Granath with a similar approach (Granath 2007; Brå 2011). According to both Granath and Rying, the majority of all killings in Sweden today occur between victims and offenders with close relations, either within the family, between partners or between male acquaintances. The subgroups of alcohol and drug abusers make up a very large percentage of both perpetrators and adult male victims. Of all homicide perpetrators, 
about $40 \%$ are considered alcohol abusers and about $25 \%$ illegal drug abusers (Granath 2011; Rying 2000).

Wikström $(1991 ; 1992)$ and von Hofer $(1990 ; 2008)$ have combined sociological theory and historical data in their research. Von Hofer (2008) studied historical variations in the frequency of homicides in Sweden for the period 1750-2005. He shows a close linkage between the changes in alcohol consumption levels and homicide rates during the entire period. The tradition of explaining changes in homicide rates by changes in alcohol consumption levels and patterns has been prevalent in both Swedish and Finnish violent crime research for a long time. Besides von Hofer, researchers such as Lenke and Verkko, among others, have supported this theory. The alcohol-dimension is also present in Wikström's studies on context-specific homicide trends in Stockholm in the 20th century. His goal was to find plausible explanations for the longterm changes in aggregated homicide rates from context-specific changes. According to him, the increase in homicide rates in the Stockholm area since the 1960 s was mainly due to a sharp increase in homicides by immigrant perpetrators (most of them with alcohol problems). The change in the ethnic composition of homicide perpetrators, i.e. the increase of the proportion of immigrants among them, continued in the 1970s and 1980s, though this could not be seen in the aggregated homicide rates due to a simultaneous decrease in the number of homicides committed by native Swedes.

Lenke's research was focused on the connections between alcohol and drug policies and violent crime levels. However, he also wrote several studies on the links between general politics and violent crime (Lenke 1990, 2009a, 2009b, 2009c). Lenke argued (2009c) that those links can be divided into two main categories: political circumstances that create violence directly and political circumstances that create violence indirectly. In the first category, direct violence functions as an accepted method of conflict resolution. In the second category, violence is the result of the frustrations created by the existing political system (social, economic, and political). According to Lenke, frustrations linked to the political system explained to a large extent the homicide rate differences between Finland and Sweden in the 20th century.

\section{Finland}

Modern sociological homicide research in Finland goes back to Verkko, who wrote several theoretical studies on homicidal crime in the 1930s and 1940s. In Finland, Verkko was the initiator of the tradition of interpreting homicide rate changes with changes in patterns and levels of alcohol consumption. However, he is perhaps best remembered internationally because of his statistical analyses on gender-related and crime level-related regularities in international homicide trends (Verkko 1951). He also laid the empirical 
foundations of Nordic comparative homicide research by systematizing and publishing the Swedish and Finnish historical cause-ofdeath data on homicides (Verkko 1948). After Verkko, there was a relatively long gap before homicide studies were resumed. The new research can be described as empirical or as a multiple factor approach which seeks to understand homicide by disaggregating it. This tradition, represented by the studies of Hakko, Kivivuori, Lehti, Savolainen and Viljanen, among others, describes how the causes of lethal violence are located in the socio-demographic structure of society as well as in the recurring temporal and spatial dimensions and rhythms of everyday life (Hakko 2000; Kivivuori 1999; Kivivuori 2002; Kivivuori \& Lehti 2006; Lehti \& Kivivuori 2005; Savolainen \& Lehti \& Kivivuori 2008; Savolainen \& Messner \& Kivivuori 2005; Viljanen 1983). The central themes in these studies have been the role of alcohol, alcohol abuse and social marginalization in criminal violence (Kivivuori \& Lehti 2010).

The works of Ylikangas again represent a combination of sociological theory and historical research. He explains historical variations in homicide levels by incorporating them under more general law-like propositions concerning human motivation and its embeddedness in structural and cultural conditions (Ylikangas 1998b). The research of Ylikangas has dealt mainly with connections between economic processes and crime in pre-industrial Finland, but his work also comprises studies on more recent phenomena of homicidal crime (see, for example, Ylikangas 1976; Ylikangas 1990; Ylikangas 1998a). The historical and cultural causes of the homicide trends of the 20th century have also been analysed by, for example, Lehti (2001), Pajuoja (1987) and Rajala (2004). In addition, Pajuoja has published studies on the dark figure of homicide (Pajuoja \& Salminen 1996) and on the forensic psychiatric examination process of homicide perpetrators (Pajuoja 2005).

In recent years, several studies have been published on homicide subtypes - for example, on female homicide perpetrators (Putkonen 2003; Weizmann-Henelius 2004), juvenile homicide offenders (Hagelstam \& Häkkänen 2006; Kaipainen 1996; Lehti 2007; Putkonen 2008), filicides (Haapasalo \& Petäjä 1999; Vanamo \& al. 2001), patricides (Säävälä 2001), infanticides (Ervasti 1995), homicide recidivists (Paanila 2004), and homicide-suicides (Kivivuori \& Lehti 2003; Nikunen 2005). Most of them have been based on forensic-psychiatric examination of the data, which form the main source for psychiatric and psychological homicide research in Finland today. This research is carried out at state psychiatric hospitals and connected universities. Many of the researchers are colleagues or pupils of Virkkunen (e.g., Eronen, Hakola, Laajasalo, Linnoila, Tiihonen) and their scientific work has been closely interconnected. One of the central themes of the research 
has been the biochemical aspects of violent behaviour (Kivivuori \& Lehti, 2010).

\section{The Netherlands}

In the Netherlands, today's sociological homicide research focuses on four main areas: epidemiology, victims and perpetrators, homicide subtypes, and sentencing policies. Although historical homicide studies have a long tradition in the Netherlands, sociological research of homicides emerged as late as in the 1990s. Until then, epidemiological homicide research was virtually non-existent, partly because of official databases being either inaccurate or not allowing for the matching of victim, perpetrator and incident characteristics (Leistra \& Nieuwbeerta 2003). Homicides were also not considered a very important topic for criminological research, because of their relatively small number (Liem \& Ganpat 2011).

Currently, epidemiological research is mainly based on national homicide data and involves the description of incident, perpetrator and victim characteristics of a particular year (Bijleveld \& Smit 2006; Smit, Bijleveld, \& Zee 2001) or multiple years combined (Leistra \& Nieuwbeerta 2003; Nieuwbeerta \& Leistra 2007; Smit $\&$ Nieuwbeerta 2007). The amount of detail available on individual homicides in these studies has often been rather small (Liem \& Ganpat 2011).

Recent studies on homicide subtypes relating to the relationship between victim and perpetrator include studies on intimate partner homicides (De Boer 1990; Fuldauer 1994), child homicides (Brants \& Koenraadt 1998; Liem \& Koenraadt 2008a; Verheugt 2007) and multiple family homicides (Liem \& Koenraadt 2008b), homicide-suicides (Liem 2010; Liem \& Koenraadt 2007; Liem \& Nieuwbeerta 2010; Liem, Postulart \& Nieuwbeerta 2009), parent homicides (Koenraadt, 1996), homicides against prostitutes (Van Gemert 1994b), and homicides against older homosexual men (Van Gemert 1994a). Other homicides outside the family realm, such as homicides in connection with arguments have hardly been studied (Liem \& Ganpat 2011). The majority of these studies have relied on data from forensic psychiatric reports and police records.

A third area of homicide research focuses on specific homicide subtypes according to motive, including criminal liquidations (Van de Port 2001) and sexual homicides (Van Beek 1999). Specific attention has also been devoted to honour-related homicides (Nauta \& Werdmölder 2002; Van Eck 2001; Yecilgöz 1995). Because of the rare occurrence of such events, most studies conducted in this area are based on a small number of cases and, therefore, take on a qualitative approach (Liem \& Ganpat 2011).

A final area of research concerns the sentencing of homicide offenders (Johnson et al. 2010) and recidivism of homicide offenders (Vries, Liem, \& Nieuwbeerta 2010). These studies have relied on 
national data stemming from the Dutch Homicide Monitor (Liem \& Ganpat 2010).

\section{Comparative European homicide research}

This report provides a comparative study of the three European countries whose homicide research traditions have been briefly described above. Needless to say, there have been prior studies comparing rates and patterns of homicide in various European countries. It can even be argued that the European homicide research tradition began with a deeply comparative research interest. After all, Verkko's laws of homicide patterns were largely based on international comparisons. He concluded that the proportion of female victims was relative to the overall homicide rate (the higher the overall rate, the lower the share of female victims) and showed that this was indeed the case in European homicide comparisons (Verkko 1951).

Today, the basic idea of Verkko's laws remains sound: homicides committed by males and young males are the most variable segment of homicidal crime. If this segment is high, the proportion of other, more stable homicide types is proportionally low (on the sustained relevance and recent revival of interest in Verkko's analyses, see Kivivuori, Savolainen \& Danielsson 2011). Furthermore, Verkko pioneered the analysis of national differences in homicide rates in Europe. Indeed, the contemporary European homicide map, examined in detail below, has not changed significantly since it was introduced by Verkko (1951).

Arguably, and with important exceptions, European comparative homicide research has been a relatively peripheral field in criminology. The overwhelming presence of the United States as the point of reference in studies on European homicide phenomena may have impeded comparative analyses between European nations (or other European aggregates such as areas or cities). . This comparison constitutes Europe and European countries as test subjects for North American-based findings and theories, downplaying variation within Europe. Indeed, several European scholars have formulated research questions from the point of view of North American-European differences. Thus, Savolainen, Messner and Kivivuori (2000: 51) compared homicide patterns in the United States and Finland. They observed the low frequency of firearms use in Finnish homicides. Similarly, Titterington and Grundies (2007) compared youth homicide in Houston, Texas, and the state of Baden-Württenberg in Germany. They also found that American perpetrators were much more likely to use firearms when committing a homicide.

Apart from these North American-European comparisons, the tradition of comparative analysis within Europe has recently been 
revived by McCall and Nieuwbeerta (2007). In contrast to our present analysis, which is based on nations, they used a dataset of 117 European cities, thus increasing the statistical power of theory testing. Their research supported the link between economic deprivation and homicidal crime. Needless to say, general comparative homicide research often includes European nations and sometimes addresses the particularity of European institutional arrangements and welfare regimes (Savolainen 2000). Some European comparative research has been inspired by the fact that Finland's homicide rate has been consistently higher than the homicide rate of other Nordic countries, a finding that appears to be difficult to explain with standard socio-political variables (Kivivuori \& Lehti 2010). One solution to this riddle has been the peculiar cultural patterns of alcohol consumption, and the manner in which such cultural patterns manifest themselves in the life patterns of seriously marginalized males, a hypothesis supported by Nordic comparative homicide research (Lehti \& Kivivuori 2005). Within alcohol studies, the broader question of the link between alcohol consumption and homicide has been explored using European homicide data. These analyses suggest that the link is particularly pronounced in northern Europe as opposed to central and southern Europe, and significantly associated with detrimental drinking patterns (Bye 2008; Landberg 2010; Rossow 2001). In spite of these contributions, there appears to be considerable room for more descriptive and explanatory homicide comparisons within Europe. In the future, the existence of a European Homicide Monitor could stimulate such work.

\section{Homicide levels in Europe}

Europe is one of the most peaceful regions of the world if measured by homicide rates. According to the International Homicide Statistics (IHS) of the United Nations Office on Drugs and Crime (UNODC) referring to the year 2004, the European Union and East Asia shared the lowest homicide rate among the sixteen subregions of the world. Half of all the countries around the world with annual homicide mortality of less than one victim per 100,000 inhabitants were in Europe and most of them were members of the European Union. 
Figure 1. Average homicide mortality rates in selected countries and the European Union as a whole in 2004-2008 (per 100,000 inhabitants) Source: IHS; WHOSIS. ${ }^{1}$

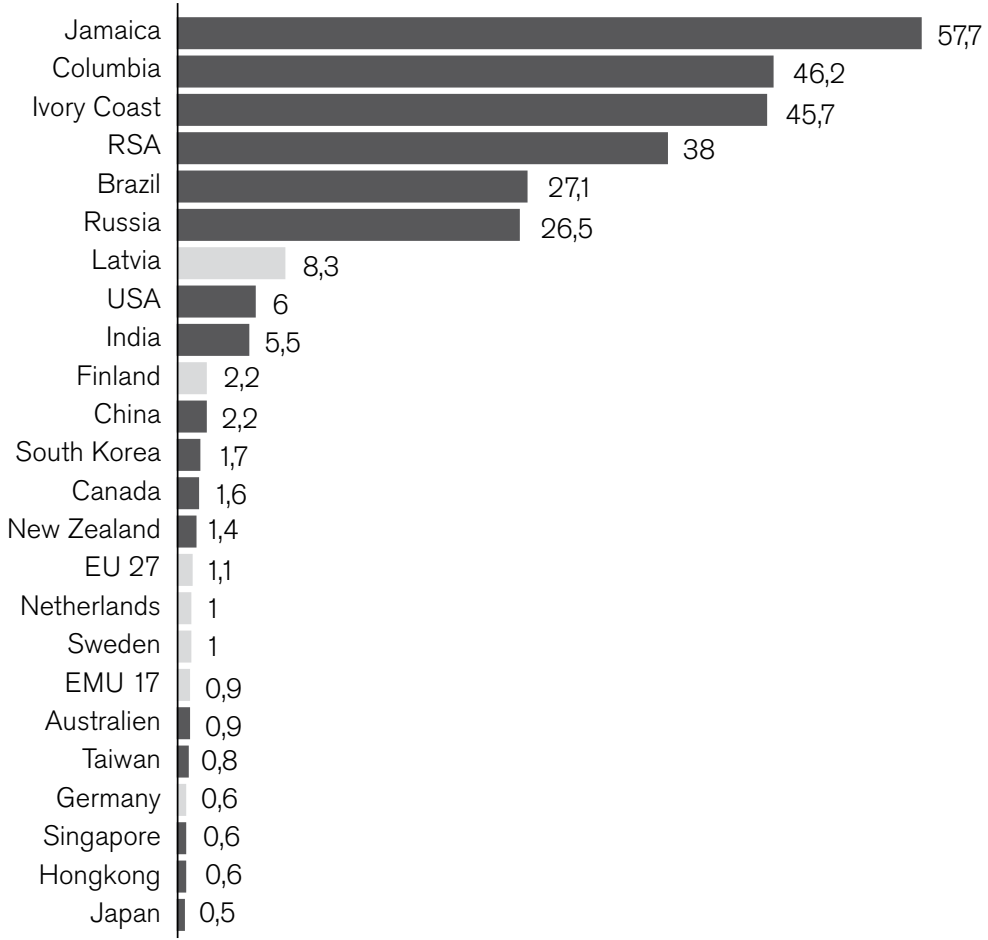

In spite of this, homicides or violent crime in general are not an unimportant problem in the European Union. Each year, 6,000 to 7,000 citizens of the member countries die from homicides. ${ }^{2}$ As previously mentioned, the financial and social costs for these types of crimes are very high (Sethi et al. 2010, 24) considering human costs to friends and family, social costs in terms of social cohesion, costs for investigating and prosecuting and imprisoning offenders etc.

It is also important to note that although Europe in general and the European Union in particular have very low homicide rates by

1 The figure shows the average homicide death rates in the EU, in the project countries, and in the major non-European industrialized countries as well as emerging economies. Currently, Latvia has the highest homicide death rate in the EU and Germany the lowest; Colombia, Jamaica and Ivory Coast are among the countries with the highest homicide mortality rates in the world (EU $27=$ the European Union; EMU 17 = the European Monetary Union).

2 Based on the number of homicide victims in 2004 in the 27 current member countries (WHOSIS). 
global standards, the rate differences between European countries are considerable. In this respect we can roughly divide Europe into two zones (see figure 2). To some extent, this division has existed at least since the 18th century, although the border between the zones has changed over time (Eisner 2008; Lehti 2001; Verkko 1931a; Verkko 1931b; Ylikangas 1976). In general, since the beginning of industrialization until the Second World War, homicide rates in Western and Central Europe were significantly lower than in its eastern and southern peripheries. Since the Second World War the homicide rates in Mediterranean Europe have decreased to western European levels, but the east and the southeast of the continent have preserved their relatively high rates.

Figure 2. Average homicide mortality rates in Europe in 2005-2009 (per 100,000 inhabitants). Source: WHO.

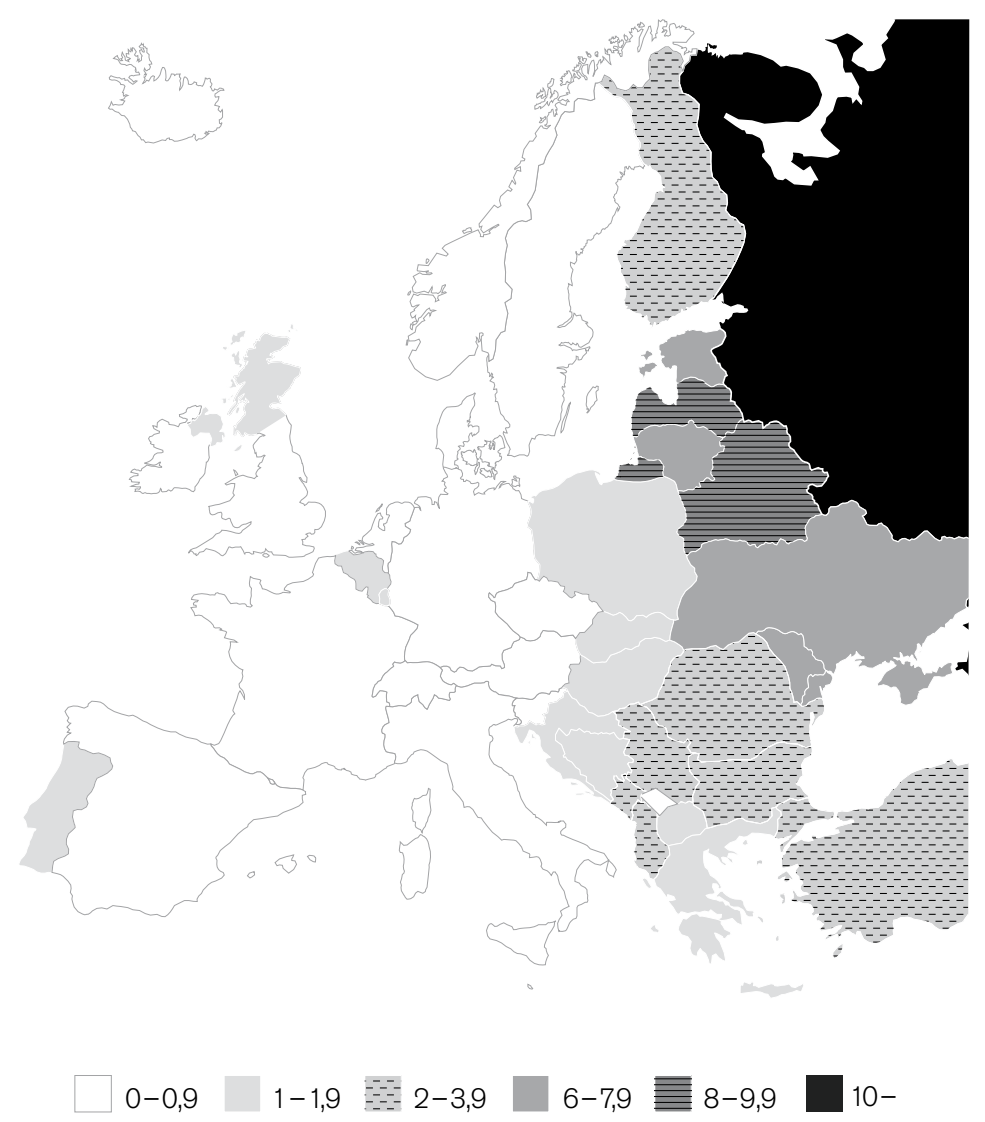


Today, the continental division distinguishing the Western European countries with lower homicide levels from the Eastern European countries with higher homicide levels goes from the Balkans in the south through Scandinavia in the north, dividing, for example, the eastern Balkan countries from the western Balkan ones and Finland from the other Nordic countries. One should note, however, that the differences between the homicide levels of the countries within the eastern side of the map are currently much larger than those in the western side. For example, the Finnish homicide death rate is about twice as high as the Swedish and Dutch rates, while the Estonian rate is nearly four times and the Russian rate over twelve times higher than the Finnish rate.

Based on the demographic characteristics of their homicide mortality, the three countries represent three different European homicide groups - the western European (the Netherlands), the Scandinavian (Sweden) and the north-eastern European (Finland). Thus, they should give us a relatively good general picture of the main characteristic variations, differences and similarities in homicidal crime in these different parts of Europe.

\section{Historical homicide trends}

Cause-of-death data form the best available source for comparisons of the homicide trends of the 20th and 21st centuries in the three countries (Eisner 2008). Over time, there have been differences in definitions and coverage but today those differences are relatively small.

During the years studied (2003-2006), the number of homicide victims registered in the Dutch cause-of-death statistics was 15 per cent lower than in the data used in this study. For Finland and Sweden the number of homicide victims registered in their national cause-of-death statistics were 10 and 5 per cent lower than in the data in this study. It is, however, probable that during the first decades of the 20th century, the differences were larger. It is also probable that cause of death data from the pre-second-world-war period are not fully comparable with those of today in any of the three countries (see, for example, Franke 1994, 87; Kivivuori \& Lehti 2010; Leistra \& Nieuwbeerta 2003, 17-26). In spite of this, cause-of-death data give a reasonably reliable picture of the main trends in homicide mortality in the three countries during the last hundred years. 
Figure 3. Homicide mortality in Finland, the Netherlands, and Sweden in 1900-2009 compared with the average homicide mortality in Western Europe (England, Wales, Scotland, Ireland, Norway, Belgium, France, Italy and Switzerland) per 100,000 inhabitants. Sources: Eisner 2008, 297; von Hofer 2008; Verkko 1948; Statistics Finland; WHOSIS.

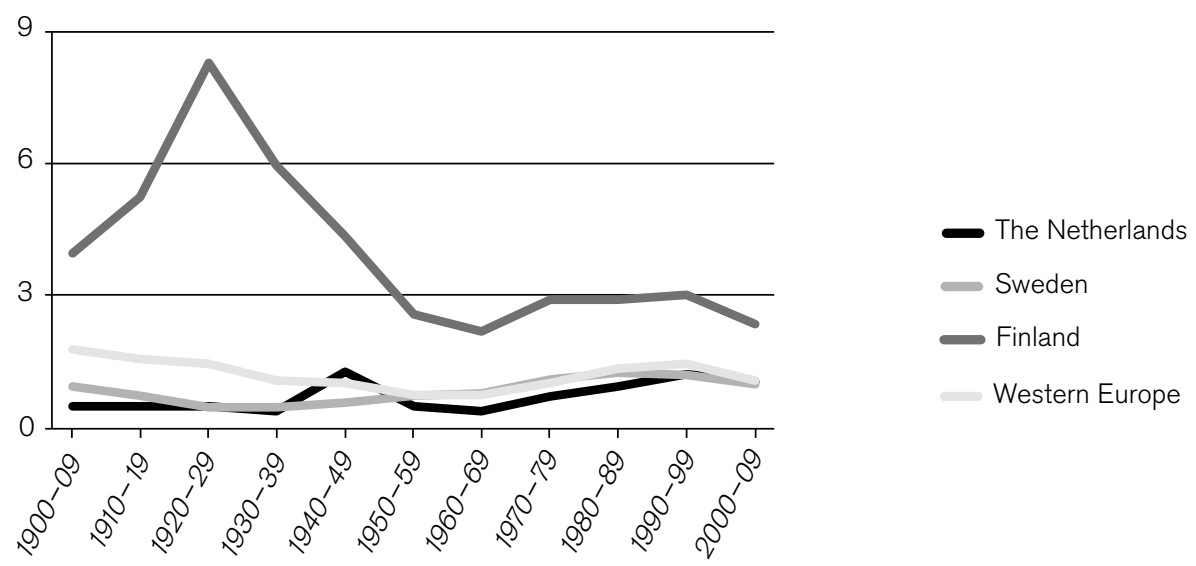

During the last century, Europe has seen a decreasing trend in homicide over the long term. According to Eisner, the mortality rates of western European countries were on average 30 per cent lower in the end of the 20th century than in the beginning of the 20th century. Today the differences are even bigger, as the decline in the rates has continued throughout the continent during the last ten years (Eisner 2008: 297).

However, when we look at the homicide trends of Finland, the Netherlands and Sweden from 1900 until today, it is hard to find any common pattern. The Swedish trend has resembled the average western European trend the most. The average death rate of 2000-2008 was 20 per cent lower than in the 1870s and approximately the same as in the beginning of the 20th century. In Finland and the Netherlands, it is hard to find any resemblance to the general pattern. First, there has been more volatility in the rates than in Sweden or in western Europe in general, mainly because of periods of political and military conflicts, during which interpersonal violence seem to have been higher; the most violent periods being the 1910s and 1920s in Finland, and the 1940s in the Netherlands, although the 1990s was extraordinarily violent in the latter. Second, the overall pattern of the long-term trends has differed in these two countries compared to in Western Europe. In Finland, the current homicide death rate is more or less the same as in the 1870 s and only about 15 per cent lower than in the beginning of the 1900s. In the Netherlands, the current rate is more than twice as high as it was a hundred years ago. 
A constant characteristic throughout the period, from the late 19th century until today, has been the difference between the levels of Finnish homicide mortality and those of Sweden and the Netherlands. Although the difference has decreased, it is still substantial. In 2000-2008, the Finnish homicide death rate was 2.4 times higher than the Swedish rate and 2.2 times higher than the Dutch rate. Throughout the last century the difference has been larger in male mortality than in female mortality, but it has been significant in the latter as well.

The changes of the last fifty years have been more similar in all three countries, although there are some differences. The rapid increase in homicide rates that characterized most European countries in the period from the late 1960s until the early 1990s was shared by all three countries (Eisner 2008). In 1990, the national homicide death rate in Finland was 24 per cent, in Sweden 46 per cent and in the Netherlands 73 per cent higher than in 1969. The peak of the increase, however, was reached in Finland and Sweden earlier than in the Netherlands - in the early 1990s, and was followed by a rapid decrease. In the Netherlands, the entire 1990s continued to be extraordinarily violent, and homicide rates peaked during the second half of the decade. After that, homicide mortality began to decrease in the Netherlands. However, while homicide rates in Finland and Sweden have returned to, or fallen below, those at the end of the 1960s, homicide mortality in the Netherlands is about 80 per cent higher than in $1969 .^{3}$

Figure 4. Trend in homicide mortality in Finland, the Netherlands and Sweden in 1960-2009 $(1969=100)$.

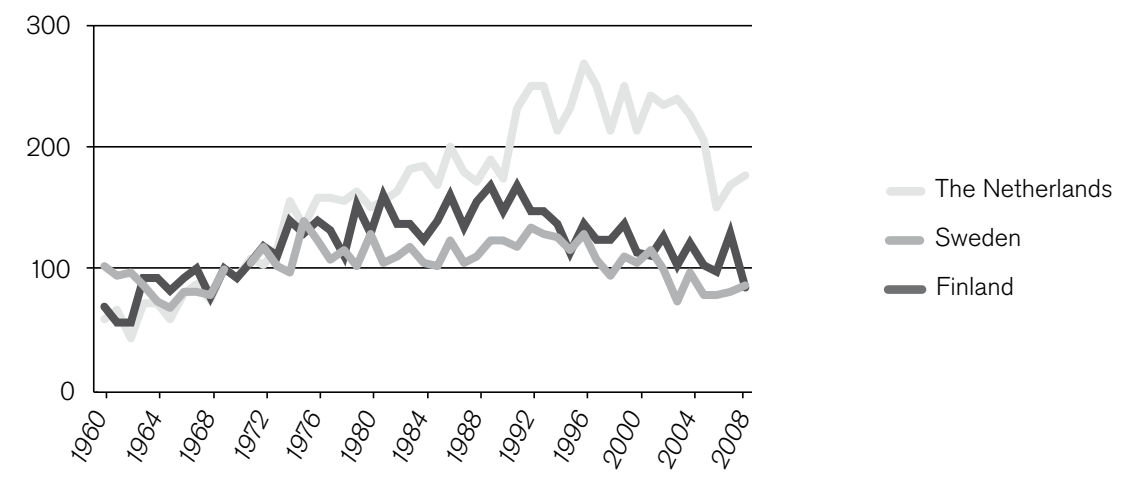

3 The annual homicide mortality rates for 1969 and 2004-2008 (victims per 100,000 inhabitants a year): Finland 1969 2.6; 2004-2008 2.1; Sweden 1969 0.9; 2004-2008 0.9; the Netherlands 1969 0.5; 2004-2008 0.9. 
The homicide trends of the three countries have followed a wider European pattern since the 1960s (Eisner 2008), although the Dutch trend has diverged from it since the early 1990s to some extent.

According to Eisner (2008, 308-311), the pan-European increase in homicide rates starting in the late 1960s and the early 1970s was caused mainly by homicides between young men in public places, who often are strangers to each other. Similarly, the decrease, which started in most Western countries in the early 1990s, was concentrated in this population group. In the 1960s and 1970s, homicides in Sweden and the Netherlands seem to have more or less followed this pattern (von Hofer 1990; von Hofer 2008; Franke 1994; Leistra \& Nieuwbeerta 2003; Loeber \& Slot 2007; Rying 2000, 50). However, after the early 1970s, the increase also comprised older male age categories in Sweden (Rying 2000, 50). In the Netherlands the phenomenon was not restricted to young men either. According to Nieuwbeerta and Leistra (2007), the increase in homicide mortality comprised all male age categories between 15 and 64 years of age, more or less equally. In Finland, the increase took place mainly in the middle-aged male population, especially after the early 1970s (Kivivuori 2002). It should also be noted that in all three countries the increase in female homicide mortality was considerable and followed more or less a similar trend as male mortality.

In the Netherlands, the increase in homicides was concentrated in the three metropolitan areas (Amsterdam, The Hague, Rotterdam), while in homicide rates remained stable or increased only slightly in the rest of the country (Nieuwbeerta \& Leistra 2007, 35-37). In Finland, the pattern was almost the opposite one. Homicide rates increased throughout the country, but most rapidly in peripheral rural areas (Kivivuori 2002; Pajuoja 1995); a trend that Finland shares with Russia (Pridemore 2003). In Sweden, the increase seems to have comprised the whole country, but unlike Finland, homicide rates in urban areas seem to have grown more rapidly than in the countryside (von Hofer 2008; Rying 2000).

\section{Gender differences in homicide trends}

As mentioned above, trends in female and male homicide victimization have followed a fairly identical pattern in all three countries since the 1960s. In Finland and Sweden, female homicide mortality peaked at the turn of the decade from the 1980s to the 1990s. In the Netherlands the peak was reached in the mid-1990s. Currently, the level in Finland is about 10 per cent lower than in 1969, while Sweden has about the same level as in 1969. In the Netherlands, however, the level is about 70 per cent higher now than in 1969. The trend in male homicide mortality in the Netherlands in 
the 1990s diverged from those of the two Nordic countries even more than in female mortality. At its highest, the annual homicide death rate of Dutch men was almost 200 per cent higher than in the late 1960s. In Finland and Sweden, the peaks were more modest and took place earlier.

\section{Possible explanations for the changes in homicide rates}

The homicide wave of the late 1960s have been explained mainly by national phenomena within each of these three countries: the main explanation in the Netherlands has been immigration (Franke 1994) or changes in the organized crime milieu caused by the drug trade (Nieuwbeerta \& Leistra 2007), in Sweden increased alcohol consumption and immigration (von Hofer 1995; Wikström 1992) and in Finland increased alcohol consumption (Kivivuori 2002). All these explanations are based on the changes in homicide characteristics, which took place during the period and were only to some extent similar in these three countries. However, it is easy to agree with Eisner that the pan-Western nature of the phenomena (i.e., the abrupt increase in rates in the late 1960s and early 1970s as well as the abrupt decrease of the rates 20 years later) suggest that these changes cannot be explained by national policies or development alone. The causes of the phenomena must to a certain extent have comprised the whole Western world. Eisner links the homicide wave starting in the 1960s to the fundamental shift in cultural values, such as how to conduct life and interact in public space, which took place in Western societies during the same period. He refers to the theories of Bellah, Turner and Riesman - to the change in the cultural code from the earlier emphasis on observing society's rules and impulse-control to expressive individualism with no constraints whatsoever. Eisner also links the beginning of the decrease in homicide rates in the early 1990s to pan-Western cultural changes: to a new emphasis on self-control and more conservative cultural values. There is plenty of evidence of these kind of rapid and radical cultural changes comprising all Western (and even Eastern European) societies in the 1960s and 1970s. When it comes to the decrease of homicide rates in the beginning of the 1990s, cultural explanations are more controversial and have been criticised by, for example, Killias and Aebi (2000, 55).

In Finland, the Netherlands and Sweden the changes in homicide rates seem neither in the 1960s nor in the 1990s to have been caused by a universal increase in violent behaviour in the entire population, but mainly by changes of behaviour in specific population groups - which differed to some extent from country to country. It is, however, probable that the pan-Western cultural changes 
taking place during the period influenced the forming of these violent sub-groups, and they may have influenced the decrease of violent behaviour in the same groups during the last decade. Whatever the causes, it is obvious that there have been differences, especially in homicide characteristics, in the homicide trends of all three countries during the last five decades, which could not be analysed adequately with existing data sources.

\section{Socio-demographic variables}

In modern criminological theory, differences in levels of lethal violence between countries are often explained by variations and varying combinations of social inequalities, concentration of poverty in poor urban areas, illegal drug markets, organized crime, gun violence, education levels, ethnic discrimination, social marginalization and substance abuse (Liem \& Pridemore 2011). In this chapter we provide a short summary of some basic socio-demographic indices (including alcohol and drug use as well as firearm prevalence) in the three project countries. These indices are often referred to as potential explanations of violent crime patterns.

\section{Population sizes and structure}

All three countries are middle-sized or small by population. The Netherlands is the largest with a population of 16.6 million, while Sweden has 9.3 million residents and Finland 5.4 million, according to Eurostat (2010). The Netherlands is one of the most densely populated regions in Europe while Finland and Sweden belong to the most sparsely populated. In the Netherlands about a fifth, in Sweden just over half and in Finland one fourth of the population live in metropolitan areas with over one million residents (Amsterdam, Rotterdam, The Hague, Stockholm, Gothenburg, Malmoe, Helsinki) (Granath 2011; Liem \& Ganpat 2011).

The populations of all three countries can be regarded as relatively homogenous from a cultural perspective. Immigrants make up 14 per cent of the Swedish population, 11 per cent of the Dutch population and 4 per cent of the Finnish population. ${ }^{4}$ In 2010, the largest foreign-born groups in the Netherlands were Turks, Moroccans, and Germans; in Sweden the largest groups were Finns, Iraqis, and Yugoslavians ${ }^{5}$; and in Finland the largest groups were

4 The percentages refer to the proportion of persons born abroad within population in 2009 (Statistics Netherlands; Statistics Finland; Statistics Sweden).

5 Natives of the former Yugoslavia, who immigrated to Sweden before the 1990s. 
Estonians, Russians, and Swedes ${ }^{6}$ (Granath 2011; Liem \& Ganpat 2011; Statistics Finland).

The average life expectancy for a girl born in Finland, in the Netherlands, or in Sweden is almost identical, and slightly higher than the European Union average. For a boy born in Finland, life expectancy is considerably lower than in the Netherlands or in Sweden, and also lower than in the western European member countries on average (Eurostat 2009). This is also reflected in the gender-balance of the Finnish population, where women comprise a larger percentage than in the Netherlands or in Sweden.

Differences in the age-structure of the population between the three countries are relatively small. The percentage of young adults is one percentage point higher in Sweden than in the Netherlands or in Finland. Their percentage has also grown fairly rapidly in Sweden since the late 1990s, because of the large cohorts of the early1990s (Granath 2011). In theory, differences in gender and age-structures can influence homicide rates. In violent crime research, young adult men are deemed to be the most violence prone demographic group; thus, the larger their share out of population, the higher the potential homicide rates. However, the differences between the three project countries are so small in this respect that they should not have any significant influence on differences in homicide rates between the countries, although they might influence changes in domestic rates over time.

Table 1. Some socio-demographic indices of the Dutch, Finnish and Swedish populations in 2010. Source: Eurostat 2010.

\begin{tabular}{lccc}
\hline Socio-demographic variable & The Netherlands & Sweden & \multicolumn{1}{c}{ Finland } \\
\hline Population (2010; million) & 16.575 & 9.340 & 5.351 \\
Women (percent) & 50.5 & 50.3 & 51.0 \\
0-14-year-olds (percent) & 17.7 & 16.7 & 16.7 \\
15-24-year-olds (percent) & 12.2 & 13.2 & 12.4 \\
25-64-year-olds (percent) & 55.1 & 52.3 & 54.1 \\
65+ years of age (percent) & 15.0 & 17.7 & 16.8 \\
Life expectancy at birth, women (years) & 82.9 & 83.5 & 83.5 \\
Life expectancy at birth, men (years) & 78.7 & 79.4 & 76.6 \\
Alcohol consumption (litres of pure alcohol per & 9.6 & 6.9 & 10.7 \\
capita in adult population) ${ }^{*}$ & & & \\
Firearm prevalence (percentage of households & 5 & 19 & 38 \\
owning a firearm/ handgun) ${ }^{* *}$ & & & \\
Handgun prevalence (percent)** & 1 & 2 & 6 \\
\hline
\end{tabular}

* (2007; OECD Health Data 2010); ** (van Dijk et al. 2007)

6 Swedes born in Sweden; there is also a relatively large historical minority group of indigenous Swedish speakers in Finland making up about 5 percent of the population. 


\section{Level of education and literacy}

Basic education is compulsory and cost-free in all three countries, and adult literacy rates of men and women are almost 100 per cent, compared to a world level of just over 80 per cent (CIA 2010). In 2009, the total public expenditure on education was 5.9 per cent of Gross Domestic Product in Finland, 5.5 per cent in the Netherlands and 6.7 per cent in Sweden. The combined gross enrolment ratios in education in the three countries are among the highest in Europe (Human Development Reports 2010).

Criminological research has found literacy to be inversely associated with homicide rates, both on a macro-level (Stickley $\&$ Pridemore 2007; Nadanovsky et al. 2009) and on an individual level (de Farias 2009). With this in mind, it is not surprising to find the homicide rates in Finland, Netherlands and Sweden being fairly low viewed from a global perspective.

\section{Prevalence of alcohol and drug use}

Historically the Netherlands has belonged to the Central-European beer zone, while Finland and Sweden have been part of Europe's northeastern spirits zone. This has influenced the drinking cultures of the countries and seems to influence them to some extent even today. In northeastern Europe most of the alcohol consumption has consisted of strong spirits and binge drinking, while in western and southern Europe, social drinking of wine and beer have made up the bulk of consumption. Binge drinking characterizes northern European drinking patterns even today, but strong spirits have lost their dominance. Currently, the Dutch and Swedish alcohol consumption levels are below the European Union average, while the Finnish consumption level is slightly over the average (table 1). In 2007 mortality due to chronic liver disease, an indicator of problematic consumption levels (WHO Global Status Report on Alcohol 2004), was about four per 100,000 inhabitants in the Netherlands, about five per 100,000 inhabitants in Sweden, and about twenty per 100,000 inhabitants in Finland; the European Union average was fourteen (Eurostat 2007).

Although absolute alcohol consumption levels seem not to have any direct link with homicide rate differences between European countries, drinking pattern-related factors may influence alcohol-related violent crime rates (Pridemore 2002; Rossow 2001). Rossow found in her study (covering fourteen European countries) a relatively strong correlation between changes in the levels of alcohol consumption and violent crime rate changes in northern Europe. This correlation was missing or less significant in southern and western parts of the continent. A similar link has also been found in several other studies covering different spiritzone countries including Finland and Sweden (see, for example, 
Bye 2008; Kivivuori 2002; Lenke 1990; Landberg 2010; Pridemore 2002; Sirén 2000; Skog \& Björk 1988). According to these studies, consumption level changes seem to have explained homicide rate changes during the 19th and 20th centuries in northern Europe to at least some degree (von Hofer 2008; Kivivuori 2002; Lehti 2001; Lehti 1997; Lenke 1990; Pridemore 2002; Sirén 2000; Skog \& Björk 1988).

Figure 5. Alcohol consumption in litres of pure alcohol per person of over 15 years of age in Finland, the Netherlands, and Sweden in 1960-2007. Source: OECD Health Data 2010.

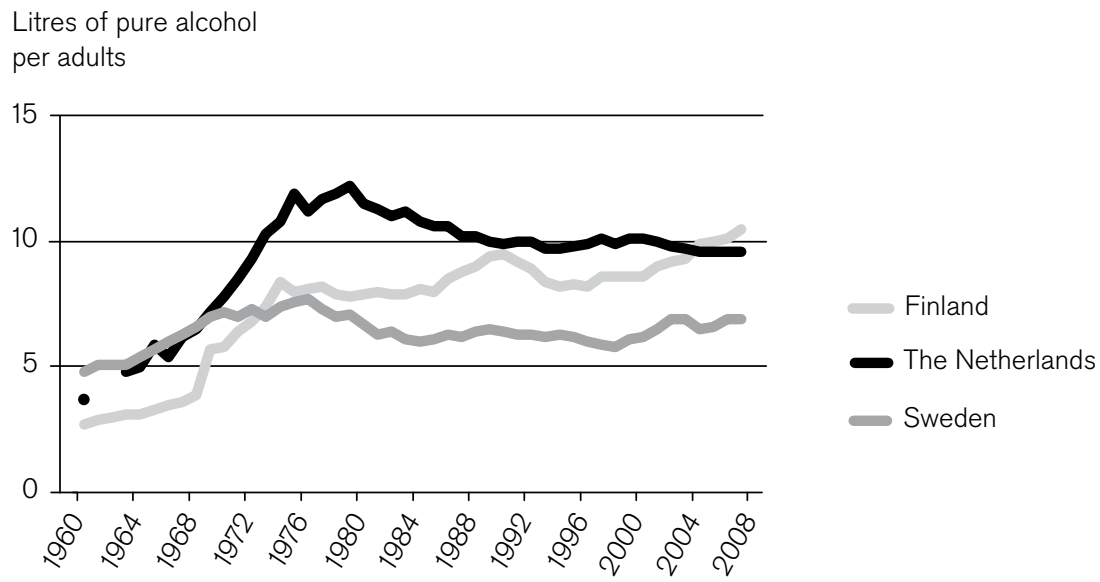

Thus, changes and trends in alcohol consumption as well as consumption patterns in the form of binge drinking may influence violent crime rates more than mere consumption levels. Figure 5 indicates that all three countries have experienced a dramatic increase in alcohol consumption during the last half of the century. In 2007, the Finnish consumption level was four times higher, the Dutch level 2.5 times higher and the Swedish level 1.5 times higher than the one in 1960. In all three countries, the most dramatic increase took place in the 1970s. However, while in the Netherlands and Sweden consumption stabilized or even decreased after the 1970s, the increasing trend has continued until today in Finland. Between the years 2003 and 2006, alcohol consumption in Finland increased by 9 per cent while consumption levels in the Netherlands and Sweden were stable (OECD Health Data 2010).

According to the World Drug Report 2010 (2010, 127), the Finnish prevalence rate of drug use was the ninth highest among the nineteen European Union member countries participating in the study. The Swedish rate was slightly lower and ranked twelfth; the Netherlands did not participate. Thus, in Finland and Sweden 
the drug situation seems to correspond more or less to the $\mathrm{Eu}$ ropean average. In the Netherlands, the prevalence of illicit drug use is higher, but not among the highest in the European Union. The drug markets of the countries differ to some extent. The prevalence of cannabis and ecstasy use is substantially higher in the Netherlands than in the Nordic countries, while the prevalence of amphetamines use is higher both in Finland and in Sweden than in the Netherlands.

\section{Private gun ownership}

All three countries have strict firearm legislation, and in all of them ownership of firearms is subject to licence. In spite of this, partly for historical reasons, firearm ownership prevalence differs substantially between the countries. The Finnish gun ownership rate is one of the highest in Europe, and the Dutch rate is one of the lowest. In Sweden, the ownership rate is higher than the European average, but considerably lower than in Finland (see table 1). Most of the guns owned by private persons in Finland and Sweden are shotguns or rifles used in hunting. The Finnish handgun ownership rate (6 per cent), although the second highest among the European Union member countries, is very low if compared, for example, with that in the United States. In the Netherlands and Sweden handgun ownership is even rarer (van Dijk et al. 2007).

There seems not to be any clear correlation between firearm ownership (at least legal firearm ownership) prevalence and homicide rates in Europe (Granath 2011; Kivivuori \& Lehti 2010). According to the International Crime Victim Surveys, for example, in Finland, in spite of the high ownership prevalence and relatively high violent crime rates, the use of guns in robberies, sexual offences, or assault crimes is almost non-existent (van Dijk \& van Kesteren \& Smit 2007, 284).

\section{General level of criminality}

According to van Dijk, van Kesteren, and Smit (2007, 244-248), the general crime levels for both property and assault crimes during the last ten years have been the lowest in Finland and the highest in the Netherlands among the three project countries. The five-year prevalence of overall victimization rate in adult population for ten crimes asked in a survey of 2005 was 42 per cent in Finland (slightly lower than the average of the participating countries), 58 per cent in the Netherlands, and 51 per cent in Sweden (both slightly higher than the average). The victimization rate for 
assaults and threats was 10 per cent in Finland, 14 per cent in the Netherlands, and 13 per cent in Sweden (all rates were above the average of the participating countries). ${ }^{7}$ The percentage of armed assaults out of all assaults and threats was similarly lower in Finland (4 per cent), than in the Netherlands (17 per cent) or in Sweden (11 per cent). However, the assault and threat rates of Amsterdam (21 per cent) and Helsinki (18 per cent) were clearly higher than the rate in Stockholm (12 per cent). Moreover, the rates for property crime were the lowest in Finland and the highest in the Netherlands, among the project countries.

7 One-year prevalence rate for assaults and threats in 2003-2004 was 2.2 per cent in Finland, 4.3 per cent in the Netherlands and 3.5 per cent in Sweden (van Dijk \& van Kesteren \& Smit 2007, 81). 


\section{Data and methods}

\section{The European Homicide Monitor data}

The data in the present study includes all cases of homicide that have been committed during the years 2003-2006 in Finland, the Netherlands and Sweden and that have become known to the judicial system. These data are called the European Homicide Monitor (EHM) data. The present study is the first to use this data source. It is probably also one of the first studies using data covering all crimes of a certain category, with detailed information on case level, from three different countries in the same dataset. Therefore, it provides directly comparable homicide data from three different countries on a large number of variables.

\section{National datasets on homicide}

The data in the EHM dataset are based on data that have already been collected and coded for existing national homicide monitors in Finland, the Netherlands and Sweden. These datasets span over different numbers of years. They include different variables and are collected by different, yet partly overlapping, means. In-depth descriptions of these national homicide datasets are available in Appendix A.

\section{The merging process}

The variables in the dataset have been chosen with regard to the information already available in the three countries' national data. During the early stages of the project the three national datasets where compared with regard to variables and variable values. The common variables where chosen to form the international dataset. In many cases, the variables, or more commonly the variable values, required recoding. 
Some variables have been chosen even though only two of the three countries have them in their national data ${ }^{8}$. When the recoding was completed the national homicide datasets where merged into an international dataset, consisting of 85 variables. A complete variable list and information about each variable is presented in The European Homicide Monitor Guidebook and coding manual in Appendix B.

\section{Definitions}

In the EHM, homicide is defined as an intentional criminal act of violence by one or more human beings resulting in the death of one or more other human beings. This definition roughly covers the definition used in the United States National Violent Death Reporting System (NVDRS) employed by the U.S. Department of Health and Human Services (Centers for Disease Control and Prevention, 2003). In Finland, Sweden and the Netherlands the definition covers the legal codes of murder, manslaughter, infanticide and assault leading to death. Attempted homicides and suicides are not included in the data. Neither are cases of involuntary manslaughter by, for example, drunk driving, nor cases of intentional but (by court decision) legally justified killings - for example police officers shooting an individual in self-defence.

\section{Data coverage}

Both solved and unsolved cases of homicide are included in the data. Therefore, there is not always information about perpetrators connected to each case. However, a majority of the cases contains such information, since the clearance rate for homicide is high. Information about perpetrators who committed suicide or died for other reasons before conviction is included in the data, and these cases are defined as solved.

As previously mentioned, only homicides committed in Finland, the Netherlands and Sweden are included. The database contains cases where foreigners staying in the country became victims of homicide. Cases of homicide involving Finnish, Dutch or Swedish citizens committed abroad are not included in the data (unless the criminal act is considered to have been initiated within the country borders). Homicides committed in 2003-2006 that became known to the authorities up until the year 2009 are included.

8 A couple of variables have also been considered important enough to include, although none of the countries have information about them. The goal is to be able to collect this information later. Before the end of the entire three-year project, it is the goal to have produced a new version of the codebook including an ideal set of variables and variable values to be collected in the future. 
However, homicides that were committed before 2003 but have become known to the authorities in 2003-2006 are not included.

The data consist of 1,577 cases of homicide, with a total of 1,666 victims and 1,917 perpetrators $^{9}$ of homicide. Nearly half of all the cases in the data are from the Netherlands, one third are from Finland and just over one fifth are from Sweden. Almost half of all the cases in the data have been given the legal definition of murder. However, the three nations differ in regard to the legal definitions given to homicide cases. In Sweden, over two thirds of the cases concern acts legally defined as murder, while in Finland a majority of the cases are legally defined as manslaughter (see table 2). Due to a large proportion of cases from the Netherlands where the legal code is missing, it is difficult to say which would be the largest category had the missing values been known.

Table 2. Number of homicide cases committed in Finland, the Netherlands and Sweden in 2003-2006, by legal definition.

\begin{tabular}{lrrrr}
\hline Legal definition & The Netherlands & Sweden & Finland & Total \\
\hline Murder & 234 & 267 & 124 & 625 \\
Manslaughter & 70 & 42 & 277 & 389 \\
Infanticide & - & 2 & 1 & 3 \\
Assault leading to death & - & 31 & 73 & 104 \\
Unknown & 456 & - & - & 456 \\
\hline Total & 760 & 342 & 475 & 1577 \\
\hline
\end{tabular}

There are no cases in the data from the Netherlands defined as assault leading to death or as infanticide. Cases of infanticide can be assumed to be part of the "unclear" category, however, since the data gathering processes for the Dutch national data include cases of infanticide. The reason behind the lack of cases of assault leading to death is that cases initially defined by such legal code are not included in the national Dutch Homicide Monitor. Although problematic, this is assumed not to affect the total number of homicides in the Dutch data to a large extent, considering the agreement between the homicide rate found in the EHM data and the cause-of-death statistics available.

As mentioned previously, during the years studied, the number of homicide victims registered in the Dutch cause-of-death statistics was 15 per cent lower than in the data used in this study, while the number of homicide victims registered in the national cause-

9 This is, however, an underestimation of the actual number of perpetrators, due to the fact that the Finnish data only includes information about one perpetrator per case. 
of-death statistics for Finland and Sweden were 10 and 5 per cent lower, respectively (see table 3 ).

The "overestimation" of homicides in the EHM data in comparison with the cause-of-death-statistics is slightly higher for the Netherlands than for Sweden and Finland, meaning that the lack of Dutch cases defined as assault leading to death in the EHM data does not seem to indicate significantly poorer data coverage of homicides in the Netherlands than in Finland or in Sweden. While the reasons for the differences between the cause-of-death rates and EHM data in the three countries have not yet been studied, it can be concluded that these results are in line with the pattern in most Western European countries; i.e. the rates of mortality statistics are lower than the police-based counts of completed homicide (European sourcebook of Crime and Criminal Justice Statistics, 2006).

Table 3. Number of homicide victims and average annual homicide rate per 100,000 inhabitants in Finland, the Netherlands and Sweden in 2003-2006 according to the European Homicide Monitor and national cause-of-death statistics.

\begin{tabular}{lcccccccc}
\hline & \multicolumn{2}{c}{ The Netherlands } & Sweden & & \multicolumn{2}{c}{ Finland } & \multicolumn{2}{c}{ Total } \\
Source & $\mathrm{N}$ & Rate & $\mathrm{N}$ & Rate & $\mathrm{N}$ & Rate & $\mathrm{N}$ \\
\hline $\begin{array}{l}\text { Cause-of-death- } \\
\text { statistics* }\end{array}$ & 695 & 1.07 & 337 & 0.94 & 441 & 2.10 & 1473 \\
EHM data & 820 & 1.26 & 355 & 0.98 & 491 & 2.34 & 1666 \\
\hline
\end{tabular}

* Source: Statistics Finland, Statistics Netherlands and the National Board of Health and Welfare in Sweden.

It is, of course, somewhat surprising that the narrower definition in the Dutch Homicide Monitor (as compared to the Swedish and Finnish monitors) do not seem to affect the EHM homicides rates to any greater extent. One possible reason is that the legal authorities in the Netherlands initially defined very few cases of homicide in the 2000s as assault leading to death, although they might assign that definition later on in the legal process. Such practice can be found in Sweden, where the police initially define very few homicide cases as assault leading to death (Rying, 2008).

\section{Data quality}

After recoding and merging the national data into the joint dataset, a number of quality control strategies were used to check for logical inconsistencies in the data. First, the frequencies on each and every variable were split up for the three countries and compared with the same frequencies in the national datasets, in order 
to check if data were lost or somehow altered during the merging process. Second, variables that should have a unique value for every individual row in the data (variables for serial- and case numbers, for example) were aggregated to check that every value appears only once ${ }^{10}$. Third, all frequencies on all variables were displayed country-wise to check if there were any: a) strange values, b) values that should be country-unique (geographic codes for example) appearing in the "wrong" country, or c) other kinds of unreasonable results for any variable. When these control strategies detected an error in the data, it was corrected or the data were re-merged. Although the authors feel that the strategies adopted are sufficient, it must always be kept in mind that some errors may not have been detected.

\section{Sources of error and drop-out-rate}

As the data are collected in three different ways and by a number of different people it is possible that coding may have been done slightly differently in the three countries. Some room for interpretation will always exist when national data is collected, which we cannot account for. Therefore, some test-retest methods were employed at the national level to ensure similar coding between the coders in each country.

Test-retest methods could not be employed between the three countries, since the majority of the data were already compiled at the start of the project. However, since the data were collected for the same purpose in each country it can be expected that the results correspond to one another to a sufficient extent. Further, in all three countries some of the national data for the EHM dataset were collected during the joint project. Because of this, frequent correspondence on data and coding issues was held between coders in the three countries.

All three countries do not have data on all variables. In addition, all countries do not have data for all the labels in each variable, e.g. it cannot be distinguished if homicides that have taken place in a private home in the Netherlands have taken place in the home of the victim, the perpetrator, or in the home of a third person. The existence of unknown variables and variable values may be due to two reasons. Either the data do not exist in the sources used to gather data, e.g. in one of the three countries information about birth country of the victim and perpetrator are often missing from the police investigations and judgments, or the information exists but was not collected because the variable is not included in the country's national data. In the results chapter, the drop-outrate is indicated in each table as unknown.

$10 \mathrm{Or}$, in the case of case-number: neither appears less than twice nor more than ten times, and only in one country. 


\section{The dark figure of homicide}

As criminological research has pointed out, homicides in European countries constitute a crime with a relatively small dark figure (see Eisner, 2008). However, unrecorded cases of homicide do exists. Crime investigation authorities in European countries cannot possibly know of all homicides occurring within their borders. Therefore, the dark figure of homicide may to some extent affect the data in this study. The study has no ambition of analysing the exact number of unrecorded cases of homicide, but there is a need to establish if, when and in which types of cases unrecorded homicides may affect the data and the outcome of our analysis.

The dark figure refers to cases of homicide that are unknown to the authorities and therefore are not part of the data. There can be at least two reasons for a homicide not to have become known to the authorities in countries such as Finland, the Netherlands and Sweden during recent years. The first reason is that the body of the victim has never been found. Even though some cases of missing persons are investigated as murders and therefore included in the data, there is reason to believe that some acts of homicide never become known to the authorities because no body is found - and no report of a murder or missing person is made. This scenario can be assumed to apply to foreigners in the country more often than permanent citizens or individuals registered by the authorities as permanently staying in the country. The latter individuals are more likely to be missed by relatives or authorities, which will raise the suspicion of murder. It is not possible to estimate the exact number of undetected bodies resulting from homicides, but since authorities in western countries monitor citizens quite well, and most individuals are surrounded by persons who will notice their disappearance, it can be assumed that the number is quite small. In addition, the dead body of an adult person is quite hard to dispose of, further suggestion that the number of unrecorded cases of homicide is fairly small.

The second reason for a homicide not to become known to the authorities is that although a dead body is found, neither doctors nor legal authorities find reason to suspect that another person has caused the death. In Finland, the Netherlands and Sweden, autopsies of varying extent are performed in most cases when an individual has been found dead and the cause is unknown. Therefore, undetected homicides of this kind can be assumed to be quite uncommon. Still, if perpetrators manipulate the crime scene or other information and/or the homicide method is sophisticated (such as poisoning, for example) doctors and legal authorities can be misled. Furthermore, some types of homicides, for example those against infants as well as those committed by medical staff in hospitals or nursing homes, are often hard to detect. These kinds of 
scenarios are assumed to be more common in homicides of elderly people or infants than in homicides of healthy adults (see Brookman \& Nolan, 2005).

In summary, the data can never completely cover all homicides that have been committed in the three countries from which data are collected. There will always be some homicides not known to the authorities. However, there are good reasons to believe that the dark figure is rather small in relation to the number of registered homicides. Furthermore, and perhaps more important, there is no reason to believe that the number of unrecorded cases would affect the comparisons between the three countries. The three countries studied are quite similar in societal organization at large. One must bear in mind, however, that victims of homicide with no strong connection to the country in which they have been killed, as well as elderly or infant victims, may to some extent be underrepresented in the data.

\section{The impact of differences in health care resources}

Another factor that might affect international comparisons of homicides, as well as long-term trend studies of such crimes, is differences in the quality or availability of health care resources. Modern criminology has stressed that countries with well-developed emergency health care, and large health care resources in general, tend to have lower homicide mortality rates than what can be predicted based on the rates of violent crimes in general.

In an international comparison of homicide rates, Chon (2002) found a significant and negative correlation between a nation's general amount of resources in health care and the risk of a serious violent crime having a deadly outcome. As Chon puts it, not only do poor countries have higher levels of serious violent crime, there is also on average a higher risk that violent acts in those countries result in the death of the victim in comparison to the same acts committed in Western European countries. In an analysis of homicide trends in the United States between the years 1960 and1999, Harris et al (2002) found indications that development in emergency health care had held back increases in homicide rates in the 1970s and the 1980s. Harris et al argued that if the risk of serious violent crimes resulting in death had not been reduced thanks to better emergency health care, the homicide rate in the United States would have risen in accordance with the sharp increase of registered incidents of aggravated assault during 1960-1999. In Swedish studies on possible health care improvements' impact on 
homicide mortality rates during 1990s and 2000s, no clear indications of such an impact were found (Granath, 2007; Rying, 2008; Granath, 2011).

The important question for this study is whether the development of emergency health care and the general amount of health care resources (including accessibility to such care) in the Netherlands, Sweden and Finland differ to such an extent that it affects the homicide mortality rates. If this is the case, analyses of homicide rates and characteristics based on the EHM would be biased. However, all three countries have a similar societal organization and, as pointed out in the previous chapter, do not differ substantially when it comes to socio-demographic variables. This probably indicates that health care performances are rather alike in the three countries. Furthermore, the infant mortality rate in all three countries is relatively similar, and at least ten times lower than the global rate (CIA World Factbook, 2010). Sweden's rate is the fourth lowest in the world, Finland's the 11th lowest and the Netherlands' the 31st lowest out of 222 countries compared in the CIA World Factbook. Chon (2002) and van Doorslaer et. al. (1997) have highlighted infant mortality rates as a valid indicator of the general amount of resources put into medical health care.

In addition, the physical accessibility to hospital facilities seems rather equal between the three countries. If we, as Chon (2002), use the number of motor vehicles per capita as an indicator for such accessibility, we find that the numbers of motor vehicles in all three countries range from 510 to 540 per 1000 inhabitants in the 2000s (World Bank, 2011). This can be compared to a world average of about 190. In the context of accessibility and infrastructure we can further note that the number of mobile cellular subscriptions per 100 inhabitants are very similar in the three countries studied (World Bank, 2011). ${ }^{11}$ Finally, the percentage of the population living in urban areas is fairly equal (83-85 per cent) in the three countries according to CIA data (CIA World Factbook, 2010).

Our general conclusion is that the differences in health care resources between the three countries are small if any during the four years studied, and that they will not significantly affect the analysis.

\section{Additional data used in the study}

To some extent the study uses other data besides the EHM data to analyse lethal violence in Finland, the Netherlands and Sweden. One such additional source of data is basic demographic data on

11 The numbers of cellular mobile phone subscriptions per 100 inhabitants in 2010 where 123 in Sweden, 128 in the Netherlands and 144 in Finland. 
the populations in the three countries. Homicide frequencies and trends must always be related to population size, population density and population structure in terms of age and sex distribution. In order to find such data, we have used the official national sources Statistics Finland (Tilastokeskus), Statistics Netherlands (CBS) and Statistics Sweden (SCB), as well as official global sources such as the CIA World Factbook.

Another additional source of data used in this study is the national cause-of-death statistics, where the international ICD-10 code system is used. These data are official, and are submitted by Statistics Finland, Statistics Netherlands and the National Board of Health and Welfare in Sweden. The cause-of-death statistics were used to confirm the overall levels of homicide displayed by the EHM. In quantitative studies of homicide, it is common to use cause-of-death statistics for quality assurance of rates and trends of homicide displayed by data from the legal authorities (von Hofer, 2008). 


\section{Results and analysis}

\section{Homicide rates and regional variations}

During the researched period the figures given by the EHM data were in line with those of the national cause-of-death statistics (although not completely identical, see table 4). The differences in the homicide rate between the three project countries corresponded to the long-term patterns described in the beginning of the report.

Table 4. Average annual homicide rate per 100,000 inhabitants in Finland, the Netherlands and Sweden in 2003-2006 according to the European Homicide Monitor database and national cause-of-death statistics.

\begin{tabular}{lcccccc}
\hline & EHM & & \multicolumn{4}{c}{ Cause-of-death statistics } \\
\hline Country & Male & Female & All & Male & Female & All \\
\hline Netherlands & 1.72 & 0.81 & 1.26 & 1.44 & 0.70 & 1.07 \\
Sweden & 1.24 & 0.73 & 0.98 & 1.21 & 0.70 & 0.94 \\
Finland & 3.46 & 1.27 & 2.34 & 3.14 & 1.11 & 2.10 \\
\hline
\end{tabular}

Finland's annual homicide rate was the highest; 85 per cent higher than the Dutch rate and 140 per cent higher than the Swedish rate. The Dutch rate was about 30 per cent higher than the Swedish rate. The differences between the national rates could be found both in male and female mortality. The risk of dying as a victim of homicide for Finnish women was about 60 per cent higher than for Dutch women and 75 per cent higher than for Swedish women. The victimization risk for men in Finland was 100 per cent higher than in the Netherlands and 180 per cent higher than in Sweden. The risk levels in the Netherlands for women were 10 per cent higher, and for men 40 per cent higher than in Sweden. Thus, in this group of countries, the national homicide rate differences mirrored variations in both male and female mortality, but differences in female homicide mortality were considerably smaller than those in male mortality.

The data cover only four years, and homicide trends cannot yet be studied on the basis of these data. Annual variations in the national homicide rates during the studied period were the sharpest in the Netherlands and the smallest in Finland. In both Finland 
and Sweden, the year 2004 was notably violent when compared to other years of the period, while homicide rates in the Netherlands decreased during the entire four-year period.

\section{Regional variations}

Regional variations of homicide rates were more pronounced in Finland and the Netherlands than in Sweden (see figures 6,7 and 8).

In the Netherlands, the difference between the lowest and highest regional levels (ranging between 0.3 and 2.8) was substantially larger than in Sweden. In general, homicide rates were higher in large cities than in rural regions; they were particularly high in the metropolitan regions of Amsterdam, The Hague and Rotterdam (Nieuwbeerta \& Leistra 2007).

In Sweden, annual average homicide rates of the administrative regions ${ }^{12}$ varied between 0.5 and 1.6 victims per 100,000 inhabitants; thus, the highest rate was about 215 per cent higher than the lowest one. The Stockholm area had a homicide level 14 per cent above the national average. Besides Stockholm, the southeastern provinces had higher than average homicide rates, while southwestern and central provinces had the lowest crime levels.

In Finland, as in the Netherlands, the difference between the highest and the lowest regional homicide rate was larger than in Sweden, varying between 0.9 and 4.2 victims per 100,000 inhabitants. The metropolitan region of Helsinki as well as the other main urban regions (Oulu, Tampere, Turku) had relatively low homicide rates corresponding more or less to the national average. The highest crime levels were found in the far north and in the eastern provinces. This pattern has been quite stable for a number of decades (Kivivuori \& Lehti 2010).

12 NUTS 3 (Nomenclature of Territorial Units for Statistics) is a standard for dividing countries into comparable areas for statistical purposes. NUTS 1, 2 and 3 are all used as a standard within the European Union. 
Figure 6. Homicide rates in the Netherlands, by region, 2003-2006 (per 100,000 inhabitants).

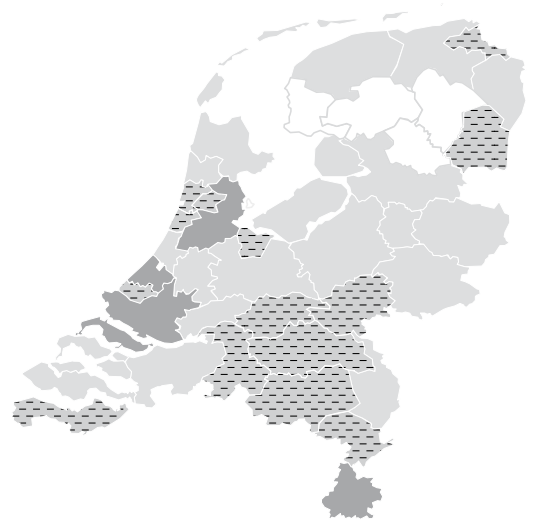

Figure 7. Homicide rates in Sweden, by region, 2003-2006 (per 100,000 inhabitants).
Figure 8. Homicide rates in Finland, by region, 2003-2006 (per 100,000 inhabitants).
$-0.4$

$0.5-0.9$

$1.0-1.9$

$2.0-2.9$
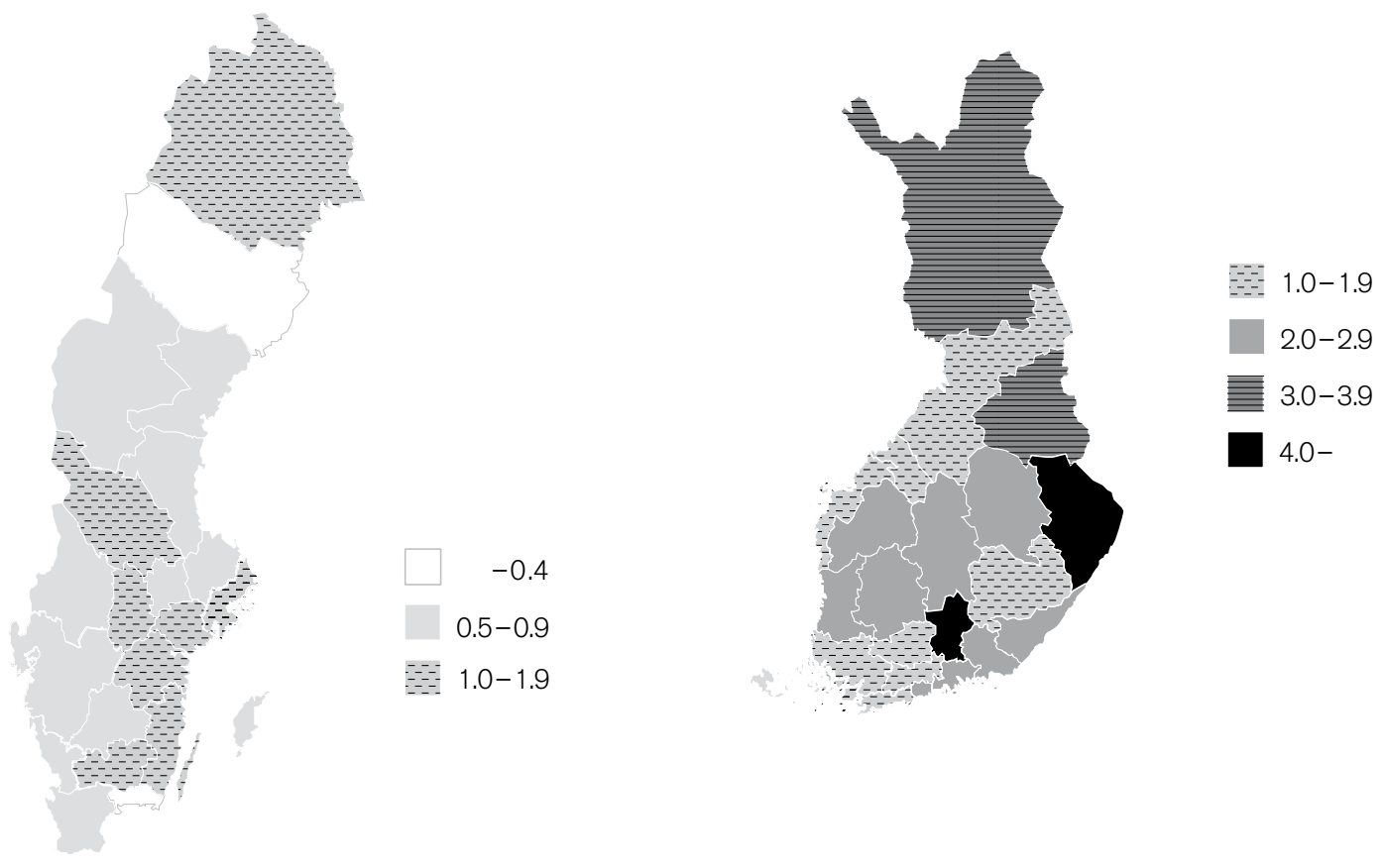
There was a clear difference between the crime levels of the Dutch and Nordic metropolises. In 2003-2006, Amsterdam and The Hague had the highest homicide rates among the metropolitan regions of the three project countries. The crime level in Amsterdam was 2.2 times higher and in The Hague twice as high as the Dutch national average. The homicide rate in Rotterdam was 74 per cent higher than the Dutch national homicide rate.

The homicide level in Helsinki was the third highest among the metropolises, but corresponded more or less to the Finnish national average (being 3 per cent higher). Stockholm had a lower crime rate than the other metropolises, although the homicide rate was 14 per cent higher than the national average. Thus, all the metropolises had higher than average homicide levels in their national contexts, but the Dutch metropolises diverged substantially more from the national average than the Nordic ones.

It should be noted, however, that these rates are probably an overestimate due to the large number of people who spend time in big cities, but are residents in surrounding areas. Because the rates are calculated for the number of homicides occurring in a region, but based on the number of permanent residents, comparisons might be misleading. This is particularly true in larger cities, since the effect will be larger for cities with a larger influx of people than for those with a smaller one.

With the above in mind, the results indicate that the regional distribution of homicides clearly differ between the Nordic countries and the Netherlands. In the Netherlands, homicides are mainly a problem in a few big cities, while homicide in the Nordic countries is distributed more evenly across all settlement types. On the other hand, this means that in the Nordic countries, and especially in Finland, the crime rates of rural communities are, on average, higher than in the Netherlands.

Table 5. The number of homicide victims and annual homicide rates per 100,000 inhabitants in the metropolitan regions of Finland, the Netherlands and Sweden in 2003-2006.

\begin{tabular}{llcc}
\hline Country & Metropolitan region & Number of victims & Homicide rate \\
\hline The Netherlands & Amsterdam & 134 & 2.80 \\
& The Hague & 79 & 2.56 \\
& Rotterdam & 119 & 2.19 \\
Sweden & Stockholm & 84 & 1.12 \\
Finland & Helsinki & 95 & 2.41 \\
\hline
\end{tabular}




\section{Incident characteristics}

In this section we describe the main characteristics of homicides in the three project countries in 2003-2006.

\section{Number of persons involved}

In all three countries, most homicide incidents ${ }^{13}$ had only one victim and one perpetrator. In Finland and Sweden, this type of incident made up about 80 per cent of all cases, while cases with multiple perpetrators made up 15 per cent and multiple victim cases about 4 per cent.

The large number of cases with an unknown number of perpetrators made the Dutch data difficult to interpret and compare with those of the two other countries, but it seems that in the Netherlands homicide incidents were more likely to involve multiple persons, especially multiple perpetrators, than in the Nordic countries. If cases with missing data are excluded, multiple victim cases made up 7 per cent of Dutch homicide incidents and multiple perpetrator cases 24 per cent. The percentage of homicides with one victim and one perpetrator was 73 per cent. It is likely that these figures corresponded to the actual situation fairly well. According to Leistra \& Niewbeerta $(2003,29)$, in 1991-2002 multiple perpetrator cases made up 22 per cent and multiple victim cases 5 per cent of homicide incidents in the Netherlands.

Table 6. Homicide incidents by the number of victims and perpetrators involved in Finland, the Netherlands, and Sweden in 2003-2006 (per cent).

\begin{tabular}{lcccc}
\hline Involved persons & $\begin{array}{l}\text { Finland } \\
(\%)\end{array}$ & $\begin{array}{l}\text { Sweden } \\
(\%)\end{array}$ & $\begin{array}{l}\text { The Nether- } \\
\text { lands (\%) }\end{array}$ & $\begin{array}{l}\text { Total number } \\
\text { of cases (N) }\end{array}$ \\
\hline $\begin{array}{l}\text { One victim, } \\
\text { one perpetrator }\end{array}$ & 81 & 80 & 59 & 105 \\
$\begin{array}{l}\text { One victim, } \\
\text { multiple perpetrators }\end{array}$ & 15 & 13 & 17 & 246 \\
$\begin{array}{l}\text { Multiple victims, } \\
\text { one perpetrator }\end{array}$ & 2 & 3 & 3 & 42 \\
$\begin{array}{l}\text { Multiple victims, } \\
\text { multiple perpetrators }\end{array}$ & 0.4 & 1 & 2 & 154 \\
$\begin{array}{l}\text { One victim, number of } \\
\text { perpetrators unknown }\end{array}$ & 2 & 2 & 18 & 8 \\
$\begin{array}{l}\text { Multiple victims, number of } \\
\text { perpetrators unknown }\end{array}$ & 0 & 0.3 & 1 & 1577 \\
\hline \begin{tabular}{l} 
Total number of cases \\
\hline
\end{tabular} & 475 & 342 & 760 & \\
\hline
\end{tabular}

13 Homicide incident includes all victims killed in the same situation, while each victim is counted as a separate homicide. 


\section{Seasonal, weekly and daily variations}

There are differences as well as similarities in the distribution of homicides in temporal space. While the weekly and daily distributions of the crimes were to a large extent the same in all three countries, there were greater variances in the annual distribution.

The results presented in figure 9 show that in Finland, most homicides were committed during winter months from October to March. In the Netherlands, on the other hand, the most violent period was spring and early summer from April to June. In Sweden, the annual distribution was more even than in the two other countries, although homicides predominantly took place during winter, similar to Finland.

Figure 9. The annual distribution of homicides in Finland, the Netherlands, and Sweden in 2003-2006 (by incident; deviation from average distribution in per cent).

\section{Percentage points}

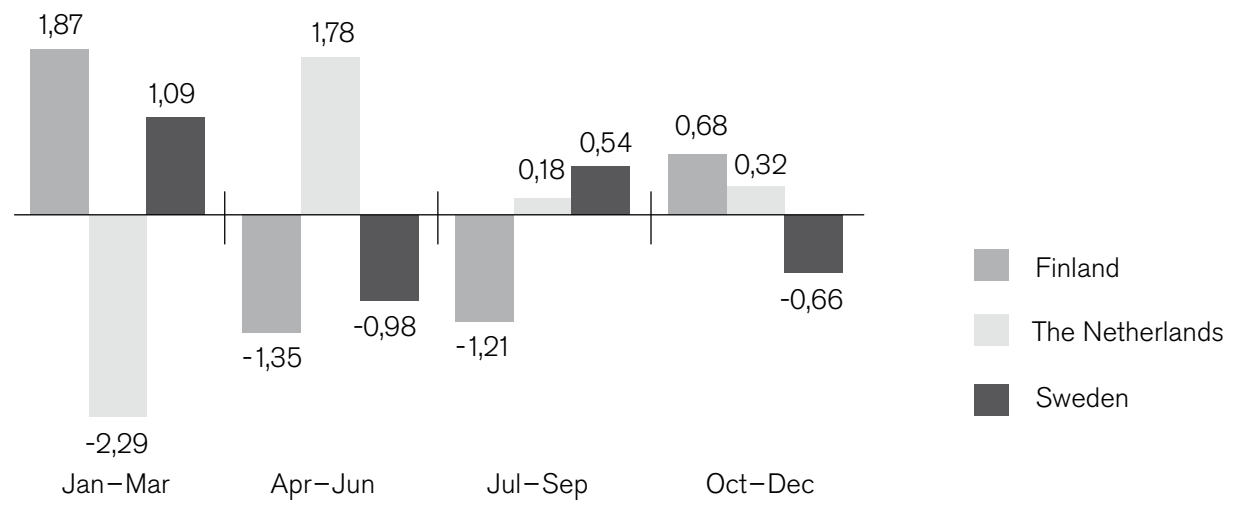

The Finnish results differed from those observed in earlier studies. According to, for example, Hakko (2000), Kivivuori (1999) and Lehti (2002), seasonal variation of homicides seems to have practically disappeared in Finland since the 1970s. These results are contradictory, making them an appropriate item for further study. In the Netherlands, the results corresponded more to those found in earlier studies, and may mirror a more stable pattern (Leistra \& Nieuwbeerta 2003). In Sweden, seasonal variations in homicides have not previously been studied. Therefore, it is not possible to assess the results in connection to other research. 
Figure 10. The weekly distribution of homicides in Finland, the Netherlands, and Sweden in 2003-2006 (by incident).

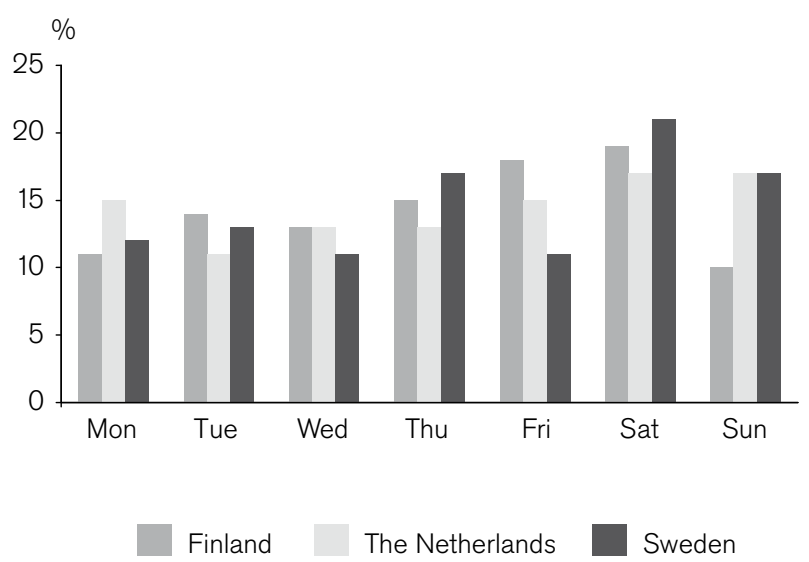

In all three countries, weekends were more lethal than weekdays (see figure 10). The pattern of homicides being concentrated to weekends, i.e. days free of work, has been found in all three countries (Lehti 2001; Leistra \& Nieuwbeerta 2003; Ylikangas 1998). In Finland, Friday and Saturday were the most lethal days of the week, while in the Netherlands and Sweden, Saturday and Sunday were the most lethal. It should be noted, however, that many homicides that technically occur on a Saturday or Sunday, are due to events taking place the night before i.e. on a Friday or Saturday evening. This is also demonstrated in figure 11 which shows that that most homicides took place between midnight and 6 a.m.

There were also differences between weekday peaks; in the two Nordic countries Thursday was the most lethal weekday while in the Netherlands Monday was the most lethal weekday.

Figure 11. The daily distribution of homicides in Finland, the Netherlands, and Sweden in 2003-2006 (by incident).

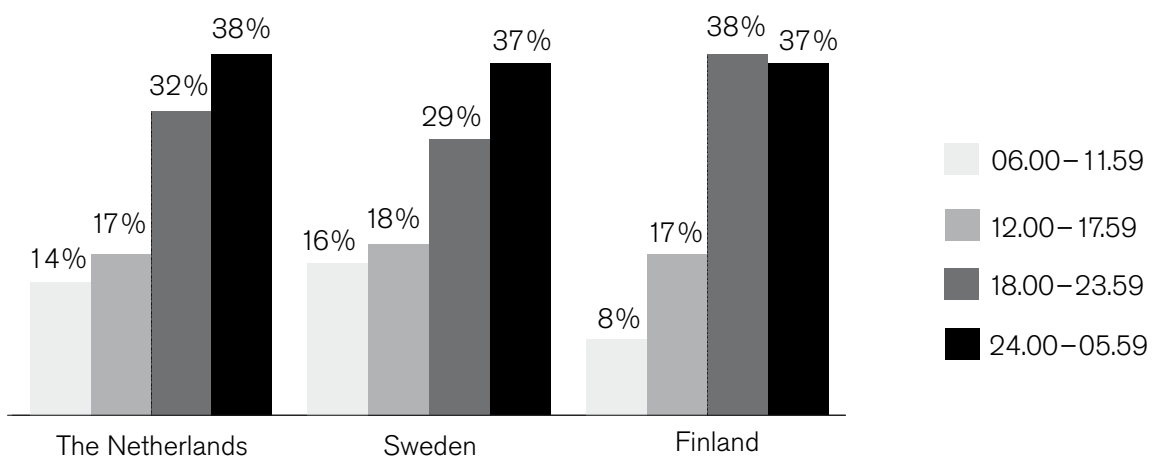


A pattern could also be observed in the daily distribution of homicides in the three countries. The majority of homicides were committed outside working-hours, i.e. in the evening and at night (see figure 11). Finland had the largest share of crimes perpetrated between 6 p.m. and 6 a.m. (75 per cent), while Sweden had the smallest share (67 per cent). In the Netherlands, the corresponding share was 70 per cent.

Due to the connection between homicide and alcohol drinking patterns, it can be expected that the concentration of homicides will be more intensely connected to times when alcohol is consumed. This is especially true for Finland where more alcohol is consumed than the other two countries, but to some extent also for Sweden. This pattern can also be seen in e.g. Russia where binge drinking and consumption of spirits is common (Pridemore 2004).

\section{Location}

In Finland and Sweden, homicides (and homicides against men in particular), were concentrated to a much higher degree in private locations than in the Netherlands, where homicides committed outdoors were more common than in the two Nordic countries. In 2003-2006, 73 per cent of homicides in Finland and 65 per cent of those in Sweden were committed in private homes; in the Netherlands the percentage was only 52 per cent. At the same time, crimes committed in streets, parks and other outdoor public places made up 38 per cent of Dutch homicides, but only 19 per cent of those in Sweden and 16 per cent in Finland. The results corresponded to those of earlier studies, and mirrored differences that have existed at least since the 1980s, perhaps even longer (Kivivuori 1999; Lehti 2002; Leistra \& Nieuwbeerta 2003; Rying 2000). 
Table 7. Location of homicides against men in Finland, the Netherlands, and Sweden in 2003-2006 (by victim).

\begin{tabular}{|c|c|c|c|c|c|c|}
\hline \multirow[b]{2}{*}{$\begin{array}{l}\text { Location of } \\
\text { homicide }\end{array}$} & \multicolumn{2}{|c|}{ The Netherlands } & \multicolumn{2}{|c|}{ Sweden } & \multicolumn{2}{|c|}{ Finland } \\
\hline & $\mathrm{N}$ & $\%$ & $\mathrm{~N}$ & $\%$ & $N$ & $\%$ \\
\hline $\begin{array}{l}\text { Home of the } \\
\text { victim }\end{array}$ & - & - & 87 & 41 & 118 & 33 \\
\hline Private home & 233 & 43 & 45 & 21 & 126 & 36 \\
\hline $\begin{array}{l}\text { Institution, } \\
\text { dormitory }\end{array}$ & - & - & 7 & 3 & 7 & 2 \\
\hline $\begin{array}{l}\text { Private ve- } \\
\text { hicle }\end{array}$ & - & - & 4 & 2 & 5 & 1 \\
\hline $\begin{array}{l}\text { Shop, restau- } \\
\text { rant }\end{array}$ & 40 & 7 & 8 & 4 & 24 & 7 \\
\hline Workplace & - & - & 4 & 2 & 0 & 0 \\
\hline Hotel, motel & - & - & 1 & 0.5 & 1 & 0.3 \\
\hline Park, forest & 40 & 7 & 11 & 5 & 39 & 11 \\
\hline Street, road & 207 & 38 & 43 & 19 & 24 & 7 \\
\hline Other & 22 & 4 & 3 & 1 & 6 & 2 \\
\hline $\begin{array}{l}\text { All valid } \\
\text { cases }\end{array}$ & 542 & 100 & 213 & 100 & 350 & 100 \\
\hline Unknown & 6 & 1 & 9 & 4 & 5 & 1 \\
\hline Total & 548 & & 222 & & 355 & \\
\hline
\end{tabular}

The differences were substantial in absolute numbers as well. The difference between the national homicide rates of Sweden and the Netherlands was made up entirely by crimes connected to street violence. ${ }^{14}$ The rate of homicides committed in private locations was identical in both countries, while the rate of street violence-related homicides was 2.5 times higher in the Netherlands. Similarly, the difference in national homicide rates between Finland and the Netherlands was caused by homicides in private homes only. The rate of street violence-related homicides in Finland was actually almost 20 per cent lower than in the Netherlands, while the rate of homicides in the domestic sphere was 2.7 times higher. The difference between the Finnish and Swedish national homicide rates was caused by both types of homicides; the rate of street violencerelated crimes was twice the Swedish rate and crimes in private homes 2.7 times higher than in Sweden. Although the percentage of victims killed in private homes was high in both countries, the share of victims killed in their own home was substantially higher in Sweden than in Finland. Correspondingly, the share of persons

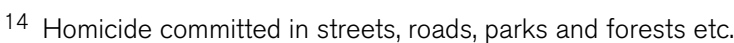


killed in apartments they did not live in was higher in Finland. In fact, for Finns the risk to be killed in their own home was only about 95 per cent higher than for Swedes, but the risk to be killed in somebody else's apartment no less than 4.9 times higher.

There were substantial gender and age related differences in the distribution of location - these were, however, more or less similar in all three countries (see tables 7 and 8). Homicides against women were concentrated to a much higher degree to private locations than those against men. Most of the women killed during the period in Finland and Sweden were killed in their own home. Because of the fact that females are more often killed by intimates than males, this was probably true also for the Dutch women, although the data in the Netherlands did not allow separating those killed in their home from those killed in other private homes. Of the Dutch women killed in private apartments, 60 per cent were killed by their partner, 27 per cent by their parents, 6 per cent by their children, 2 per cent by their siblings and 3 per cent by their flatmates or neighbours, thus most of the crimes were domestic violence-related and it is likely that most of them took place in the home of the victim, like similar crimes in the Nordic countries.

Table 8. Location of homicides against women in Finland, the Netherlands, and Sweden in 2003-2006 (by victim).

\begin{tabular}{lrrrrrr}
\hline & The Netherlands & \multicolumn{2}{c}{ Sweden } & \multicolumn{2}{c}{ Finland } \\
Location of homicide & $N$ & $\%$ & $N$ & $\%$ & $N$ & $\%$ \\
\hline Home of the victim & - & - & 89 & 70 & 83 & 61 \\
Private home & 185 & 71 & 11 & 9 & 30 & 22 \\
Institution, dormitory & - & - & 3 & 2 & 1 & 1 \\
Private vehicle & - & - & 4 & 3 & 0 & 0 \\
Shop, restaurant & 3 & 1 & 4 & 3 & 1 & 1 \\
Workplace & - & - & 2 & 2 & 0 & 0 \\
Hotel, motel & - & - & 0 & 0 & 0 & 0 \\
Park, forest & 13 & 5 & 7 & 6 & 12 & 9 \\
Street, road & 46 & 18 & 6 & 5 & 5 & 4 \\
Other & 10 & 0 & 1 & 0.8 & 4 & 3 \\
All valid cases & 257 & 100 & 127 & 100 & 136 & 100 \\
\hline Unknown & 3 & 1 & 6 & 5 & 0 & 0 \\
Total & 260 & & 133 & & 136 & \\
\hline
\end{tabular}

Differences by age-group followed a similar pattern in all three countries. 15 to 29 -year-olds had the lowest percentage of victims killed in the domestic sphere, but the highest percentage of victims of street violence (see figure 12). In all three countries, between 70 
to 100 per cent of child victims and victims over the age of 65 were killed in private locations - usually in their own homes.

Figure 12. The percentage of homicide victims killed in private apartments by age category in Finland, the Netherlands, and Sweden in 2003-2006 (by victim).

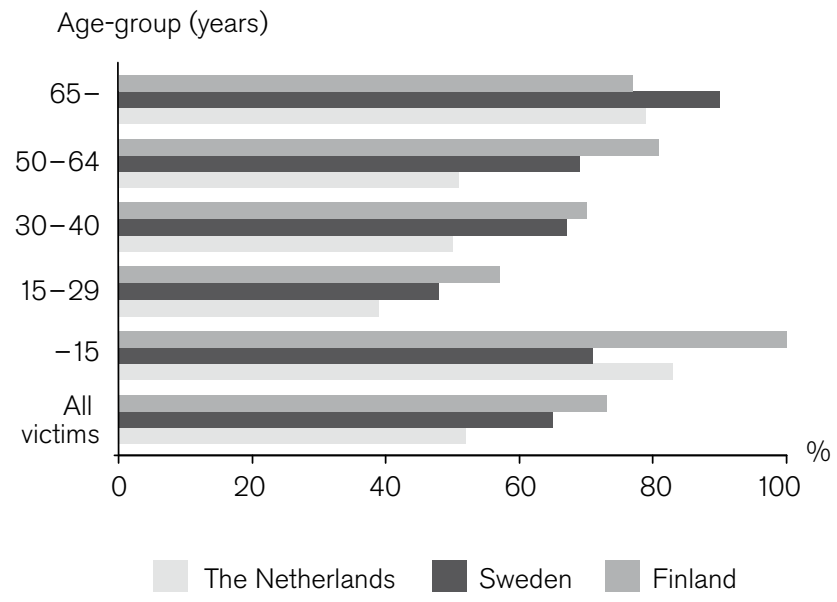

The high percentage of street violence-related homicides in the Netherlands, when compared to Finland and Sweden, was not caused by differences in the age structures of homicidal crime. As figure 13 indicates, street violence-related homicide deaths were much more common in the Netherlands in all age categories of the adult population than in Finland or in Sweden.

Figure 13. The percentage of victims of street violence-related homicides by age category in Finland, the Netherlands, and Sweden in 2003-2006 (by victim).

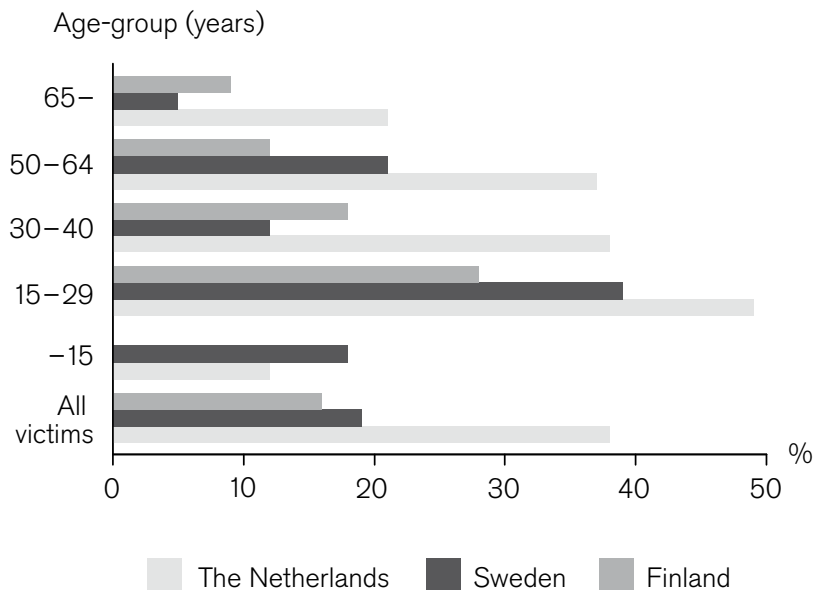


The locations of homicides seem to have changed in opposite directions in Finland and the Netherlands since the 1960s. The Netherlands does not have any systematic data on the locations of homicides before the 1990s, but the structural and demographic changes which took place in the 1960s and 1970s indicate that the percentage of crimes outside the private sphere (and very probably outside private homes) has increased substantially (Nieuwbeerta \& Leistra 2007, 36-39). Thus, it seems likely that the proportion of Dutch homicides that occurred outside the private sphere has increased during the last five decades.

In Finland, the trend has been the opposite. In the 1960s the majority of Finnish homicides took place in public or semi-public places. The current situation, where over 70 per cent of lethal violence occurs in private homes, is a recent phenomenon emerging in the last few decades (Kivivuori \& Lehti 2010). In Sweden, the situation seems to have been stable. Private flats were by far the most common location of homicides as early as in the 1950s, and little seems to have changed after that. The majority of Swedish homicides have been committed in private locations during the last five decades (Rying 2000).

\section{Weapon use}

The modus operandi of homicides differed clearly between the two Nordic countries and the Netherlands (see table 9). In the Nordic countries, sharp instruments (usually kitchen knives) were the most commonly used weapons while in the Netherlands firearms were the most common.

This is interesting, considering that the Nordic countries in general, and in Finland in particular, have a much higher prevalence of firearm ownership than the Netherlands. The annual rate of firearm homicide deaths was the highest in the Netherlands (3.9 per million inhabitants) although the Finnish rate (3.7) was only slightly lower. The rate in Sweden (1.5) was by far the lowest. In the EHM, data on the legality of the firearms used in homicides were available for Finland and Sweden. In both countries, the majority of weapons used in homicides were illegal; in Sweden 74 per cent and in Finland 64 per cent. The Finnish data also provided information about the types of firearm used in homicides; 44 per cent were handguns, 47 per cent shotguns or hunting rifles and 8 per cent sawn-off shotguns. 
Table 9. Weapon use in homicides in Finland, the Netherlands, and Sweden in 2003-2006 (by victim).

\begin{tabular}{lrrrrrr}
\hline & \multicolumn{2}{c}{ The Netherlands } & \multicolumn{2}{c}{ Sweden } & \multicolumn{2}{c}{ Finland } \\
Weapon & $\mathrm{N}$ & $\%$ & $\mathrm{~N}$ & $\%$ & $\mathrm{~N}$ & $\%$ \\
\hline Hitting/ kicking* & 76 & 10 & 40 & 12 & 85 & 18 \\
Strangulation & 63 & 9 & 31 & 9 & 45 & 9 \\
Sharp instrument** & 250 & 34 & 154 & 45 & 202 & 42 \\
Blunt object & 47 & 6 & 34 & 10 & 41 & 8 \\
Firearm & 256 & 35 & 56 & 17 & 77 & 16 \\
Explosive & - & - & 1 & 0.3 & - & - \\
Poison & 9 & 1 & 3 & 1 & 10 & 2 \\
Drowning & 7 & 1 & 5 & 1 & 4 & 1 \\
Fire & 10 & 1 & 8 & 2 & 10 & 2 \\
Motor vehicle & 7 & 1 & 3 & 1 & 2 & 0.4 \\
Other & - & - & 4 & 1 & 9 & 2 \\
All valid cases & 725 & 100 & 339 & 100 & 485 & 100 \\
\hline Unknown & 95 & 13 & 16 & 5 & 6 & 1 \\
All cases & 820 & & 355 & & 491 & \\
\hline
\end{tabular}

* Including pushing

** Including axe.

The gender and age of the perpetrator was related to weapon use. In all three countries, a sharp instrument was the most common weapon for both genders. ${ }^{15}$ In relative terms, women were more likely to use poison or suffocation as their method of killing, and less likely to use firearms or mere physical violence. In absolute terms, poisoning was the only method used where women surpassed the number of homicides committed by men - and only in Finland and Sweden. In the Netherlands, more men than women committed homicides through poisoning, although proportionally, poisoning was more commonly used by female perpetrators.

In table 10, we can also see that the main country level differences concerned both genders. In the Netherlands, firearm homicides were much more common among both men and women than in the Nordic countries, while Nordic men and women more often committed their homicides using sharp instruments, compared with Dutch men or women. The figures in table 10 exclude homicides where the gender of the principal perpetrator was unknown. These excluded homicides do not affect the results for Finland (2 per cent) or Sweden (8 per cent), where the number of unknown cases was relatively small, but they do have some impact on the

15 Calculated from the gender of the principal perpetrator. 
Table 10. Weapon use by the gender of the principal perpetrator in Finland, the Netherlands, and Sweden in 2003-2006 (by principal perpetrator; percent).

\begin{tabular}{lcccccc}
\hline & \multicolumn{2}{c}{ The Netherlands } & \multicolumn{2}{c}{ Sweden } & \multicolumn{2}{c}{ Finland } \\
Weapon & Men (\%) & Women (\%) & Men (\%) & Women (\%) & Men (\%) & Women (\%) \\
\hline Firearm & 31 & 16 & 17 & 0 & 17 & 4 \\
Sharp instrument* & 39 & 36 & 49 & 48 & 42 & 51 \\
Blunt object & 6 & 7 & 10 & 12 & 9 & 4 \\
Poison & 1 & 7 & 0,4 & 3 & 1 & 8 \\
Strangulation & 9 & 13 & 7 & 21 & 9 & 10 \\
Hitting/ kicking & 12 & 9 & 12 & 3 & 19 & 8 \\
Other & 2 & 13 & 5 & 12 & 4 & 16 \\
All valid cases & 100 & 100 & 100 & 100 & 100 & 100 \\
\hline Unknown (N) & 33 & 8 & 3 & 0 & 2 & 1 \\
All cases (N) & 566 & 53 & 274 & 33 & 413 & 52 \\
\hline
\end{tabular}

* Including axe.

** Including pushing.

Dutch data. This is because of their higher percentage (19 per cent) and because the weapons used in homicides with an unknown perpetrator differed from those in homicides with a known perpetrator -53 per cent of the missing data cases were firearm homicides and 17 per cent were committed using a sharp instrument. ${ }^{16}$ These firearm homicides comprised 22 per cent of all firearm homicides in the Netherlands in 2003-2006. It is likely that most of them were committed by men. ${ }^{17}$ Thus, the figures in table 10 probably do not give a correct picture of the weapons used by Dutch men it is likely that firearms were their main method of killing during the period.

The large number of missing cases made it difficult to compare age category-related differences in killing methods between the Netherlands and the other two countries. It seems, however, that the difference in the number of firearm homicides (in both relative and absolute terms) between the Netherlands and the two Nordic countries was caused mainly by young and middle-aged male perpetrators (see figure 14). In the Nordic homicides, firearms were clearly a weapon utilized by older men while differences between age categories and weapon choice in the Netherlands were much smaller.

$16 \mathrm{~N}=94$; excluding cases with unknown instrument.

17 Based on the fact that firearm homicides were predominantly a weapon used by men in homicides for which weapon data were available, and the fact that homicides committed in a criminal milieu were probably overrepresented among the missing cases. In the known cases of criminal milieu homicides, the perpetrators were mostly men. 
Figure 14. The percentage of firearm homicides committed by men, by age category, in Finland, the Netherlands, and Sweden in 2003-2006 (by principal victim).

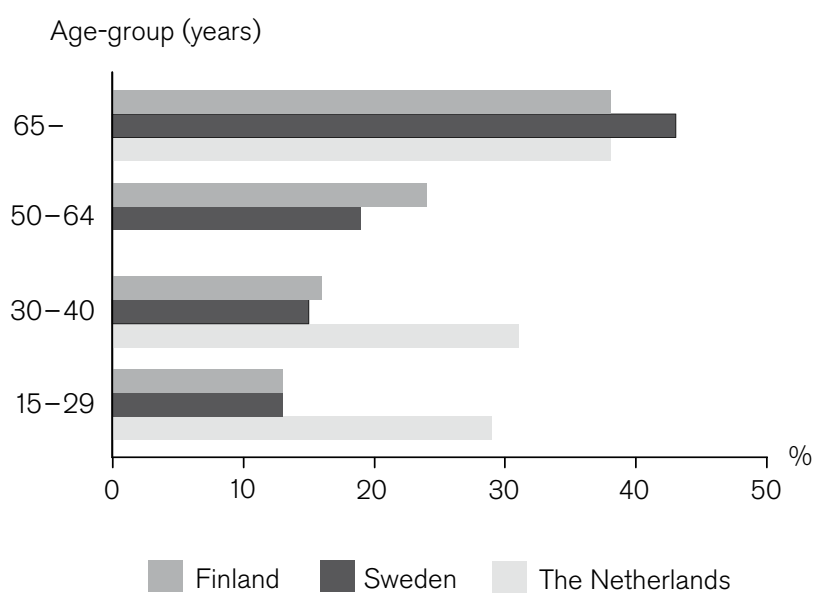

Weapon use varied by crime location. In private homes sharp instruments were the most commonly used weapon in all three countries, making up the modus operandi in 39 per cent of homicides in the Netherlands, 47 per cent in Finland and 49 per cent in Sweden. However, firearm homicides in private homes made up a substantially larger share in the Netherlands (24 per cent) than in Finland or Sweden (14 per cent each). The percentage of crimes committed using no instruments except the perpetrators own body (i.e. primarily using hands, arms and legs to hit, kick, push or suffocate) in private homes was more or less the same (20-25 per cent) in all three countries.

Figure 15. Weapon use in homicides in private homes in Finland, the Netherlands, and Sweden in 2003-2006 (by victim; cases with missing data excluded; d.m. = data missing: percentage of missing cases).

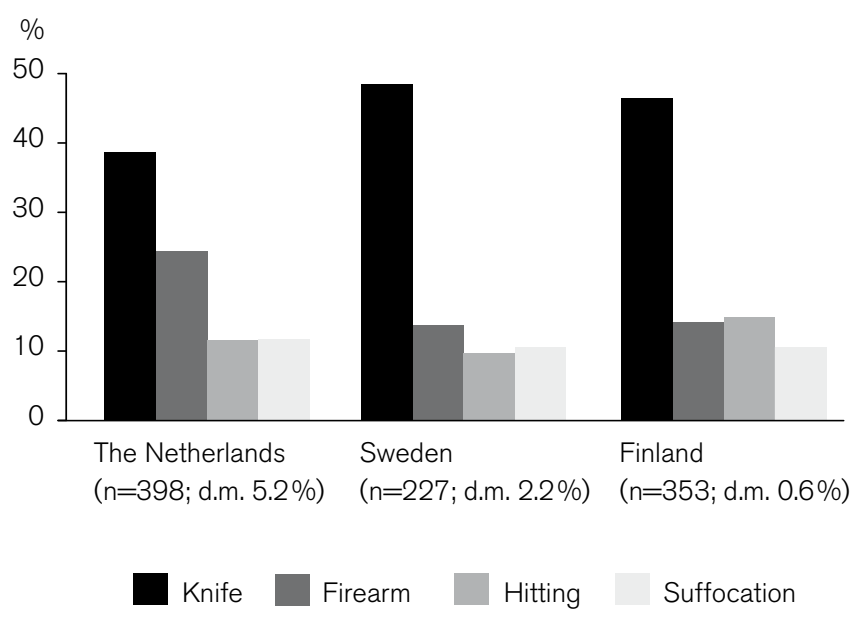


Street violence-related homicides displayed greater differences in terms of methods used in. The clearest difference concerned firearm usage. In the Netherlands, 46 per cent of street violence homicides were committed with a firearm, while the proportion was much smaller in Finland and Sweden (24 and 20 per cent, respectively). In both Nordic countries the percentage of homicides committed using no instruments except the perpetrators own body was substantially larger (about 30 per cent) than in the Netherlands (12 per cent). The share of homicides perpetrated using sharp instruments was more or less the same in all three countries (29 per cent to 34 per cent), and clearly smaller than in crimes committed in private homes.

\section{Figure 16. Weapon use in street violence-related homicides in Finland, the Netherlands, and Sweden in 2003-2006 (by victim; cases with missing data excluded; d.m. = data missing: percentage of missing cases).}

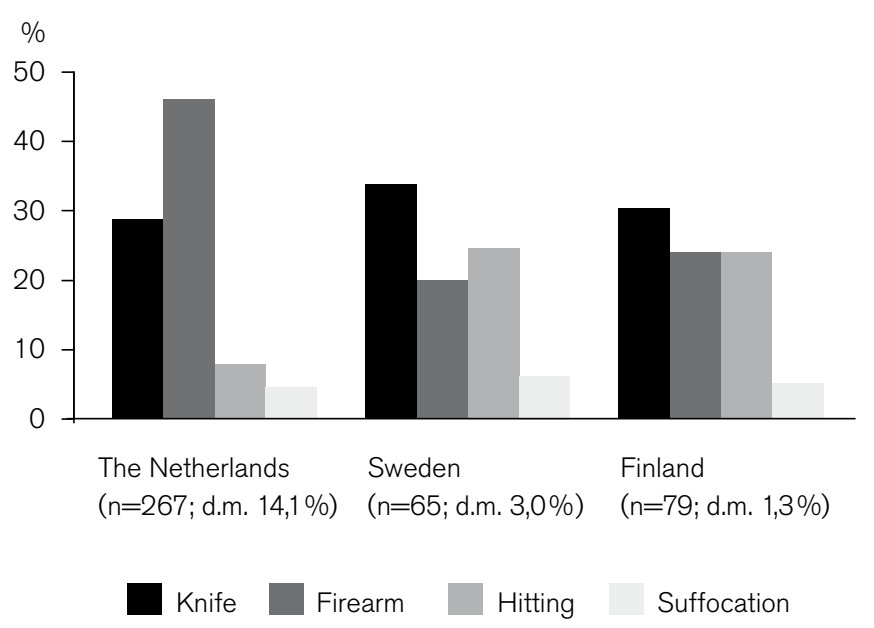

\section{Homicide types}

The classification of homicides is not a simple task. Homicides can be classified according to several different characteristics and principles, all of which have their flaws and none of which give a comprehensive or unambiguous result. In this report we have used the EHM classification, which was based partly on the relationship between the persons involved, partly on the circumstances of the crime, and partly on motives. The aim was to give a general picture of homicidal crime as a social phenomenon by describing the kind of social interactions, relations and situations in which the crimes take place. In this we have succeeded only partly. 
Table 11. Homicides by type in Finland, the Netherlands, and Sweden in 20032006 (by victim).

\begin{tabular}{lrrrrrr}
\hline & \multicolumn{2}{c}{ The Netherlands } & \multicolumn{2}{c}{ Sweden } & \multicolumn{2}{c}{ Finland } \\
Homicide type & $\mathrm{N}$ & $\%$ & $\mathrm{~N}$ & $\%$ & $\mathrm{~N}$ & $\%$ \\
\hline Intimate partner killing & 152 & 24 & 92 & 29 & 112 & 24 \\
Child-killing: family & 39 & 6 & 15 & 5 & 24 & 5 \\
Other familial killing & 59 & 9 & 35 & 11 & 31 & 7 \\
Criminal milieu & 123 & 19 & 38 & 12 & 13 & 3 \\
Robbery: business & 12 & 2 & 3 & 1 & 1 & 0.2 \\
Robbery: private home & 32 & 5 & 15 & 5 & 9 & 2 \\
Robbery: street & 14 & 2 & 5 & 2 & 3 & 1 \\
Nightlife violence & 22 & 3 & 31 & 10 & 23 & 5 \\
Mental illness: non-family & 12 & 2 & 19 & 6 & 25 & 5 \\
Child-killing: non-family & - & - & - & - & 5 & 1 \\
Sexual motive & 18 & 3 & 1 & 0.3 & 1 & 0.2 \\
Other in non-criminal & & & & & & \\
milieu & 148 & 23 & 62 & 19 & 208 & 45 \\
Other & - & - & 2 & 1 & 3 & 1 \\
All valid cases & 631 & 100 & 318 & 100 & 458 & 100 \\
\hline Unknown & 189 & 23 & 37 & 10 & 33 & 7 \\
Total & 820 & & 355 & & 491 & \\
\hline
\end{tabular}

These findings should be interpreted with caution, first, because of the large number of crimes with missing data in the Netherlands and, second, because of even larger number of crimes recoded from national data into the "other" categories in all three countries. In the first case, on the basis of the modus operandi and location in these crimes we could assume that the missing cases are evenly distributed across all homicide types, although crimes between persons not related to each other and those committed in criminal milieu were probably overrepresented. The second problem concerned all three countries, but Finland in particular. In Finland, a 45 per cent of homicides were recoded into the "other" categories; however, their size was larger than desirable both in the Netherlands (23 per cent) and in Sweden (19 per cent). Because of these problems, Sweden was the only country where the results could be assessed as satisfactory, as 72 per cent of the cases could be recoded according to the agreed classification. In Finland the percentage was only 50 per cent and in the Netherlands 59 per cent.

It is likely that the results gave a distorted picture of the distribution among homicide types in Finland and the Netherlands to some extent, and that their data were not fully comparable with 
the Swedish data. It is probable that the information concerning homicides in a familial milieu was the most reliable - their coding principles were unambiguous and it is likely that they were not overrepresented among the Dutch missing data cases, thus the Dutch numbers in table 11 should represent the maximum level. As we can see in table 11, homicides in a familial milieu made up 36 to 45 per cent of all homicides in the project countries. However, the percentage was substantially larger in Sweden (45 per cent), than in the Netherlands ( 39 per cent) or in Finland (36 per cent). Intimate-partner homicides were the most common type of familial killings, making up 29 per cent of all homicides in Sweden and 24 per cent of those in Finland and in the Netherlands.

In Sweden and Finland, information about homicides related to robberies, sexual crimes and other criminal offences were also fairly reliable and comparable. It can also be assumed that the Dutch data did not overstate these types of homicides, but rather that the numbers are lower than the actual frequency. In both Sweden ( 8 per cent) and the Netherlands ( 9 per cent) murder-robberies made up a larger percentage of homicides than in Finland ( 3 per cent). In the Netherlands, the percentage of homicides related to sexual crimes ( 3 per cent) was very high compared to Sweden $(0.3$ per cent) or Finland (0.2 per cent). Similarly, homicides committed in a criminal milieu were more common in the Netherlands (19 per cent) than in Sweden (12 per cent) or in Finland (3 per cent) this in spite of the fact that they were probably underrepresented among the coded homicides in the Dutch data and those shown in table 11.

Table 12. Annual crime rates of some homicide types in Finland, the Netherlands, and Sweden in 2003-2006 (victims per million inhabitants)

\begin{tabular}{lccc}
\hline Homicide type & The Netherlands & Sweden & Finland \\
\hline $\begin{array}{l}\text { Intimate-partner killings against } \\
\text { women* }\end{array}$ & 3.5 & 4.0 & 8.2 \\
$\quad$-in a separation situation* & 1.6 & 1.8 & 1.8 \\
Intimate-partner killings against & 1.2 & 1.1 & 2.3 \\
men** $^{* *}$ & & & \\
Child-killings & & & \\
Murder-robberies & 2.7 & 1.9 & 6.6 \\
Sexual crime related & 0.9 & 0.6 & 0.6 \\
Criminal milieu related & 0.3 & 0.0 & 0.0 \\
\hline
\end{tabular}

* Victims per million women, separation situation refers to the legal status of the relationship.

** Victims per million men.

${ }^{* \star *}$ All types of child-killings; victims per million 0-17-year-olds. 
To sum up, in spite of the aforementioned cautionary statements, the classification seems to have shown fairly reliably the main differences in homicide type between the countries. Homicidal crime was the most instrumental in the Netherlands and the most expressive in Finland. This was underlined by the fact that instrumental homicides were probably overrepresented among the missing data cases in the Dutch data and the bulk of Finnish homicides in the "other" categories were made up by expressive drunken brawls. It seems that homicides in the Netherlands have a closer connection to other organized and non-organized crime than in the Nordic countries. In the Nordic countries, especially in Finland, homicides seem to be results of trivial altercations and quarrels more often than in the Netherlands - as we can see later in this chapter, most of the victims and perpetrators in these quarrels are intoxicated.

\section{Relationship between victim and perpetrator}

The comparability of the data regarding the relationship between the victim and perpetrator was affected by the differences in data quality. Information was missing in 46 per cent of the Dutch cases. Therefore, it is probable that the comparisons regarding the Dutch data overestimate the share of homicides committed in a familial milieu and underestimate homicides between strangers and acquaintances.

Table 13. Victim-perpetrator relationship in homicides in Finland, the Netherlands, and Sweden in 2003-2006 (by victim).

\begin{tabular}{lrrrrrr}
\hline & \multicolumn{2}{c}{ The Netherlands } & \multicolumn{2}{c}{ Sweden } & \multicolumn{2}{c}{ Finland } \\
$\begin{array}{l}\text { Victim-perpetrator } \\
\text { relation }\end{array}$ & $N$ & $\%$ & $N$ & $\%$ & $N$ & $\%$ \\
\hline $\begin{array}{l}\text { Intimate-partner/ } \\
\text { ex-partner }\end{array}$ & 124 & 28 & 87 & 28 & 109 & 23 \\
Homosexual partner & 5 & 1 & 1 & 0.3 & 3 & 1 \\
Child & 42 & 9 & 16 & 5 & 27 & 6 \\
Parent & 19 & 4 & 24 & 8 & 18 & 4 \\
Sibling & 8 & 2 & 5 & 2 & 4 & 1 \\
Other relative & 22 & 5 & 6 & 2 & 6 & 1 \\
Acquaintance & 191 & 43 & 129 & 41 & 257 & 54 \\
Stranger & 32 & 7 & 43 & 14 & 51 & 11 \\
All valid cases & 443 & 100 & 311 & 100 & 475 & 100 \\
\hline Unknown & 377 & 46 & 44 & 12 & 16 & 3 \\
All cases & 820 & & 355 & & 491 & \\
\hline
\end{tabular}


The share of homicides in close relationships (between intimate partners, family members or relatives) made up a much larger percentage of Dutch (49 per cent) and Swedish (45 per cent) homicides than of Finnish homicides ( 36 per cent). While the figures reflected an actual difference between the Nordic countries, the Dutch data were more problematic to interpret. If calculated on the basis of all homicides, then the percentage of homicides in close relationships was only 27 per cent, substantially lower than in Finland. Homicides between strangers made up a larger percentage of Swedish homicides than of Finnish homicides, and the share of homicides between acquaintances was substantially larger in Finland (54 per cent) than in Sweden (41 per cent).

Table 14. Victim-perpetrator relationship in homicides against men in Finland, the Netherlands, and Sweden in 2003-2006 (by victim).

\begin{tabular}{lrrrrrr}
\hline & The Netherlands & \multicolumn{2}{c}{ Sweden } & \multicolumn{2}{c}{ Finland } \\
Victim-perpetrator & $N$ & $\%$ & $N$ & $\%$ & $N$ & $\%$ \\
relationship & & & & & & \\
\hline Intimate-partner/ & 20 & 8 & 18 & 10 & 21 & 6 \\
ex-partner & 4 & 2 & 1 & 1 & 3 & 1 \\
Homosexual partner & 19 & 7 & 6 & 3 & 18 & 5 \\
Child & 11 & 4 & 12 & 6 & 10 & 3 \\
Parent & 5 & 2 & 3 & 2 & 3 & 1 \\
Sibling & 12 & 5 & 6 & 3 & 4 & 1 \\
Other relative & 166 & 63 & 110 & 58 & 231 & 68 \\
Acquaintance & 27 & 10 & 33 & 17 & 49 & 14 \\
Stranger & 264 & 100 & 189 & 100 & 339 & 100 \\
All valid cases & 284 & 52 & 33 & 15 & 16 & 5 \\
\hline Unknown & 548 & & 222 & & 355 & \\
All cases & & & & &
\end{tabular}

Patterns of victimization were different for men and women (and similar in all three countries). The majority of women were killed by their partners, while most men were killed by acquaintances. In Finland and Sweden, homicides committed by strangers against women were much rarer than those committed by strangers against men. This was likely the case in the Netherlands too, even if there were a large number of unknown cases. 
Table 15. Victim-perpetrator relationship in homicides against women in Finland, the Netherlands, and Sweden in 2003-2006 (by victim).

\begin{tabular}{|c|c|c|c|c|c|c|}
\hline \multirow[b]{2}{*}{$\begin{array}{l}\text { Victim-perpetrator } \\
\text { relationship }\end{array}$} & \multicolumn{2}{|c|}{ The Netherlands } & \multicolumn{2}{|c|}{ Sweden } & \multicolumn{2}{|c|}{ Finland } \\
\hline & $\mathrm{N}$ & $\%$ & $\mathrm{~N}$ & $\%$ & $\mathrm{~N}$ & $\%$ \\
\hline $\begin{array}{l}\text { Intimate-partner/ } \\
\text { ex-partner }\end{array}$ & 104 & 59 & 69 & 57 & 88 & 65 \\
\hline $\begin{array}{l}\text { Homosexual } \\
\text { partner }\end{array}$ & 1 & 1 & 0 & 0 & 0 & 0 \\
\hline Child & 20 & 11 & 10 & 8 & 9 & 7 \\
\hline Parent & 8 & 5 & 12 & 10 & 8 & 6 \\
\hline Sibling & 3 & 2 & 2 & 2 & 1 & 1 \\
\hline Other relative & 10 & 6 & 0 & 0 & 2 & 1 \\
\hline Acquaintance & 25 & 14 & 19 & 16 & 26 & 19 \\
\hline Stranger & 5 & 3 & 10 & 8 & 2 & 1 \\
\hline All valid cases & 176 & 100 & 122 & 100 & 136 & 100 \\
\hline Unknown & 84 & 32 & 11 & 8 & 0 & 0 \\
\hline All cases & 260 & & 133 & & 136 & \\
\hline
\end{tabular}

There were some differences between male and female victimization patterns in the three countries. In Finland, intimate-partner homicides made up a larger percentage of homicides against women than in Sweden or the Netherlands. In spite of this, the percentage of female victims killed outside close relations was almost the same in Finland (20 per cent) and in Sweden ( 24 per cent), and it is possible that it was more or less the same in the Netherlands (if most of the missing data cases were crimes outside a familial milieu, this was probably the case). In intra-familial homicides, the difference between Finland and Sweden in intimate-partner homicides was levelled off by a larger percentage of mothers killed by their children in Sweden. In the Netherlands, women killed by relatives other than family-members were more common than in Finland or Sweden.

In homicides against men, the percentage of intimate-partner homicides was the smallest and the percentage of crimes committed outside close relationships the largest in Finland. Filicides ${ }^{18}$ made up a larger percentage of male killings in Finland and the Netherlands than in Sweden, while the percentage of fathers killed by their children was the largest in Sweden.

18 Children (irrespective of age) killed by their parents. 
Table 16. Victim-perpetrator relationship in homicides committed by men in Finland, the Netherlands, and Sweden in 2003-2006 (by principal perpetrator).

\begin{tabular}{|c|c|c|c|c|c|c|}
\hline \multirow[b]{2}{*}{$\begin{array}{l}\text { Victim-perpetrator } \\
\text { relationship }\end{array}$} & \multicolumn{2}{|c|}{ The Netherlands } & \multicolumn{2}{|c|}{ Sweden } & \multicolumn{2}{|c|}{ Finland } \\
\hline & $\mathrm{N}$ & $\%$ & $\mathrm{~N}$ & $\%$ & $\mathrm{~N}$ & $\%$ \\
\hline $\begin{array}{l}\text { Intimate-partner/ } \\
\text { ex-partner }\end{array}$ & 102 & 30 & 70 & 26 & 88 & 22 \\
\hline $\begin{array}{l}\text { Homosexual } \\
\text { partner }\end{array}$ & 4 & 1 & 0 & 0 & 3 & 1 \\
\hline Child & 13 & 4 & 7 & 3 & 7 & 2 \\
\hline Father & 11 & 3 & 12 & 4 & 9 & 2 \\
\hline Mother & 7 & 2 & 6 & 2 & 8 & 2 \\
\hline Sibling & 8 & 2 & 5 & 2 & 4 & 1 \\
\hline Other relative & 13 & 4 & 5 & 2 & 6 & 1 \\
\hline Acquaintance & 153 & 45 & 120 & 45 & 236 & 58 \\
\hline Stranger & 30 & 9 & 42 & 16 & 46 & 11 \\
\hline All valid cases & 341 & 100 & 267 & 100 & 407 & 100 \\
\hline Unknown & 225 & 40 & 7 & 3 & 6 & 1 \\
\hline All cases & 566 & & 274 & & 413 & \\
\hline
\end{tabular}

There were also clear differences in the relationship data related to the gender of the perpetrator. In all three countries, women killed mainly their intimate partners or ex-partners. However, in Sweden the percentage of this type of homicides was considerably larger (56 per cent) than in Finland (40 per cent) or in the Netherlands (39 per cent). Furthermore, the percentage of parents killed by their children was by far the largest in Sweden. On the other hand, filicides made up a bigger percentage of homicides by women in the Netherlands ( 24 per cent) and Finland ( 23 per cent) than in Sweden (19 per cent), and both countries had a larger share of crimes outside close relationships than Sweden. 
Table 17. Victim-perpetrator relationship in homicides committed by women in Finland, the Netherlands, and Sweden in 2003-2006 (by principal perpetrator).

\begin{tabular}{|c|c|c|c|c|c|c|}
\hline \multirow[b]{2}{*}{$\begin{array}{l}\text { Victim-perpetrator } \\
\text { relationship }\end{array}$} & \multicolumn{2}{|c|}{ The Netherlands } & \multicolumn{2}{|c|}{ Sweden } & \multicolumn{2}{|c|}{ Finland } \\
\hline & $\mathrm{N}$ & $\%$ & $\mathrm{~N}$ & $\%$ & $\mathrm{~N}$ & $\%$ \\
\hline $\begin{array}{l}\text { Intimate-partner/ } \\
\text { ex-partner }\end{array}$ & 13 & 39 & 18 & 56 & 21 & 40 \\
\hline Homosexual partner & 1 & 3 & 0 & 0 & 0 & 0 \\
\hline Child & 8 & 24 & 6 & 19 & 12 & 23 \\
\hline Parent & 2 & 6 & 4 & 13 & 0 & 0 \\
\hline Sibling & 0 & 0 & 0 & 0 & 0 & 0 \\
\hline Other relative & 1 & 3 & 0 & 0 & 0 & 0 \\
\hline Acquaintance & 7 & 21 & 4 & 13 & 16 & 31 \\
\hline Stranger & 1 & 3 & 0 & 0 & 3 & 6 \\
\hline All valid cases & 33 & 100 & 32 & 100 & 52 & 100 \\
\hline Unknown & 20 & 36 & 1 & 3 & 0 & 0 \\
\hline All cases & 53 & & 33 & & 52 & \\
\hline
\end{tabular}

The victims of men were usually acquaintances. Intimate-partner homicides made up a smaller percentage of victims in Finland (22 per cent) than in Sweden ( 26 per cent) or the Netherlands (30 per cent). The overall percentage of homicides in close relationships was the largest in the Netherlands, although the large number of missing data made the comparability of the results uncertain. In Sweden, homicides outside close relationships made up a slightly smaller percentage (61 per cent) than in Finland (69 per cent). 
Table 18. The prevalence of different relationship type homicides in Finland, the Netherlands, and Sweden in 2003-2006.

\begin{tabular}{|c|c|c|c|c|c|c|}
\hline \multirow[b]{2}{*}{ Homicide type } & \multicolumn{2}{|c|}{ The Netherlands } & \multicolumn{2}{|c|}{ Sweden } & \multicolumn{2}{|c|}{ Finland } \\
\hline & $\mathrm{N}$ & rate $^{*}$ & $\mathrm{~N}$ & rate* $^{*}$ & $\mathrm{~N}$ & rate $^{*}$ \\
\hline $\begin{array}{l}\text { Women killed by heterosexual } \\
\text { partner }\end{array}$ & 104 & 3.2 & 69 & 3.8 & 88 & 8.2 \\
\hline $\begin{array}{l}\text { Men killed by heterosexual } \\
\text { partner }\end{array}$ & 20 & 0.6 & 18 & 1.0 & 21 & 2.0 \\
\hline $\begin{array}{l}\text { Men killed by homosexual } \\
\text { partner }\end{array}$ & 4 & 0.1 & 1 & 0.1 & 3 & 0.1 \\
\hline Infanticides ${ }^{\star \star}$ & 13 & 16.6 & 3 & 7.4 & 7 & 30.4 \\
\hline Children killed by parents ${ }^{* * *}$ & 27 & 2.4 & 11 & 1.9 & 15 & 4.4 \\
\hline Adults killed by parents & 2 & 0.0 & 2 & 0.1 & 5 & 0.2 \\
\hline Fathers killed by children & 11 & 0.3 & 12 & 0.7 & 10 & 1.0 \\
\hline Mothers killed by children & 8 & 0.2 & 12 & 0.7 & 8 & 0.7 \\
\hline Men killed by other relatives & 17 & 0.5 & 9 & 0.5 & 7 & 0.7 \\
\hline Women killed by other relatives & 13 & 0.4 & 2 & 0.1 & 3 & 0.3 \\
\hline Men killed by acquaintances & 166 & 5.2 & 110 & 6.1 & 231 & 22.5 \\
\hline Women killed by acquaintances & 25 & 0.8 & 19 & 1.0 & 26 & 2.4 \\
\hline Men killed by strangers & 27 & 0.8 & 33 & 1.8 & 49 & 4.8 \\
\hline Women killed by strangers & 5 & 0.2 & 10 & 0.5 & 2 & 0.2 \\
\hline All valid cases & 442 & & 311 & & 475 & \\
\hline Unknown & 378 & 5.7 & 44 & 1.2 & 16 & 0.8 \\
\hline All cases & 820 & 12.6 & 355 & 9.8 & 491 & 23.4 \\
\hline
\end{tabular}

Table 18 shows the relative levels of different relation type homicides per million inhabitants in the three countries. The ratios are based on cases with known relationships only, meaning that the Dutch figures are approximately 46 per cent, the Swedish rates 12 per cent, and the Finnish rates 3 per cent lower than they would have been had there been no missing cases. It is probable that in all three countries the difference is bigger in homicides outside close relationships than in those committed in a familial milieu.

The Dutch general homicide rate in the data was almost 30 per cent higher than the Swedish rate. However, as we can see in table 18, the Dutch rates were well below the Swedish rates for most types of relations. This was probably mainly due to the large number of missing data in the Dutch data. However, in spite of this, in a few crime types the Dutch rates were clearly higher than the Swedish ones. Infanticides, homicides against children in general, and homicides against women by relatives other than 
family members were more prevalent in the Netherlands than in Sweden. The Finnish general homicide rate was about 140 per cent higher than the Swedish rate. However, the difference was much greater in some types of homicide. The rate of infanticides was over 400 per cent higher than in Sweden and the rate of homicides between acquainted men almost 370 per cent higher -the latter difference was particularly important since that crime type was the most common in both countries. On the other hand, in some homicide types the difference was smaller than in the general homicide rate, e.g. intimate-partner homicides against women as well as men, children killed by their parents and fathers killed by their children. The rates of mothers killed by their children, and homicides committed by parents against their adult children were the same in both countries. The only type of homicide that was less common in Finland than in Sweden during the period was women killed by strangers. The rates of most homicide types were higher in the Finnish data than in the Dutch data. This was probably mainly due to the large number of missing cases in the Dutch data, but could in some homicide types also reflect actual differences between the two countries. The largest differences could be found in the rates of homicides between acquainted men and homicides against men by strangers. In addition, the rates for parents killed by their children and intimate-partner homicides (against men and women) displayed greater differences than the general homicide rate. The only homicide type in the data that was rarer in Finland than in the Netherlands was homicides against women by relatives other than family members.

\section{Alcohol and drugs}

The EHM includes data on whether the victims and perpetrators had been drinking alcohol or taken drugs at the time of the crime as well as information about alcohol and substance abuse. This information is so far only available for Finland and Sweden.

Figure 17. Percentage of alcohol intoxicated adult female and male homicide victims and perpetrators in Finland and Sweden in 2003-2006.

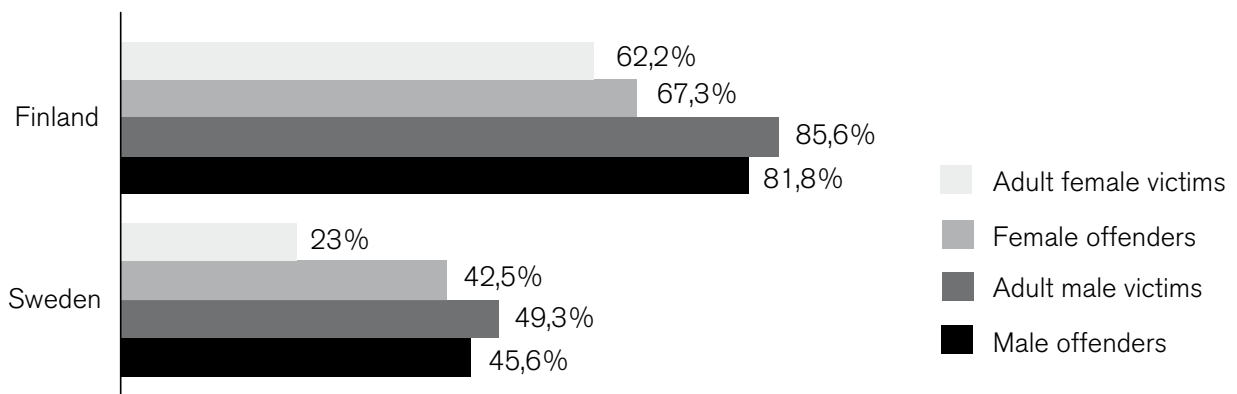


In both countries, there existed a clear link between alcohol consumption and homicidal crime, although this connection was stronger in Finland than in Sweden. In Sweden, about 45 per cent of both male and female perpetrators as well as adult male victims had been drinking alcohol at the time of the crime and about one third were described as alcoholics ${ }^{19}$ (see figures 17 and 18). In Finland, over 80 per cent of all adult men and about 65 per cent of all adult women involved in homicides had been drinking, and 50 to 60 per cent of the men and over 40 per cent of the women were described as alcoholics.

Figure 18. Percentage of adult female and male homicide victims and perpetrators in Finland and Sweden in 2003-2006 who were alcoholics.

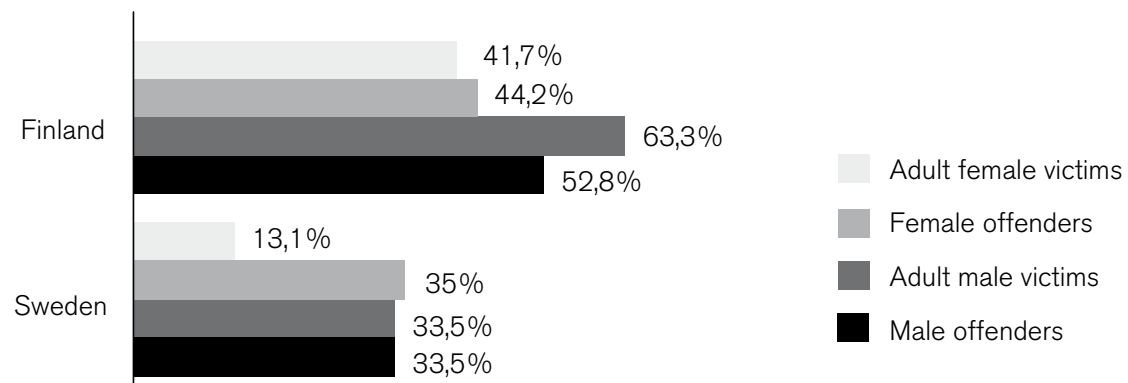

In 83 per cent of homicides in Finland, at least one of the persons involved had been drinking alcohol. The corresponding figure in Sweden was 46 per cent (58 per cent excluding unknown cases). In Sweden, 33 per cent ( 42 per cent), and in Finland 14 per cent of homicides had no connection to alcohol consumption.

19 A victim or perpetrator is defined as an alcoholic if there are circumstances that indicate that the individual has excessive drinking patterns such as consuming large amounts of alcohol over a period of several days or having been diagnosed and/or treated clinically for alcoholism or alcohol-related problems. 
Figure 19. The percentages of all homicides that were alcohol-related in Finland and Sweden in 2003-2006 (by victim; the intoxication status of victim and principal perpetrator).

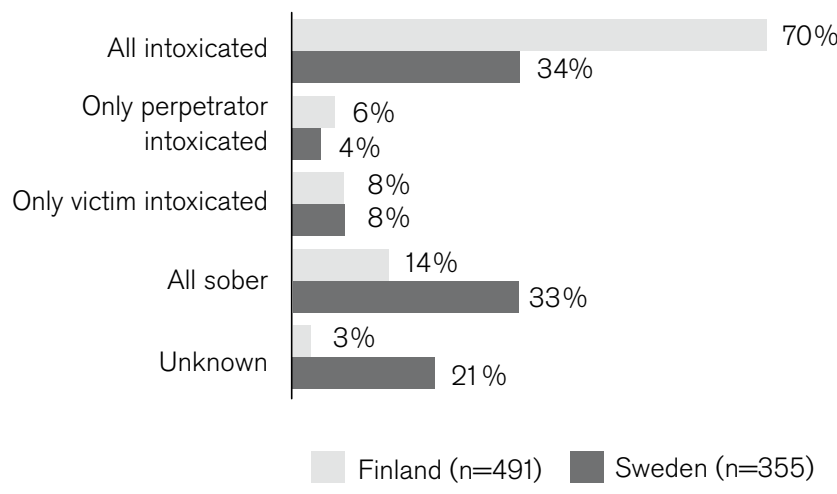

If we convert these percentages into victimization rates, we can see that the difference between the general homicide rates of Finland and Sweden can be attributed entirely to alcohol-related homicides (see figure 20). The difference between the rates of homicides that are strongly related to alcohol (i.e., those where both the victim and primary perpetrator were intoxicated) was particularly large.

Figure 20. The annual victimization rates of alcohol-related and non-alcoholrelated homicides in Finland and Sweden in 2003-2006 (strongly alcohol related $=$ all the persons involved intoxicated; to some extent alcohol related $=$ some of the persons involved intoxicated; not alcohol related $=$ all the persons involved sober). Per 100,000 inhabitants.

\begin{tabular}{r|c|c|}
\multicolumn{3}{|c}{ Homicides per 100000 pop. a year } \\
Strongly alcohol related & 0,33 & 1,63 \\
To some extent alcohol & 0,32 & \\
related & 0,12 & \\
Not alcohol related & 0,33 & \\
\cline { 2 - 3 } Unknown & 0,33 & \\
General homicide rate & 0,06 & \\
& & \\
& & \\
& & \\
& Finland & Sweden
\end{tabular}


The figures concerning the involvement of drugs in homicides were similar in both countries (see figures 21 and 22). About one fifth of male perpetrators were under the influence of either illicit drugs or psychosomatic drugs (often taken together with alcohol) at the time of the crime. The percentages for female perpetrators and victims as well as male victims were lower.

Figure 21. Percentage of adult homicide victims and perpetrators under the influence of drugs at the time of the crime in Finland and Sweden in 2003-2006.

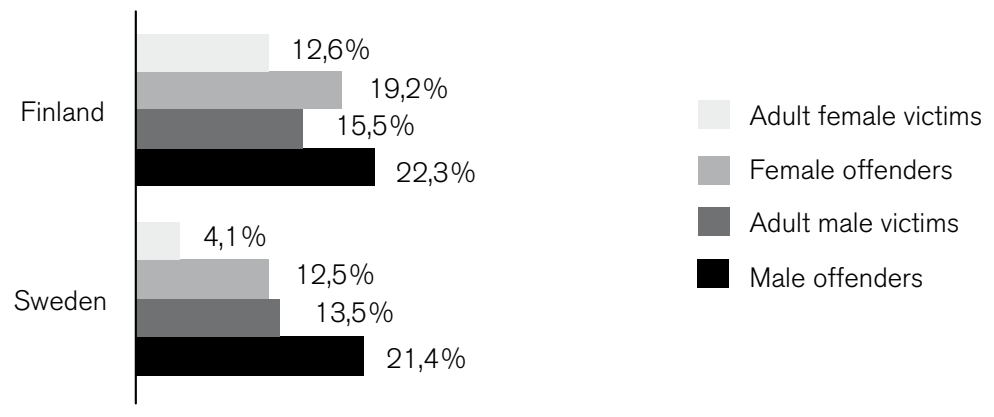

In Finland, about 30 per cent and in Sweden almost 40 per cent of male homicide perpetrators were described as drug abusers. ${ }^{20}$ For female perpetrators and adult male victims the percentages were between 10 and 20 per cent, and for adult female victims the rate was under 10 per cent.

Figure 22. Percentage of adult homicide victims and perpetrators who were drug abusers at the time of the crime in Finland and Sweden in 2003-2006.

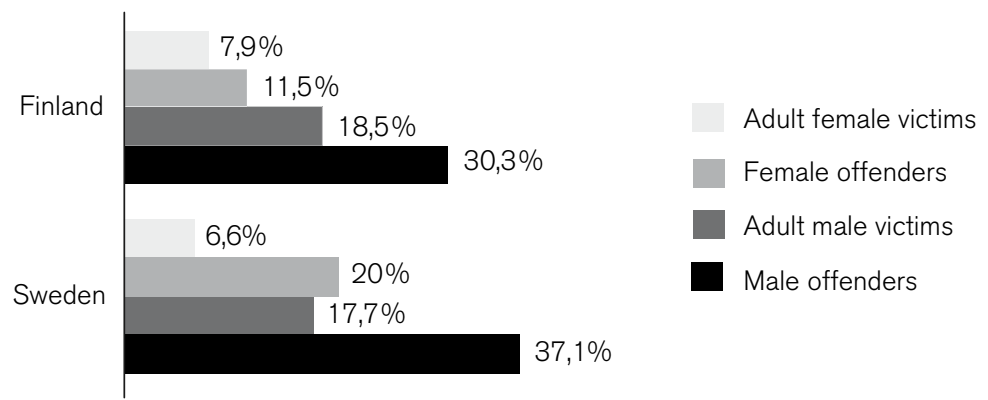

20 A victim or perpetrator is defined as a drug abuser if there are circumstances that indicate that the individual has excessive drug use patterns at the time of the crime, such as using "hard" or large amounts of drugs over a period of several days or having been diagnosed and/or treated clinically for drug abuse or drugrelated problems. 


\section{Victim's death and professional medical care}

The EHM includes information on whether the victim received professional medical care after the crime, before or during his/her death. At the time of this report, these data were available only for Finland and Sweden. Table 19 indicates that in both countries, the majority of homicide victims died before they had had a chance to receive any professional medical care. However, the percentage of those who had received care before their death was substantially larger in Sweden (19 per cent) than in Finland ( 8 per cent). This probably reflects differences in the typical circumstances of homicides in the two countries (the larger percentage of alcohol related crimes in Finland may cause the difference because serious intoxication often delays calling for an ambulance). A contributing explanation can be the fact that a larger percentage of homicides in Finland have been found to take place in rural areas that take longer for ambulances to reach. Improvements in the quality of medical care would probably not have an effect on the number of homicide deaths in the two countries, because most of the victims die before they are able to receive any care. Improvements in the time in which medical care is available may on the other hand have some effect on the number of homicide deaths.

Table 19. Homicide victims and professional medical care in Finland and Sweden in 2003-2006 (by victim).

\begin{tabular}{lrrrr}
\hline & \multicolumn{2}{c}{ Sweden } & \multicolumn{2}{c}{ Finland } \\
Medical care received & $N$ & $\%$ & N & $\%$ \\
\hline Deceased before care & 262 & 81 & 449 & 92 \\
Deceased during/after care & 63 & 19 & 39 & 8 \\
All valid cases & 325 & 100 & 488 & 100 \\
\hline Unknown & 30 & 8 & 3 & 1 \\
All cases & 355 & & 491 & \\
\hline
\end{tabular}

\section{Reporting and solving of homicides}

Data on the lapse of time from when the crime took place until it was reported were available only for the Nordic countries. The majority of homicides became known to the police in less than twenty-four hours (in Sweden 89 per cent, in Finland 80 per cent). In both countries, 3 per cent of all homicides were discovered more than one month after they had taken place. 
According to the data, the clearance rate $^{21}$ of homicides in 2003-2006 was relatively high in all three countries. However, it was clearly higher in Finland (98 per cent) than in Sweden (86 per cent) or the Netherlands (61 per cent to 87 per cent; the clearance status of the crime was unknown in 26 per cent of the Dutch cases).

Table 20. Number of days between the homicide and the arrest of the principal perpetrator in Finland, the Netherlands, and Sweden in 2003-2006 (by homicide incident).

\begin{tabular}{lrrrrrr}
\hline & The Netherlands & \multicolumn{2}{c}{ Sweden } & \multicolumn{2}{c}{ Finland } \\
Number of days & $\mathrm{N}$ & $\%$ & $\mathrm{~N}$ & $\%$ & $\mathrm{~N}$ & $\%$ \\
\hline within 24 hours & 47 & 23 & 183 & 58 & 284 & 62 \\
1 day & 10 & 5 & 12 & 4 & 52 & 11 \\
2-7 days & 11 & 5 & 32 & 10 & 67 & 15 \\
8-30 days & 13 & 6 & 21 & 7 & 21 & 5 \\
31-365 days & 19 & 9 & 30 & 9 & 17 & 4 \\
More than 366 days & 4 & 2 & 0 & 0 & 5 & 1 \\
Crime not yet solved & 101 & 49 & 40 & 13 & 10 & 2 \\
All valid cases & 205 & 100 & 318 & 100 & 456 & 100 \\
\hline Perpetrator died before & 16 & 2 & 16 & 5 & 14 & 3 \\
arrest & 539 & 71 & 8 & 2 & 5 & 1 \\
\hline Unknown & 760 & & 342 & & 475 & \\
All cases & & & & & & \\
\hline
\end{tabular}

In Finland and Sweden, perpetrators were usually arrested shortly after the reporting of the crime. In Finland, 73 per cent of the principal perpetrators were arrested before the end of the next day from when the crime was reported, and in Sweden the equivalent figure was 62 per cent. In the Netherlands, the figure is only 28 per cent.

The three countries are more alike regarding cases where more than one month lapsed before an arrest was made; 5 per cent in Finland, 9 per cent in Sweden and 11 per cent in the Netherlands. In the Netherlands, it seems to take longer for homicides to be solved than in the Nordic countries. This can be an indication of differences in homicide characteristics (instrumentally motivated homicides in general and homicides related to organized crime in particular are usually harder to solve than expressive homicides).

21 A case is considered cleared when at least one perpetrator is known to the police. This includes cases where the perpetrator is known but has committed suicide, is diseased for other reasons, or has gone missing. 
Although the number of missing cases makes it difficult to reach any conclusions about the Dutch data, it is noteworthy that the number of unsolved cases differs to the extent it does.

\section{Victim characteristics}

\section{Number of homicide victims}

In the period 2003-2006, a total of 1666 victims were involved in homicides in the three countries; 491 homicide victims were killed in Finland, 820 in the Netherlands, and 355 in Sweden. On average, Finland assumed a middle position regarding the number of homicide victims per year $(\mathrm{N}=123)$. The Netherlands had the highest number of homicide victims per year $(\mathrm{N}=205)$, and Sweden had the lowest average number of homicide victims per year $(\mathrm{N}=89)$ when compared to the other two countries.

When comparing the homicide victimization rates between the three countries, on average, Finland had the highest victimization rate (2.34) per 100,000 inhabitants, followed by the Netherlands (1.26). Sweden, on the other hand, had the lowest average victimization rate $(0.98)$ (see table 21).

Table 21. Annual number of homicide victims and victimization rate in the Netherlands, Sweden and Finland in 2003-2006 (per 100,000 inhabitants).

\begin{tabular}{lrrrrrr}
\hline & \multicolumn{2}{c}{ The Netherlands } & \multicolumn{2}{c}{ Sweden } & \multicolumn{2}{c}{ Finland } \\
Year & Victims & Rate & Victims & Rate & Victims & Rate \\
\hline 2003 & 249 & 1.54 & 84 & 0.94 & 106 & 2.03 \\
2004 & 219 & 1.35 & 109 & 1.21 & 148 & 2.83 \\
2005 & 205 & 1.26 & 81 & 0.90 & 117 & 2.23 \\
2006 & 147 & 0.90 & 81 & 0.89 & 120 & 2.27 \\
\hline Average & 205 & 1.26 & 89 & 0.98 & 123 & 2.34 \\
\hline
\end{tabular}

\section{Gender of the victims}

In all three countries, most homicide victims were male (see table 22). In Finland less than one third of the victims were female, in the Netherlands about a third of the victims were female and in Sweden, almost 40 per cent of the victims were female. These results correspond to earlier studies on homicide in the countries (e.g. Kivivuori, 1999; Lehti, 2002; Nieuwbeerta \& Leistra, 2003; Rying, 2000). This result could be interpreted as being part of a well-known pattern; that the higher the homicide rate in a certain country, a certain part of the world or a certain historical time, the higher the share of male victims. Therefore, variations in homicide 
rates over time and place are usually dependent on variations in male homicide victimization (von Hofer, 2008).

Table 22. Gender of homicide victims in the Netherlands, Sweden and Finland in 2003-2006.

\begin{tabular}{lrrrrrr}
\hline & \multicolumn{2}{c}{ The Netherlands } & \multicolumn{2}{c}{ Sweden } & \multicolumn{2}{c}{ Finland } \\
Gender & $\mathrm{N}$ & $\%$ & $\mathrm{~N}$ & $\%$ & $\mathrm{~N}$ & $\%$ \\
\hline Male & 548 & 68 & 222 & 63 & 355 & 72 \\
Female & 260 & 32 & 133 & 38 & 136 & 28 \\
All valid cases & 808 & 100 & 355 & 100 & 491 & 100 \\
\hline Unknown & 12 & 1 & 0 & 0 & 0 & 0 \\
Total & 820 & & 355 & & 491 & \\
\hline
\end{tabular}

\section{Age of the victims}

In all three countries, homicide victims who were under the age of 24 or over the age of 64 were uncommon, accounting for approximately one third of the total number of victims in each country (see table 23). In fact, in all countries more than two thirds of the homicide victims were between the age of 25 and 64. However, when comparing the average age of the homicide victims in the three countries we did notice some differences. Homicide victims in Finland and Sweden presented almost identical figures regarding the age of the victim. Victims in these Nordic countries were on average older (42.1 years in Finland and 41.5 years in Sweden) compared to victims in the Netherlands ( 37.4 years). These differences could be explained by homicides related to the criminal milieu. Compared to Finland and Sweden, the Netherlands displays a relatively high percentage of homicides in this category, as indicated in the previous chapter, and crime-related homicides are more likely to involve relatively young perpetrators and victims.

Finland had a relatively high degree of victims in the age category 25-64 years (80 per cent) when compared to the Netherlands (71 per cent) and Sweden (68 per cent) (table 23). More than half of the homicide victims in Finland were between 40 and 64 years old; one third of the Dutch homicide victims were between 40 and 64 years old; while 40 per cent of homicide victims in Sweden belonged to this age group. 
Table 23. Age of homicide victims in the Netherlands, Sweden and Finland in 2003-2006.

\begin{tabular}{lcrrrrr}
\hline & \multicolumn{2}{c}{ The Netherlands } & \multicolumn{2}{c}{ Sweden } & \multicolumn{2}{c}{ Finland } \\
Age & $\mathrm{N}$ & \multicolumn{1}{c}{$\%$} & $\mathrm{~N}$ & $\%$ & $\mathrm{~N}$ & $\%$ \\
\hline-17 & 82 & 10 & 23 & 7 & 30 & 6 \\
$18-24$ & 91 & 11 & 41 & 13 & 38 & 8 \\
$25-39$ & 301 & 38 & 92 & 28 & 139 & 29 \\
$40-64$ & 265 & 33 & 133 & 40 & 249 & 51 \\
$65+$ & 61 & 8 & 40 & 12 & 35 & 7 \\
Mean (standard & & & & & & \\
deviation) & $37.4( \pm 18.2)$ & $41.5( \pm 18.5)$ & $42.1( \pm 16.4)$ \\
Minimum age & & 0 & & 0 & & 0 \\
Maximum age & & 96 & & 89 & & 85 \\
\hline All valid cases & 800 & 100 & 329 & 100 & 491 & 100 \\
\hline Unknown & 20 & 2 & 26 & 7 & 0 & 0 \\
Total & 820 & & 355 & & 491 & \\
\hline
\end{tabular}

\section{Age of the victims by type of homicide}

Table 24 displays the age of the victims in the most common types of homicide. Overall, the age of the victims in various types of homicide did not differ substantially among the three countries. Of all subcategories, victims of child killings within the family were on average the youngest; victims of other familial killings, as well as victims of robbery killings, were generally the oldest. This could be explained by a relatively high degree of parent killings among the other familial killings, as well as the relative vulnerability of elderly people as victims of robbery.

One exception to the relative similarities between the three countries concerned the age of victims of intimate partner homicides. In the Netherlands, victims of this type of homicide were generally younger (35.4 years) compared to intimate partner homicide victims in Finland (43.9 years) and Sweden (44.1 years). The results further indicated that victims of child killings within the family were older in Sweden (6.6 years) compared to the Netherlands (2.5 years) and Finland (3.4 years). Other exceptions concerned the average age of victims of homicides related to nightlife violence - in the Netherlands, victims of this type of homicide were generally younger ( 28.5 years) than their Swedish ( 34.0 years) and Finnish (36.9 years) counterparts. On the other hand, victims of non-family homicides motivated by a mental illness were generally older in the Netherlands (58.1) than in Finland (46.2 years) and Sweden (51.1 years). A final exception to the overall equally distributed victim age was the relatively high age of victims killed in 
other non-criminal homicides in Finland - their average age (43.4 years) was higher than the average age of victims of this kind in the Netherlands (35.9 years) and Sweden (38.7 years).

Table 24. Mean age of homicide victims by type of homicide in the Netherlands, Sweden and Finland in 2003-2006.

\begin{tabular}{|c|c|c|c|}
\hline Homicide type & $\begin{array}{l}\text { The Netherlands } \\
\text { Mean (standard } \\
\text { deviation) }\end{array}$ & $\begin{array}{l}\quad \text { Sweden } \\
\text { Mean (standard } \\
\text { deviation) }\end{array}$ & $\begin{array}{l}\text { Finland } \\
\text { Mean (standard } \\
\text { deviation) }\end{array}$ \\
\hline Intimate partner killing & $35.4( \pm 14.2)$ & $44.1( \pm 17.6)$ & $43.9( \pm 13.3)$ \\
\hline Child-killing: family & $2.50( \pm 3.1)$ & $6.6( \pm 5.3)$ & $3.37( \pm 4.7)$ \\
\hline Other familial killing & $50.8( \pm 21.9)$ & $53.2( \pm 17.9)$ & $54.0( \pm 17.6)$ \\
\hline Criminal milieu & $35.7( \pm 10.3)$ & $38.3( \pm 12.8)$ & $37.8( \pm 11.0)$ \\
\hline Robbery & $54.5( \pm 20.0)$ & $50.5( \pm 20.5)$ & $50.7( \pm 11.8)$ \\
\hline Nightlife violence & $28.5( \pm 8.5)$ & $34.0( \pm 12.4)$ & $36.9( \pm 12.9)$ \\
\hline $\begin{array}{l}\text { Mental illness: non- } \\
\text { family }\end{array}$ & $58.1( \pm 13.3)$ & $51.1( \pm 21.4)$ & $46.2( \pm 16.0)$ \\
\hline Child-killing: non-family & - & - & $34.6( \pm 20.3)$ \\
\hline $\begin{array}{l}\text { Other in non-criminal } \\
\text { milieu }\end{array}$ & $35.9( \pm 14.9)$ & $38.7( \pm 13.8)$ & $43.4( \pm 12.8)$ \\
\hline Other & - & - & $78.3( \pm 7.6)$ \\
\hline Total & $37.4( \pm 18.2)$ & $41.4( \pm 18.7)$ & $42.1( \pm 16.4)$ \\
\hline
\end{tabular}

\section{Age by gender of the victims}

When considering the age distribution by gender of the homicide victims, all three countries showed a similar pattern, in which the majority of both male and female homicide victims were between the age of 25 and 64.

The results, however, also showed differences between countries regarding the age distribution by gender. On average, female victims in the Netherlands were younger than female victims in Sweden and Finland. More than half of the female homicide victims in Finland and Sweden were 40 years or older, while the majority of the Dutch female homicide victims were younger than 40 years. This difference could be explained by looking at the type of homicide in each country. The results show that a relatively high percentage of homicides in Sweden involve cases where mothers are killed. In Finland, a relatively high percentage of homicides involved intimate partner homicides. In the Netherlands, as outlined in the previous chapter, cases of women being killed by relatives other than family members were relatively more common than in Finland or Sweden. Female victims of parent homicides and inti- 
mate partner homicides tend to be older than female victims killed by non-family members, which could explain the age differences observed.

The differences in the age of female victims were also reflected in the age of male victims. With an average age of 41.9 years, Finland had the oldest male victims compared to Sweden (40.7 years) and the Netherlands (38.0 years). More specifically, while more than half of the Finnish male homicide victims (58 per cent) were 40 years or older, at least half of the male homicide victims in Sweden and the Netherlands were younger than 40 years. These observations could be explained by examining the type of homicide. As described above, homicides in the criminal milieu tend to involve younger victims compared to homicides not linked to other criminal acts. As outlined in the previous chapter, homicides related to the criminal milieu were more common in the Netherlands (19 per cent) and Sweden (12 per cent) than in Finland ( 3 per cent), giving a possible explanation for these differences in victim age.

Another difference between the countries was that female victims in Finland and Sweden were on average older than male victims, while female victims in the Netherlands were on average younger than male victims.

Table 25. Age by gender of homicide victims in the Netherlands, Sweden and Finland in 2003-2006.

\begin{tabular}{|c|c|c|c|c|c|c|c|c|c|c|c|c|}
\hline \multirow[b]{3}{*}{ Age } & \multicolumn{4}{|c|}{ The Netherlands } & \multicolumn{4}{|c|}{ Sweden } & \multicolumn{4}{|c|}{ Finland } \\
\hline & \multicolumn{2}{|c|}{ Male victims } & \multicolumn{2}{|c|}{ Female victims } & \multicolumn{2}{|c|}{ Male victims } & \multicolumn{2}{|c|}{ Female victims } & \multicolumn{2}{|c|}{ Male victims } & \multicolumn{2}{|c|}{ Female victims } \\
\hline & $\Lambda$ & $\%$ & $\mathrm{~N}$ & $\%$ & N & $\%$ & N & $\%$ & $\mathrm{~N}$ & $\%$ & $\mathrm{~N}$ & $\%$ \\
\hline-17 & 46 & 9 & 33 & 13 & 9 & 5 & 14 & 11 & 19 & 5 & 11 & 8 \\
\hline $18-24$ & 6 & 12 & 27 & 11 & 27 & 13 & 14 & 11 & 29 & 8 & 9 & 7 \\
\hline $25-39$ & 19 & 37 & 102 & 40 & 64 & 32 & 28 & 22 & 101 & 29 & 38 & 28 \\
\hline $40-64$ & 19 & 36 & 70 & 27 & 83 & 41 & 50 & 39 & 189 & 53 & 60 & 44 \\
\hline $65+$ & 35 & 7 & 26 & 10 & 18 & 9 & 22 & 17 & 17 & 5 & 18 & 13 \\
\hline $\begin{array}{l}\text { Mean (stand- } \\
\text { ard deviation) }\end{array}$ & 38.0 & 17.3) & 36.7( & 19.7) & 40.7( & 16.1) & 42.7( & 21.7) & 41.9 & 15.5) & 42.8( & 18.5) \\
\hline All valid cases & 537 & 100 & 258 & 100 & 201 & 100 & 118 & 100 & 355 & 100 & 136 & 100 \\
\hline Unknown & 11 & 2 & 2 & 1 & 21 & 10 & 15 & 11 & 0 & 0 & 0 & 0 \\
\hline Total & 548 & & 260 & & 222 & & 133 & & 355 & & 136 & \\
\hline
\end{tabular}

When taking into account the age structure of the population in each country, the victimization rate for men and women in all age categories was the highest in Finland. The Netherlands had the second highest rate - compared to Sweden, the risk of being the victim of a homicide in the Netherlands is higher in all gender and age categories, with the exception of females aged 40 and older. 
When examining risk per country, the data show that Finnish men between the age of 40 and 64, and to a slightly lesser extent men between the age of 25 and 39 , run the highest risk of being the victim of homicide (see table 25). This corresponds to the figures found in the Netherlands and Sweden. In both countries, men between the age of 25 and 39 run the highest risk of being victimized. In all three countries, women in almost all age categories (with the exception of the very young) run a lower risk to be victimized than men. In Finland and the Netherlands, the risk for women to be victimized is the highest in the age category $25-39$, whereas in Sweden, as outlined above, the risk for women to be victimized is concentrated in higher age categories, from age 40 and older.

Table 26. Sex- and age-specific homicide victimization rates in the Netherlands, Sweden and Finland in 2003-2006 (per 100,000 inhabitants, annually).

\begin{tabular}{lcccccc}
\hline & \multicolumn{2}{c}{ The Netherlands } & \multicolumn{2}{c}{ Sweden } & \multicolumn{2}{c}{ Finland } \\
Age & Male & Female & Male & Female & Male & Female \\
\hline-17 & 0.63 & 0.47 & 0.23 & 0.37 & 0.84 & 0.51 \\
$18-24$ & 2.32 & 1.01 & 1.79 & 0.97 & 3.09 & 1.00 \\
$25-39$ & 2.79 & 1.47 & 1.72 & 0.79 & 4.98 & 1.95 \\
$40-64$ & 1.74 & 0.64 & 1.39 & 0.86 & 5.10 & 1.62 \\
$65+$ & 0.91 & 1.96 & 0.68 & 0.63 & 1.27 & 0.89 \\
\hline Total & 1.67 & 0.78 & 1.13 & 0.71 & 3.46 & 1.27 \\
\hline
\end{tabular}

\section{Birth country of victims}

When we consider the birth country of homicide victims, the majority of the victims in Finland and Sweden were born in the country where the crime was committed. In table 27 , this is indicated by the term 'native born'. In the Netherlands, 57 per cent of victims were born in the country where the homicide took place. However, this finding should be interpreted with caution, as the birth country of a high percentage of the Dutch victims (45 per cent) was unknown. Nevertheless, compared to Sweden and Finland, the Netherlands had a higher degree of homicide victims who were born in a foreign country (43 per cent), while in Finland and Sweden, foreign-born victims accounted 'only' for 4 per cent and 20 per cent, respectively. As outlined before, immigrants make up four per cent of the Finnish population, eleven per cent of the Dutch population and fourteen per cent of the Swedish population. In contrast to Finland, victims who were born in a foreign country were overrepresented in the Netherlands and Sweden, compared to their representation in the general population. 
In Finland, immigrants who were relatively overrepresented as homicide victims compared to their representation in the overall population were individuals of Kurdish decent, and to a lesser extent of Somali, Russian and Estonian descent. In the Netherlands, victims of Moroccan, Dutch Antillean, Surinamese and Turkish descent where overrepresented. In Sweden, on the other hand, overrepresentation among immigrants mainly concerned those who were born in Iraq or former Yugoslavia.

When examining relative mortality figures, the results indicated that Finnish citizens ran a risk of 2.3 per 100,000 inhabitants to become a homicide perpetrator. For foreign citizens residing in the country, this risk was 2.7 per 100,000 inhabitants. Those belonging to an ethnic minority ran a higher risk of becoming a homicide perpetrator, ranging from 10.0 per 100,000 inhabitants for Roma people, 5.1 per 100,000 inhabitants for individuals with a Kurdish background to 3.0 per 100,000 inhabitants for individuals of Somali descent. Other ethnic groups with an elevated mortality rate included people of Russian origin (2.7 per 100,000 inhabitants) and individuals with an Estonian background (2.4 per 100,000 inhabitants). These findings, especially the high homicide victimization rate among Roma people (an historical ethnic minority in Finland), corresponded to those of earlier studies (Grönfors, 1981; Lehti, 2001; Lehti, 2007; Kivivuori \& Lehti, 2010).

In the Netherlands, someone is regarded as having a nonDutch ethnicity if at least one parent is born outside the Netherlands. Individuals of Dutch ethnicity run a risk of 1.9 per 100,000 inhabitants to become a homicide victim, while the relative risk for individuals of Antillean descent is 19.9 per 100,000 inhabitants, 8.8 for individuals of Surinamese descent, 6.7 for individuals of Turkish descent and 5.1 for individuals of Moroccan descent. The relatively high degree of Dutch victims who were born in a foreign country corresponds to findings reported in earlier studies (Ganpat \& Liem, 2011; Nieuwbeerta \& Leistra, 2007). When assessing these characteristics according to type of homicide, Ganpat $\&$ Liem found that among criminal homicides, two-thirds of the perpetrators and 70 per cent of the victims were born outside the Netherlands. Turkish perpetrators and victims in particular are overrepresented in this category, with roughly one-fifth of the perpetrators and victims of criminal liquidations of Turkish origin. Turkish perpetrators and victims are further overrepresented among domestic homicides, which typically involve honour killings.

In Sweden, individuals of Swedish ethnicity run a risk of 0.7 per 100,000 inhabitants of being the victim of a homicide, as compared to 1.1 per 100,000 inhabitants for foreign-born individuals. This overrepresentation of foreign-born individuals corresponds fairly well to the findings in earlier studies on homicide in Sweden 
(Rying, 2000). Individuals born in former Yugoslavia ran a relative risk of 4.67 of becoming a homicide victim; for people born in Iraq the risk was 2.55 per 100,000 inhabitants. It should be emphasized that these figures are based on the birth country of the individual, rather than on the self-ascribed ethnic status.

Table 27. Birth country of homicide victims in the Netherlands, Sweden and Finland in 2003-2006.

\begin{tabular}{lccrrrr}
\hline & \multicolumn{2}{c}{ The Netherlands } & \multicolumn{2}{c}{ Sweden } & \multicolumn{2}{c}{ Finland } \\
Birth country & $\mathrm{N}$ & $\%$ & $\mathrm{~N}$ & $\%$ & $\mathrm{~N}$ & $\%$ \\
\hline Native & 256 & 57 & 229 & 80 & 461 & 96 \\
Foreign-born & 193 & 43 & 59 & 20 & 20 & 4 \\
All valid cases & 449 & 100 & 288 & 100 & 481 & 100 \\
\hline Unknown & 371 & 45 & 67 & 19 & 10 & 2 \\
Total & 820 & & 355 & & 491 & \\
\hline
\end{tabular}

\section{Birth country of victims by gender}

Similarly, when we consider the distribution of the birth country by gender, the large majority of female and male victims in Finland and Sweden were born in the same country as the crime took place (table 28). In contrast, the results show that in the Netherlands, 62 per cent of female and 54 per cent of male victims were born in the same country as the crime took place. However, with regard to these results, it should be noted that the birth country was unknown for a relatively high percentage of the Dutch homicide victims (45 per cent).

Table 28. Birth country of homicide victims by gender in the Netherlands,

Sweden and Finland in 2003-2006.

\begin{tabular}{lrrrrrrrrrrrrrrr}
\hline & \multicolumn{3}{c}{ The Netherlands } & \multicolumn{4}{c}{ Sweden } & \multicolumn{4}{c}{ Finland } \\
& Male victims & \multicolumn{1}{c}{ Female victims } & Male victims & \multicolumn{1}{c}{ Female victims } & Male victims & \multicolumn{2}{c}{ Female victims } \\
Birth country & $\mathrm{N}$ & $\%$ & $\mathrm{~N}$ & $\%$ & $\mathrm{~N}$ & $\%$ & $\mathrm{~N}$ & $\%$ & $\mathrm{~N}$ & $\%$ & $\mathrm{~N}$ & $\%$ \\
\hline Native & 162 & 54 & 92 & 62 & 132 & 79 & 97 & 81 & 337 & 97 & 124 & 93 \\
Foreign-born & 137 & 46 & 56 & 38 & 36 & 21 & 23 & 19 & 11 & 3 & 9 & 7 \\
All valid cases & 299 & 100 & 148 & 100 & 168 & 100 & 120 & 100 & 348 & 100 & 133 & 100 \\
\hline Unknown & 249 & 45 & 112 & 43 & 54 & 24 & 13 & 10 & 7 & 2 & 3 & 2 \\
Total & 548 & & 260 & & 222 & & 133 & & 355 & & 136 \\
\hline
\end{tabular}




\section{Marital status of the victims}

When considering the marital status of homicide victims, more than 40 per cent of homicide victims in Finland and Sweden were married, cohabitants or in a boyfriend/girlfriend relationship (table 29). Furthermore, about one in four victims were single. Due to the large proportion of unknown marital status in the Netherlands, these data are not reported.

Table 29. Marital status of homicide victims in Sweden and Finland in 2003-2006.

\begin{tabular}{lrrrr}
\hline & \multicolumn{2}{c}{ Sweden } & \multicolumn{2}{c}{ Finland } \\
Marital status & $\mathrm{N}$ & $\%$ & $\mathrm{~N}$ & $\%$ \\
\hline Married & 83 & 23 & 84 & 17 \\
Cohabitants & 43 & 12 & 80 & 16 \\
In a boyfriend/girlfriend relationship & 25 & 7 & 53 & 11 \\
Single & 137 & 39 & 214 & 44 \\
Divorced & - & - & 17 & 4 \\
Widowed & - & - & 7 & 1 \\
All valid cases & 288 & 100 & 455 & 100 \\
\hline Unknown & 67 & 19 & 36 & 7 \\
Total & 355 & & 491 & \\
\hline
\end{tabular}

\section{Marital status of the victims by gender}

In both Finland and Sweden, male victims were more likely to be single than their female counterparts. The majority of the female victims in Finland (71 per cent) as well as in Sweden (60 per cent) were married, cohabitants or in a boyfriend/girlfriend relationship. These figures seem to point to, which has been outlined previously, intimate partner homicides. This is particularly true for Finland, where the share of single female victims (19 per cent) is lower than in Sweden (33 per cent). 
Table 30. Marital status of homicide victims by gender in Sweden and Finland in 2003-2006.

\begin{tabular}{|c|c|c|c|c|c|c|c|c|}
\hline \multirow[b]{3}{*}{ Marital status } & \multicolumn{4}{|c|}{ Sweden } & \multicolumn{4}{|c|}{ Finland } \\
\hline & \multirow{2}{*}{$\begin{array}{c}\text { Male } \\
\text { N }\end{array}$} & \multirow{2}{*}{$\begin{array}{r}\text { victims } \\
\%\end{array}$} & \multicolumn{2}{|c|}{ Female victims } & \multirow{2}{*}{$\begin{array}{c}\text { Male } \\
\mathrm{N}\end{array}$} & \multirow{2}{*}{$\begin{array}{r}\text { victims } \\
\%\end{array}$} & \multicolumn{2}{|c|}{ Female victims } \\
\hline & & & $\mathrm{N}$ & $\%$ & & & $\mathrm{~N}$ & $\%$ \\
\hline Married & 37 & 17 & 46 & 35 & 45 & 13 & 39 & 29 \\
\hline Cohabitants & 21 & 10 & 22 & 17 & 46 & 13 & 34 & 25 \\
\hline $\begin{array}{l}\text { In a boyfriend/girl- } \\
\text { friend relationship }\end{array}$ & 15 & 7 & 10 & 8 & 30 & 9 & 23 & 17 \\
\hline Single & 93 & 42 & 44 & 33 & 188 & 53 & 26 & 19 \\
\hline Divorced & - & - & - & - & 11 & 3 & 6 & 4 \\
\hline Widowed & - & - & - & - & 3 & 1 & 4 & 3 \\
\hline All valid cases & 166 & 100 & 122 & 100 & 323 & 100 & 132 & 100 \\
\hline Unknown & 56 & 25 & 11 & 8 & 32 & 9 & 4 & 3 \\
\hline Total & 222 & & 133 & & 355 & & 136 & \\
\hline
\end{tabular}

\section{Employment status of the victims}

Attempts were made to look at the employment status of the victims, but the data did not give a representative view due to a lack of data and a large number of unknown values.

\section{Perpetrator characteristics}

\section{Number of homicide perpetrators}

In the period 2003-2006, a total of 1917 perpetrators were involved $^{22}$ in homicides in the three project countries; 475 perpetrators in Finland, 1022 in the Netherlands and 420 in Sweden. On average, the Netherlands had the highest number of perpetrators per year $(\mathrm{N}=256)$, followed by Finland $(\mathrm{N}=119)$ and Sweden $(\mathrm{N}=105)$.

Finland had the highest homicide offending rate $(2.22$ per 100,000 inhabitants), followed by the Netherlands (1.57 per 100,000 inhabitants) (see table 31). Sweden had the lowest offending rate (1.16 per 100,000 inhabitants).

22 The number of perpetrators includes all cases with known perpetrator characteristics, i.e. both solved and unsolved cases are included. Information can be available for unsolved cases when perpetrators are in hiding or, according to the perpetrator definition used, a person is suspected of and/or charged with homicide but not yet sentenced, meaning that the case is not yet considered solved. 
Table 31. Annual number of perpetrators and homicide offending rate in the Netherlands, Sweden and Finland in 2003-2006 (per 100,000 inhabitants).

\begin{tabular}{lcccccc}
\hline & \multicolumn{2}{c}{ The Netherlands } & \multicolumn{2}{c}{ Sweden } & \multicolumn{2}{c}{ Finland } \\
Year & Perpetrators & Rate & Perpetrators & Rate & Perpetrators & Rate \\
\hline 2003 & 309 & 1.91 & 100 & 1.11 & 105 & 2.01 \\
2004 & 263 & 1.62 & 135 & 1.50 & 141 & 2.70 \\
2005 & 247 & 1.51 & 100 & 1.11 & 112 & 2.13 \\
2006 & 203 & 1.24 & 85 & 0.93 & 117 & 2.22 \\
\hline Average & 256 & 1.57 & 105 & 1.16 & 119 & 2.26 \\
\hline
\end{tabular}

\section{Gender of the perpetrators}

In all three countries, homicides are predominantly committed by men. Approximately 90 per cent of all homicide perpetrators were male, and only 10 per cent were female (see table 31 ).

Table 32. Gender of homicide perpetrators in the Netherlands, Sweden and Finland in 2003-2006.

\begin{tabular}{lrrrrrr}
\hline & \multicolumn{2}{c}{ The Netherlands } & \multicolumn{2}{c}{ Sweden } & \multicolumn{2}{c}{ Finland } \\
Gender & N & $\%$ & N & $\%$ & N & $\%$ \\
\hline Male & 778 & 90 & 340 & 89 & 413 & 89 \\
$\quad$ Female & 91 & 10 & 40 & 11 & 52 & 11 \\
$\begin{array}{l}\text { All valid } \\
\text { cases }\end{array}$ & 869 & 100 & 380 & 100 & 465 & 100 \\
\hline Unknown & 153 & 15 & 40 & 10 & 10 & 2 \\
Total & 1022 & & 420 & & 475 & \\
\hline
\end{tabular}

\section{Age of the perpetrators}

In all three countries, more than 60 per cent of the homicide perpetrators were found to be between the age of 25 and 64 years old (see table 31 ). Finland (38 per cent) and Sweden (37 per cent) had a relatively high proportion of homicide perpetrators in the age category 40-64 years when compared to the Netherlands (23 per cent).

On average, homicide perpetrators in the Netherlands were younger (31.9 years) than homicide perpetrators in Finland (37.5 years) and Sweden (34.7 years).

These age differences in perpetrators resemble age differences in victims, as reported above. Similarly, these differences might be partially explained by considering the type of homicide in each 
country. Homicides related to the criminal milieu tend to be committed by young males - these homicides are more common in the Netherlands than in Finland and Sweden. It should also be noted that in all three countries perpetrators were on average younger than their victims.

Table 33. Age of homicide perpetrators in the Netherlands, Sweden and Finland in 2003-2006.

\begin{tabular}{lrrrrrr}
\hline & \multicolumn{2}{c}{ The Netherlands } & \multicolumn{2}{c}{ Sweden } & \multicolumn{2}{c}{ Finland } \\
Age & $N$ & $\%$ & $N$ & $\%$ & $N$ & $\%$ \\
\hline-17 & 33 & 4 & 22 & 6 & 8 & 2 \\
$18-24$ & 215 & 27 & 92 & 25 & 78 & 17 \\
$25-39$ & 369 & 46 & 137 & 37 & 188 & 40 \\
$40-64$ & 182 & 23 & 103 & 28 & 175 & 38 \\
$65+$ & 10 & 1 & 17 & 5 & 16 & 3 \\
Mean (standard deviation) & $31.9( \pm 11.3)$ & $34.7( \pm 14.8)$ & $37.5( \pm 13.0)$ \\
Minimum age & & 14 & & 14 & & 13 \\
Maximum age & & 83 & & 85 & & 79 \\
\hline All valid cases & 809 & 100 & 371 & 100 & 465 & 100 \\
\hline Unknown & 213 & 21 & 49 & 12 & 10 & 2 \\
Total & 1022 & & 420 & & 475 & \\
\hline
\end{tabular}

\section{Age of the perpetrators by type of homicide}

Table 34 shows the average age of the perpetrators for the largest homicide types. Overall, the age of perpetrators in the various types of homicide did not differ much between the three countries, and neither did the age of the victims. Of all subcategories, perpetrators of nightlife violence and robbery killings were on average the youngest, while perpetrators of intimate partner homicides and other family killings were generally the oldest.

One exception to the relative similarities between the three countries concerned the age of perpetrators of other family homicides. In Finland, perpetrators of this type of homicide were generally older (38.6 years) than perpetrators of other family homicides in the Netherlands (30.7 years) and Sweden (33.2 years). The results further indicated that perpetrators of nightlife violence-associated homicides in Finland were older (33.5 years) than perpetrators of this type of homicide in the Netherlands (24.7 years) and Sweden (23.2 years). A third difference concerned perpetrators who committed a non-family homicide motivated by mental illness. In Finland, perpetrators of this type were generally older 
(37.4 years), compared with perpetrators in the Netherlands ( 30.6 years) and Sweden (32.0 years). These figures correspond to the overall higher average age of perpetrators in Finland when compared with perpetrators in both the Netherlands and Sweden.

Table 34. Mean age of homicide perpetrators by type of homicide in the Netherlands, Sweden and Finland in 2003-2006.

\begin{tabular}{|c|c|c|c|}
\hline Homicide type & $\begin{array}{l}\text { The Netherlands } \\
\text { Mean }\end{array}$ & $\begin{array}{l}\text { Sweden } \\
\text { Mean }\end{array}$ & $\begin{array}{l}\text { Finland } \\
\text { Mean }\end{array}$ \\
\hline $\begin{array}{l}\text { Intimate partner } \\
\text { killing }\end{array}$ & $39.2( \pm 11.9)$ & $45.4( \pm 17.7)$ & $43.9( \pm 13.2)$ \\
\hline Child-killing: family & $29.3( \pm 8.8)$ & $33.3( \pm 9.0)$ & $32.1( \pm 8.8)$ \\
\hline Other familial killing & $30.7( \pm 13.4)$ & $33.2( \pm 11.8)$ & $38.6( \pm 15.5)$ \\
\hline Criminal milieu & $30.1( \pm 9.1)$ & $31.5( \pm 10.7)$ & $31.0( \pm 6.6)$ \\
\hline Robbery & $27.7( \pm 10.5)$ & $25.4( \pm 9.1)$ & $28.1( \pm 11.3)$ \\
\hline Nightlife violence & $24.7( \pm 7.6)$ & $23.2( \pm 9.9)$ & $33.5( \pm 9.6)$ \\
\hline $\begin{array}{l}\text { Mental illness: } \\
\text { non-family }\end{array}$ & $30.6( \pm 7.6)$ & $32.0( \pm 7.9)$ & $37.4( \pm 14.9)$ \\
\hline $\begin{array}{l}\text { Child-killing: } \\
\text { non-family* }\end{array}$ & - & - & $25.6( \pm 8.6)$ \\
\hline $\begin{array}{l}\text { Other in non-criminal } \\
\text { milieu }\end{array}$ & $30.8( \pm 11.3)$ & $36.0( \pm 12.7)$ & $36.5( \pm 12.1)$ \\
\hline Other ${ }^{*}$ & - & - & $54.3( \pm 1.5)$ \\
\hline Total & $31.9( \pm 11.3)$ & $34.7( \pm 14.8)$ & $37.5( \pm 13.0)$ \\
\hline
\end{tabular}

* Due to small numbers, the age characteristics of perpetrators in the category cannot be calculated.

\section{Age by gender of the perpetrators}

In all three countries, male perpetrators were on average younger than female perpetrators. Furthermore, all three countries had in common that the majority of both male and female perpetrators were aged between 25 and 64 . In all three countries, there were very few perpetrators over the age of 65 - both male and female.

When we consider the age distribution by gender, male and female perpetrators in the Netherlands were on average younger than male and female perpetrators in the other two countries (table 35). By contrast, male and female perpetrators in Finland were on average older than perpetrators from the other two countries.

In comparison to Finland, younger perpetrators - both male and female aged 17 and under - were more prevalent in the Netherlands and Sweden. As outlined in the previous chapters, this can be explained by the relatively higher prevalence of homicides re- 
lated to the criminal milieu, robberies and nightlife violence in the Netherlands and Sweden (in total 31 per cent and 30 per cent of all homicides, respectively, compared to 11 per cent in Finland). It can be argued that these types of homicides are more likely to involve young persons compared with other types of homicides, such as domestic homicides.

Table 35: Age characteristics of homicide perpetrators in the Netherlands, Sweden and Finland in 2003-2006.

\begin{tabular}{|c|c|c|c|c|c|c|c|c|c|c|c|c|}
\hline \multirow[b]{3}{*}{ Age } & \multicolumn{4}{|c|}{ The Netherlands } & \multicolumn{4}{|c|}{ Sweden } & \multicolumn{4}{|c|}{ Finland } \\
\hline & \multicolumn{2}{|c|}{$\begin{array}{c}\text { Male } \\
\text { perpetrators }\end{array}$} & \multicolumn{2}{|c|}{$\begin{array}{c}\text { Female } \\
\text { perpetrators }\end{array}$} & \multicolumn{2}{|c|}{$\begin{array}{c}\text { Male } \\
\text { perpetrators }\end{array}$} & \multicolumn{2}{|c|}{$\begin{array}{c}\text { Female } \\
\text { perpetrators }\end{array}$} & \multicolumn{2}{|c|}{$\begin{array}{c}\text { Male } \\
\text { perpetrators }\end{array}$} & \multicolumn{2}{|c|}{$\begin{array}{c}\text { Female } \\
\text { perpetrators }\end{array}$} \\
\hline & $\mathrm{N}$ & $\%$ & $\mathrm{~N}$ & $\%$ & N & $\%$ & $\mathrm{~N}$ & $\%$ & $\mathrm{~N}$ & $\%$ & $\mathrm{~N}$ & $\%$ \\
\hline-17 & 29 & 4 & 4 & 5 & 19 & 6 & 3 & 8 & 8 & 2 & 0 & 0 \\
\hline $18-24$ & 201 & 28 & 14 & 16 & 85 & 26 & 7 & 18 & 72 & 17 & 6 & 12 \\
\hline $25-39$ & 324 & 45 & 43 & 50 & 125 & 38 & 12 & 31 & 162 & 39 & 26 & 50 \\
\hline $40-64$ & 158 & 22 & 23 & 27 & 86 & 26 & 17 & 44 & 155 & 38 & 20 & 39 \\
\hline $65+$ & 8 & 1 & 2 & 2 & 17 & 5 & 0 & 0 & 16 & 4 & 0 & 0 \\
\hline $\begin{array}{c}\text { Mean } \\
\text { (standard } \\
\text { deviation) }\end{array}$ & \multicolumn{2}{|c|}{$31.7( \pm 11.2)$} & \multicolumn{2}{|c|}{$33.8( \pm 12.2)$} & \multicolumn{2}{|c|}{$34.6( \pm 15.1)$} & \multicolumn{2}{|c|}{$35.4( \pm 12.5)$} & \multicolumn{2}{|c|}{$37.5( \pm 13.2)$} & \multicolumn{2}{|c|}{$37.9( \pm 11.1)$} \\
\hline $\begin{array}{l}\text { All valid } \\
\text { cases }\end{array}$ & 720 & 100 & 86 & 100 & 332 & 100 & 39 & 100 & 413 & 100 & 52 & 100 \\
\hline Unknown & 58 & 8 & 5 & 6 & 8 & 2 & 1 & 3 & 0 & 0 & 0 & 0 \\
\hline Total & 778 & & 91 & & 340 & & 40 & & 413 & & 52 & \\
\hline
\end{tabular}

In general, men in all age categories are more likely to become a homicide perpetrator than women. In all three countries, men between the age of 18 and 39 are the most likely to become a homicide perpetrator, while women under the age of 17 and over the age of 65 are the least likely.

In Finland, the relative risk of becoming a homicide perpetrator is higher than in the other two countries in the majority of the age and gender categories (see table 34 below). There are notable exceptions, however. With regard to men under the age of 17 , the risk of becoming a homicide perpetrator is the highest in Sweden (1.91 per 100,000 inhabitants), followed by the Netherlands (1.58 per 100,000 inhabitants). In addition, the relative risk for young women to become a homicide perpetrator is higher in Sweden and in the Netherlands than it is in Finland. This is in contrast to the observed pattern in Finland, where the risk of becoming a homicide perpetrator for women between the age of 25 and 64 is considerably higher than in the other two countries. 
Table 36. Relative risk of becoming a homicide perpetrator, by gender and age, in the Netherlands, Sweden and Finland in 2003-2006 (per 100,000 inhabitants, annually).

\begin{tabular}{lcccccc}
\hline & \multicolumn{2}{c}{ The Netherlands } & \multicolumn{2}{c}{ Sweden } & \multicolumn{2}{c}{ Finland } \\
Age & Male & Female & Male & Female & Male & Female \\
\hline-17 & 0.40 & 0.06 & 0.48 & 0.08 & 0.36 & 0.00 \\
$18-24$ & 7.29 & 0.52 & 5.65 & 0.49 & 7.66 & 0.67 \\
$25-39$ & 4.59 & 0.62 & 3.37 & 0.34 & 7.99 & 1.34 \\
$40-64$ & 1.41 & 0.21 & 1.44 & 0.29 & 4.18 & 0.54 \\
$65+$ & 0.21 & 0.04 & 0.64 & 0.00 & 1.20 & 0.00 \\
\hline Total & 2.23 & 0.26 & 1.86 & 0.22 & 4.02 & 0.49 \\
\hline
\end{tabular}

\section{Birth country of perpetrators}

The majority of the perpetrators in Finland (95 per cent) and Sweden (75 per cent) were born in the country where the crime was committed (see table 37). In Finland, most non-native perpetrators were of Russian descent. In Sweden, non-native perpetrators were mainly from Yugoslavia, Finland and Iraq. In the Netherlands, however, only about half of all perpetrators were born in the country where the homicide took place. This should be interpreted with caution, however, as the birth country of more than one third of the perpetrators was unknown. Of the perpetrators born outside the Netherlands, those of Dutch Antillean, Surinamese, Turkish or North African descent were the most prevalent.

When examining relative rates of homicide perpetrators, foreign citizens residing in Finland were slightly more likely to commit a homicide compared with Finnish citizens (2.4 and 2.1 per 100,000 inhabitants, respectively). Individuals from the ethnic Roma group ran a risk of 14.3 per 100,000 inhabitants, individuals of Kurdish ethnic groups ran a risk of 5.1 per 100,000 inhabitants, and people with a Somali ethnic background ran a risk of 3.1 per 100,000 inhabitants. Other ethnic groups with elevated rates of homicide perpetrators included those of Russian descent $(3.0$ per 100,000 inhabitants) and Estonian descent (2.4 per 100,000 inhabitants).

The relative rate of homicide perpetrators in the Netherlands showed that individuals of Dutch descent ran a risk of 2.5 per 100,000 inhabitants of becoming a homicide perpetrator, while the risk for people of Antillean descent was 39.8 per 100,000 inhabitants. Individuals of Surinamese origin ran a risk of 16.1 per 100,000 inhabitants, for people of Turkish origin the risk was 9.1 and for individuals of Moroccan descent the risk was 7.9 per 100,000 inhabitants. 
In Sweden, the rate of homicide perpetrators was 0.73 per 100,000 inhabitants for people of Swedish descent. For individuals born outside Sweden, the rate was 1.5 per 100,000 inhabitants. Of the non-Swedish ethnic groups, people born in former Yugoslavia were the most prevalent among known homicide perpetrators, running a risk of 7.9 per 100,000 inhabitants of becoming a homicide perpetrator.

Table 37. Birth country of homicide perpetrators in the Netherlands, Sweden and Finland in 2003-2006.

\begin{tabular}{lcccrrr}
\hline & \multicolumn{2}{c}{ The Netherlands } & \multicolumn{2}{c}{ Sweden } & \multicolumn{2}{c}{ Finland } \\
Birth country & $\mathrm{N}$ & \multicolumn{1}{c}{$\%$} & $\mathrm{~N}$ & $\%$ & $\mathrm{~N}$ & $\%$ \\
\hline Native & 332 & 53 & 232 & 75 & 435 & 95 \\
& & & & & & \\
Foreign-born & 301 & 48 & 78 & 25 & 23 & 5 \\
All valid cases & 633 & 100 & 310 & 100 & 458 & 100 \\
\hline Unknown & 389 & 38 & 110 & 26 & 17 & 4 \\
Total & 1022 & & 420 & & 475 & \\
\hline
\end{tabular}

\section{Birth country of perpetrators by gender}

Distribution of birth country by gender shows that, in all three countries, most female perpetrators were born in the country where the crime took place (table 38). The results further reveal several differences between countries with regard to the birth country of male perpetrators. The majority of the male perpetrators in Sweden and Finland were born in the country were the crime was committed (table 38). In the Netherlands, however, half of male homicide perpetrators were born in a foreign country. However, as mentioned before, it should be taken into account that the birth country was unknown for almost a third of all perpetrators.

Table 38. Birth country of homicide perpetrators by gender in the Netherlands, Sweden and Finland in 2003-2006.

\begin{tabular}{|c|c|c|c|c|c|c|c|c|c|c|c|c|}
\hline \multirow[b]{3}{*}{ Birth country } & \multicolumn{4}{|c|}{ The Netherlands } & \multicolumn{4}{|c|}{ Sweden } & \multicolumn{4}{|c|}{ Finland } \\
\hline & \multicolumn{2}{|c|}{$\begin{array}{c}\text { Male perpe- } \\
\text { trators }\end{array}$} & \multicolumn{2}{|c|}{$\begin{array}{c}\text { Female per- } \\
\text { petrators }\end{array}$} & \multicolumn{2}{|c|}{$\begin{array}{c}\text { Male perpe- } \\
\text { trators }\end{array}$} & \multicolumn{2}{|c|}{$\begin{array}{c}\text { Female per- } \\
\text { petrators }\end{array}$} & \multicolumn{2}{|c|}{$\begin{array}{l}\text { Male perpe- } \\
\text { trators }\end{array}$} & \multicolumn{2}{|c|}{$\begin{array}{c}\text { Female per- } \\
\text { petrators }\end{array}$} \\
\hline & $\mathrm{N}$ & $\%$ & $N$ & $\%$ & $\mathrm{~N}$ & $\%$ & $N$ & $\%$ & $\mathrm{~N}$ & $\%$ & $\mathrm{~N}$ & $\%$ \\
\hline Native & 285 & 50 & 47 & 76 & 201 & 62 & 29 & 76 & 385 & 94 & 50 & 96 \\
\hline Foreign-born & 284 & 50 & 15 & 24 & 126 & 39 & 9 & 24 & 24 & 6 & 2 & 4 \\
\hline All valid cases & 569 & 100 & 62 & 100 & 327 & 100 & 38 & 100 & 409 & 100 & 52 & 100 \\
\hline Unknown & 210 & 27 & 29 & 32 & 13 & 20 & 2 & 10 & 4 & 2 & 0 & 0 \\
\hline Total & 779 & & 91 & & 340 & & 40 & & 413 & & 52 & \\
\hline
\end{tabular}




\section{Marital status of the perpetrators}

When it comes to the marital status of homicide perpetrators, a large proportion of homicide perpetrators in Finland and Sweden were single (table 39). However, Finland had a higher degree of homicide perpetrators who were married, cohabitants or in a boyfriend/girlfriend relationship (53 per cent) when compared to Sweden (44 per cent). Nevertheless, the marital status was unknown for one third of the homicide perpetrators in Sweden, and no comparison with Dutch homicide perpetrators was possible as there was no data available on this characteristic.

Table 39. Marital status of homicide perpetrators in Sweden and Finland in 2003-2006.

\begin{tabular}{lrrrr}
\hline & \multicolumn{2}{c}{ Sweden } & \multicolumn{2}{c}{ Finland } \\
Marital status & $N$ & $\%$ & $N$ & $\%$ \\
\hline Married & 65 & 23 & 87 & 21 \\
Cohabitants & 50 & 18 & 76 & 18 \\
In a boyfriend/girlfriend relationship & 9 & 3 & 59 & 14 \\
Single & 156 & 56 & 174 & 42 \\
Divorced & - & - & 22 & 5 \\
Widowed & - & - & 1 & 0 \\
All valid cases & 280 & 100 & 419 & 100 \\
\hline Unknown & 140 & 33 & 56 & 12 \\
Total & 420 & & 475 & \\
\hline
\end{tabular}

\section{Marital status of perpetrators by gender}

When we consider the marital status by gender of the homicide perpetrators, we find that at least half of all female perpetrators in Sweden and Finland were either married, cohabitants or in a boyfriend/girlfriend relationship (table 40). Other similarities between the two countries included the marital status of the perpetrators. With regard to male perpetrators, a larger proportion of Swedish perpetrators (56 per cent) were single than were Finnish perpetrators (44 per cent).

However, the results further indicated differences between the two countries regarding to the marital status distribution by gender. While half of all male perpetrators in Finland were either married, cohabitants or in a boyfriend/girlfriend relationship, only one in four male perpetrators in Sweden matched this status. Furthermore, while 43 per cent of female perpetrators in Sweden were single, the majority (61 per cent) of female perpetrators in Finland 
were where in some kind of a relationship at the time of the homicide.

Table 40. Marital status of homicide perpetrators by gender in Sweden and Finland in 2003-2006.

\begin{tabular}{|c|c|c|c|c|c|c|c|c|}
\hline \multirow[b]{3}{*}{ Marital status } & \multicolumn{4}{|c|}{ Sweden } & \multicolumn{4}{|c|}{ Finland } \\
\hline & \multicolumn{2}{|c|}{$\begin{array}{c}\text { Male } \\
\text { perpetrators }\end{array}$} & \multicolumn{2}{|c|}{$\begin{array}{c}\text { Female } \\
\text { perpetrators }\end{array}$} & \multicolumn{2}{|c|}{$\begin{array}{c}\text { Male } \\
\text { perpetrators }\end{array}$} & \multicolumn{2}{|c|}{$\begin{array}{c}\text { Female } \\
\text { perpetrators }\end{array}$} \\
\hline & N & $\%$ & $N$ & $\%$ & $\mathrm{~N}$ & $\%$ & $\mathrm{~N}$ & $\%$ \\
\hline Married & 53 & 22 & 12 & 34 & 72 & 20 & 15 & 31 \\
\hline Cohabitants & 44 & 18 & 6 & 17 & 68 & 18 & 8 & 16 \\
\hline $\begin{array}{l}\text { In a boyfriend/girlfriend } \\
\text { relationship }\end{array}$ & 7 & 3 & 2 & 6 & 52 & 14 & 7 & 14 \\
\hline Single & 141 & 56 & 15 & 43 & 162 & 44 & 12 & 25 \\
\hline Divorced & - & - & - & - & 15 & 4 & 7 & 14 \\
\hline Widowed & - & - & - & - & 1 & 0 & 0 & 0 \\
\hline All valid cases & 245 & 100 & 35 & 100 & 370 & 100 & 49 & 100 \\
\hline Unknown & 95 & 28 & 5 & 13 & 43 & 10 & 3 & 6 \\
\hline Total & 340 & & 40 & & 413 & & 52 & \\
\hline
\end{tabular}

\section{Employment status of perpetrators}

With regard to the profession of homicide perpetrators, less than one-fifth of homicide perpetrators in Finland and in Sweden had a blue-collar profession, and very few could be considered an intermediate, manager or professional (table 41).

Finland had a considerably higher degree of homicide perpetrators who were unemployed, compared with Sweden. About half (51 per cent) of all homicide perpetrators in Finland were unemployed while more than one in three (42 per cent) homicide perpetrators in Sweden were unemployed. In addition, Finland also had a slightly higher degree of homicide perpetrators who were on sick leave, on early retirement, or who were disabled, compared with Sweden (17 per cent in Finland versus 11 per cent in Sweden).

However, it should be noted that for 35 per cent of homicide perpetrators in Sweden the profession was unknown. Previous studies indicate that about 50 per cent of the homicide perpetrators in the period 1990-2006 in Sweden were unemployed (Brå, 2008), which corresponds fairly well to the results presented here. Unfortunately, no comparison of profession could be made with homicide perpetrators in the Netherlands, as no data was available for this variable. 
Table 41. Employment status of homicide perpetrators in Finland and Sweden in 2003-2006.

\begin{tabular}{lrrrr}
\hline & \multicolumn{2}{c}{ Sweden } & \multicolumn{2}{c}{ Finland } \\
Employment status & $\mathrm{N}$ & $\%$ & $\mathrm{~N}$ & $\%$ \\
\hline Working class & 56 & 20 & 65 & 15 \\
Intermediate, managers and professionals & 21 & 8 & 21 & 5 \\
Retired & 13 & 5 & 18 & 4 \\
Unemployed & 115 & 42 & 226 & 51 \\
Sick-listed, disabled, early retired & 29 & 11 & 74 & 17 \\
Student & 20 & 7 & 21 & 5 \\
Military service & - & - & - & - \\
Housewife/-husband/stay-at-home par- & & & & \\
ent & - & - & 10 & 2 \\
Asylum seeker & 20 & 7 & - & - \\
Other & - & - & 9 & 2 \\
All valid cases & 274 & 100 & 444 & 100 \\
\hline Unknown & 146 & 35 & 31 & 7 \\
Total & 420 & & 475 & \\
\hline
\end{tabular}

\section{Employment status of the perpetrators by gender}

When considering the profession of perpetrators by gender, approximately 15 per cent of male perpetrators in Finland had a blue-collar profession, while the equivalent rate in Sweden was about 20 per cent. Finland had a higher degree of unemployed male perpetrators compared to Sweden: 52 per cent of male perpetrators in Finland were unemployed while 40 per cent of the male perpetrators in Sweden were unemployed. On the other hand, when it comes to the female perpetrators, a higher degree of female perpetrators in Sweden were unemployed compared to female perpetrators in Finland (61 per cent in Sweden and 39 per cent in Finland, respectively). In addition, one-fifth of the female perpetrators in Finland were housewives/stay-at-home parents. Unfortunately, data for this variable were not available for Sweden, and it is important to note that the profession of a relatively large number of homicide perpetrators in Sweden was unknown. Comparisons with Dutch homicide perpetrators were not possible, as no data was available for this variable.

When comparing the profession of male and female perpetrators, we find that approximately one-third of the female perpetrators in Finland were unemployed while half of the Finnish male perpetrators were unemployed. In contrast, almost half of the female perpetrators in Sweden were unemployed and less than one third of the male perpetrators were unemployed. 


\section{Conclusions}

\section{Conclusions from the analysis}

\section{Finland has the highest homicide rate}

Finland had the highest homicide rate of the three countries, with 2.34 homicides per 100,000 inhabitants during the years 20032006. Sweden had the lowest rate with 0.98 and the Netherlands the second lowest with 1.26. Being the most populated country, the Netherlands had the largest number of homicides (760 as compared to a total of 475 in Finland and 342 in Sweden). The differences in homicide rates between the three countries are not unique for the years 2003-2006. Finland has had significantly higher homicide rates than the Netherlands and Sweden for many decades, and the Netherlands has had slightly higher rates than Sweden for most years since the mid-1990s. The development over time has differed slightly between the three countries, however. While all three countries have a lower homicide rate during the 2000 s than during the 1990s, the decrease took place in the early 1990s in Finland and Sweden, but was not apparent in the Netherlands until the end of the decade.

\section{Different geographical distribution, but similar temporal distribution}

In Finland, homicides were more frequently committed in rural areas less frequently in urban areas, while in Sweden and the Netherlands homicides were to some extent concentrated to the largest cities. However, this pattern was more apparent in the Netherlands than in Sweden, where the regional differences in homicide distribution were rather small.

Weekends were more violent than weekdays in all three countries. Homicides were most often committed on Fridays and Saturdays in Finland and on Saturdays and Sundays in Sweden and the Netherlands. Homicides were also more prevalent during evenings and nights than during the morning or afternoon in all three countries. We did not find any clear seasonal patterns in the distribution of homicides in the three project countries. 


\section{Homicides are most expressive in Finland and most instrumental in the Netherlands}

The results from our study show that the location and modus operandi of the homicide, the relationship between the victim and perpetrator, and thus also the homicide type tend to differ in the three countries. In other words, there were different homicide patterns that characterize the results for all of the above-mentioned variables.

In the Netherlands, a larger proportion of homicides were connected to a criminal milieu (19 per cent). In line with this finding, the Netherlands had the largest proportion of homicides committed outdoors ( 38 per cent) of the three countries. The Netherlands also had the largest proportion of homicides committed with the use of firearms (35 per cent), as well as homicides involving young or middle-aged men who do not know, or have an unknown relationship to each other. Further, the Netherlands had a larger proportion of robbery-related murders. Therefore, we can conclude that homicides in the Netherlands are the most instrumental. In addition, the Netherlands had the largest number of cases with missing or unknown values. Apart from being a methodological disadvantage in the study, this is also a likely symptom of the fact that cases tied to a criminal milieu more frequently have unknown variables.

Homicides in Finland, on the other hand, tended to be more connected to expressive motives. Of the three countries, Finland had the highest share of homicides committed in private homes (73 per cent), and also the highest share of homicides committed against men where the perpetrator and victim where acquaintances (68 per cent). Further, a very large proportion (over 80 per cent) of both victim and perpetrators where intoxicated by alcohol, and closer to half of the homicides here committed with a sharp instrument (mostly kitchen knives).

The Swedish numbers are somewhere between the two other countries. While the proportion of homicides that took place within a criminal milieu was closer to that in the Netherlands (12 per cent), most homicides still took place in private homes (59 per cent). Sharp instruments were used as widely as in Finland ( 45 per cent) and were the primary weapon used both outdoors and indoors. The victim and perpetrator were usually acquaintances (41 per cent) and about half of all victims and perpetrators had been drinking alcohol at the time of the crime.

The temporal distribution of homicides in the three countries also reflects on the types of homicide committed. The results for yearly, weekly and daily distributions for Finland, and to a somewhat lesser extent Sweden, reflect on the leisure-times when large quantities of alcohol are consumed during evenings and nights, weekends and during the winter months. For the Netherlands, the 
larger proportion of outdoor homicides among youths in criminal contexts result in a larger proportion of homicides during the spring and summer months, although still concentrated to evenings and weekends.

To better illustrate the differences between the three countries, we could say that the difference in homicide rates between the Netherlands and Sweden was made up mainly of organized crimerelated homicides outdoors, while the difference in homicide rates between Finland and Sweden on the one hand and the Netherlands on the other was made up mainly of homicides between intoxicated acquaintances.

\section{There were many similarities among the three countries}

There were also many similarities among the three countries. In all three countries, homicide victims and perpetrators were usually acquaintances. Homicides committed solely with the perpetrators body (e.g., by hitting or kicking) were relatively rare (10-18 per cent). Another similarity was the proportion and pattern concerning intimate partner violence (23-28 per cent of all homicides take place between current or ex-partners), where the majority of these victims (70-85 per cent) were victimized indoors. The likelihood of female victims being killed by their current or ex-partners was high (57-65 per cent) in all three countries.

\section{Victims and perpetrators are older in Finland and younger in the Netherlands}

In all three countries, a majority of the homicide cases had only one victim and one perpetrator. Therefore, the victimization rate and the rate of homicide perpetrators were largely the same as the general homicide rates in the three countries, though multiple perpetrators were more common in the Netherlands than in the other two countries. This difference can be partially explained by a larger proportion of homicide in the context of gangs and a criminal milieu in the Netherlands as compared to the other two countries.

In all three countries, nine out of ten homicide perpetrator were male, and in 60-70 per cent of the cases so was the victim. Two-thirds of the victims and perpetrators were between the age 25 and 64 . The mean age of the victims (37-42 years) was slightly higher than the mean age of the perpetrators (32-38 years) in all three countries. On average, Finland had the oldest victims and perpetrators, while the Netherlands had the youngest. In all three countries, male perpetrators and victims were on average younger than female perpetrators.

In all three countries, a majority of cases involved a victim born in the country the crime took place in. In both Sweden and the Netherlands, however, foreign-born persons were over-represented among the victims. The highest share of victims born outside 
the country was found in the Netherlands ( 43 per cent), while the lowest was found in Finland (4 per cent). A majority of the perpetrators in all three countries were born in the country where the crime took place, although the proportion was much larger in Sweden and Finland. Due to a large proportion of missing data from the Netherlands, the true divide between native and foreignborn victims and perpetrators could not be established.

The study also attempted to look more closely at the marital status, profession and level of education of both victims and perpetrators. The results were fairly mixed, due to the complete lack of data from the Netherlands and a large number of unknown or missing values in the Swedish data.

\section{Possible explanations}

Although the aim of this study was to describe the main similarities and differences in homicide characteristics and the homicide rates among the three countries, we have also decided to provide some possible explanations for these similarities and differences. Finland, the Netherlands and Sweden have a similar societal organization and demographic structure. High economic development, a high standard of living, a high level of education and high average life expectancy characterize all three countries. In a global perspective, all three countries have low homicide rates, and although differences do exist, they are a matter of differences in proportion rather than type. This is probably due to the fact that the three countries are rather alike in terms of the variables commonly used to explain differences in the levels of homicide on a global level.

There are, however, a number of differences in the homicide characteristics between the three countries, as well as in the overall homicide rates, which do not seem to be explained by these social and demographic factors. While such factors may have an explanatory value when comparing homicide rates on a global scale, they are of less use when trying to explain the variations between these three Western European countries. This suggests that there may be other explanations to the differences observed.

The variations might best be explained with the help of a routine activity and situational variables approach. Homicide is a highly heterogeneous offence, extending over time and space and dependent on a wide range of contextual factors. For example, the presence of a criminal milieu and the frequency and characteristics of alcohol consumption are two factors that have a large impact on homicide characteristics. The results indicate that the higher prevalence of organized crime-related homicides in the Netherlands explains most of the structural differences between Swedish and Dutch homicidal crime, as well as the difference between the 
countries' national homicide rates. The results also indicate that drunken brawl-related homicides between unemployed alcoholic men cause most of the difference in the structure and rate of homicidal crime between Finland and the other two countries.

These structural differences affect the results of a majority of the presented variables; the location of the crimes and when they occur, the killing methods used, the age structure of victim and perpetrator, as well as the clearance rates, in a predictive way. Homicides committed within a criminal milieu are instrumental in nature and the perpetrators are mainly young men. Firearm use is common and the element of pre-planning manifests itself in lower clearance rates and unanswered questions during investigations, which in turn lead to missing data and unknown variables. Homicides related to substance abuse by marginalized men are usually (at least in northern Europe) committed indoors. Victim and perpetrator usually know each other, and a knife is often used in this type of homicide. The victim and perpetrator of a homicide that is related to substance abuse usually have a higher mean age than those in homicides committed in a criminal milieu, and the weapon is usually one that is easily available in the private home, such as knives, pieces of furniture etc.

In conclusion, the similarities in traditional social and demographic factors may contribute to the many commonalities between the studied countries. Other differences and similarities, on the other hand, can be explained by the context in which they occur, affected by situational characteristics and based on the routine activities of individuals.

\section{Methodological conclusions, limitations and suggested improvements}

A number of methodological conclusions, questions and issues have become evident during our work with the analysis. These have highlighted limitations of the data as well as possible improvements. These limitations should be addressed before other countries start collecting data in the EHM format.

Finland, the Netherlands and Sweden have national datasets that are updated continuously. For the purpose of our analysis, the variables in the European Homicide Monitor were chosen with regard to the information already available in the three countries' national data. Now that this first descriptive analysis has been completed, revisions can be made to the codebook used (see Appendix B) before the project comes to an end. If the EHM is continued and expanded, an ideal set of variables should be created. These variables should be attempted to be collected regardless of their current inclusion in national databases. The number of vari- 
ables must be realistic and carefully defined, and the data must be possible to collect through available sources. The EHM could then serve as a standard instrument for other national agencies that collect homicide data.

There are many difficulties associated with comparative criminological research. Difficulties have been encountered during this project, mainly with regard to variations in the proportion of missing and unknown values. Therefore, some variables have a small number of observations, rendering the results for these variables unreliable. For other variables there have been no observations at all, rendering comparisons impossible.

It is difficult to assess how the large number of unknown values would be distributed had they been known. Therefore, it is difficult to conclude whether the distribution of known values is representative for each country, or whether there are any differences between the countries. The results have shown that a larger proportion of homicides that take place in a criminal milieu have unknown values, indicating that young male perpetrators may be somewhat underrepresented. However, since the clearance-rate of homicides is rather high for all three countries ${ }^{23}$ it is fairly safe to assume that there is little skewness between the three countries in the lack of data emerging from unsolved cases. Differences in clearance rates must however be taken into consideration in the event of adding national data from other countries where clearance rates may be lower.

Improvements that can be made due to the above-mentioned limitations are evident. Decreasing the number of missing or unknown values should be the primary priority in order to be able to use the data as comprehensively as possible. Another goal is to keep adding data to the database. This is important in order to increase the number of observations for individual variables and values, so that meaningful comparisons can be made, but also so that development over time can be studied.

Furthermore, the data from the three countries differ somewhat with regard to their definitions. Although a small legal category, all countries should aim to include assault resulting in death in their datasets. There are also practical differences in how homicide cases are handled in the three countries, not least judicially, that result in structural differences. These may not be fair to compare, as they may reflect differences in e.g. enforcement measures and not differences in how they are applied. If additional countries collect data, then it is imperative to analyse to what extent differences in the judicial systems or sentencing practices affect the results and the conclusions that can be made from said differences.

23 In all three countries, about 85-97 percent of all homicide cases in the 2000s were considered cleared, meaning that there was at least one suspect known to the police (see Granath, 2011; Ganpat \& Liem, 2011; Lehti and Kivivuori, 2011). 
Problems were also encountered during the classification of homicide types. Homicides can be classified according to several different characteristics and principles, all of which have their flaws and none of which give a comprehensive or unambiguous result. In the analysis we used our own classification, which was based partly on the relationship between the persons involved, partly on the circumstances of the crime, and partly on motives. The aim was to give a general picture of homicidal crime as a social phenomenon by describing in what kind of social interactions, relations and situations the crimes take place. In this we succeeded only partly, mainly due to problems with recoding existing national categories into new ones. For Finland, this resulted in 45 per cent of homicides being recoded into the "other" categories. However, the size of the "other" category was larger than desirable in the Netherlands and Sweden as well. This problem needs to be addressed in order to improve the quality of future data collection. Therefore, an inclusive classification system should be pursued in order to reduce the amount of unknown or "other" cases.

Lastly, a question for future study is whether the development of emergency health care and the general amount of health care resources (including accessibility to such care) differ to such an extent that it affects the homicide mortality rates in different European countries. While the conclusion has been drawn in this report that this does not affect the comparability of homicide rates in the Netherlands, Sweden and Finland, it must be taken into account if the EHM expands to other countries, as this may bias analyses of homicide rates and characteristics based on the EHM data.

\section{Recommendations for future research}

The aim of this section is to shed some light on additional research topics that can be studied with the help of data from the EHM. The results in this report have illustrated a select number of variables through basic comparison of data from the three countries involved in the project. Considering the content of the database as well as the number of variables, it is obvious that the possibilities for future research are numerous and that the data in the EHM has the potential of being used in a wide range of homicide and lethal violence research. The suggestions below are not in any way exhaustive. There are several other issues of interest that can be explored further with the help of the data.

For example, there are numerous in-depth studies that can be conducted using a selected number of variables. An advantage of collecting data from multiple countries is that unusual types of homicide that occur seldom in one country may be studied by making the number of observations large enough to reach meaningful conclusions. Suggested topics to look at more closely include 
studying specific homicide types such as intimate partner violence, homicides that take place within families, homicide-suicides or homicides that take place within a criminal milieu.

Another suggestion is to look more closely at other characteristics on case level, such as the prevalence of different types of modus, when and how different types of homicide occur, to look more closely at multiple-victim or multiple-perpetrator homicides, or to study the small number of cases where the same perpetrator has committed homicide at two or more different occasions (serial homicide).

The large number of unknown cases for the variables 'birth country' and 'citizenship' currently renders it meaningless to study to what extent homicide in the three countries is committed by natives against natives or by foreign-born persons against foreign-born persons. Additional data will make this a possible topic in the future.

Additional studies could focus on the individual characteristics of perpetrators and victims, such as previous sentences, violent history, social background variables, substance abuse or the role of mental disorders in homicide. These variables have not been given any greater attention in the analysis.

There are also possibilities of exploring the data from a more law-oriented perspective. Variables concerning sentencing, types of sanctions and sentence length can be useful for comparing sentencing practices in different countries. It could also be interesting to look at the extent to which different types of sanctions are chosen depending on the homicide type and which country the sentence has been issued in.

For the sake of ensuring data quality in the EHM, other studies can attempt to compare homicide records based on other sources, newspaper reports, coroners reports, autopsies, and to what extent the information from these sources differ with regard to individual cases, as well as whether they produce missing values for other variables.

There are also lessons to be learned from comparing the EHM data to other sources of homicide data. The mismatch between cause-of-death statistics (or other mortality statistics), the EHM and other sources used to present homicide statistics in comparative research should be analysed more closely in order to improve the quality of such tools. Our study, as well as others, has shown that cause-of-death statistics show lower homicide rates that do police data. Differences presented in the report suggest that discrepancies are probably due to more than definitional differences between the three countries.

Further, studies comparing the EHM data to data from other homicide monitors, such as the FBI's Supplementary Homicide Report (SHR) or National Incident Based Reporting System (NIBRIS) 
in the US and the Australian National Homicide Monitoring Program (NHMP) could give valuable insights into what characterizes homicides in Europe compared to those committed in other parts of the world.

If the European Homicide Monitor grows to include data from a larger number of countries as well as data from a longer series of years, the development in homicide rates can be monitored. Future research could look closer at the trends that appear and formulate hypotheses as to why these changes have occurred. Contributions of data will also make it possible to study regional similarities and differences by comparing data from countries in different parts of Europe and to use external predictors to explain area variation in homicide risk. Regional and national variations can also be used to test hypotheses relating to the impact of emergency medical care, social structure variables such as income or resource distribution, relationship patterns, etc. Policy-oriented studies can also determine the effects of national gun policy, alcohol policy or homicide prevention strategies.

The authors hope that the suggestions above, as well as the findings in this report, will inspire further use of the EHM data and that it will be recognized as an important source for both national and international research on homicide and lethal violence.

\section{The future of the European Homicide Monitor}

The three project partners recognize themselves as the nucleus or steering group of the European Homicide Monitor. All of the project partners are committed to continue their national data collection and to combine their data at regular intervals. Finland will be able to add new data annually, while Sweden will add new data biannually and the Netherlands will do so triennially.

The project partners welcome other European countires to collect data and join the EHM. One goal, yet hard to reach, is for the EHM to be used as a standard instrument for collecting homicide data in Europe, in order to create directly comparable data systematically on an international level. It is very important that the data are directly comparable, and the format should be followed strictly in order to assure direct comparability. This will maximize the added value of the homicide data.

With the current system, countries that want to get hold of the EHM data must turn to each individual country in order to receive that country's national data, due to data protection requirements. This must be solved in order for the database to function in the way envisioned by the project partners. Another obstacle that has to be overcome is setting up an IT technical solution for the man- 
agement of the database that meets possible requirements of other member states.

It is important to stress the possibilities that exist for comparative research, criminal justice measures, preventive strategies and policy evaluation because of this unique data source. The numerous possibilities for future research have already been mentioned above. The wider context in which these data can be used is elaborated below.

As part of European research infrastructure, the EHM offers an unprecedented prospect of knowledge accumulation, as it offers standardized comparability for countries and areas to compare their homicide patterns. In addition, the EHM encompasses information on case level as well as on individual victims and perpetrators, using data from multiple sources. It includes, to the best of our knowledge, all cases of homicide in each country, enabling studies of general patterns and trends as well as disaggregated data to specify what sub-types of homicide may account for such patterns and trends. The database also enables quantitative analysis of rare homicide phenomena, which can only be studied qualitatively on a national level, e.g. familicide, politically/ideologically motivated homicide or hate crimes. The data are also valuable for drawing attention to the victims and perpetrators of homicide who are poorly represented in society.

The EHM also helps the targeting of homicide prevention efforts. Since homicide is not randomly distributed in physical and social space, the database can help governments and agencies target homicide prevention efforts in terms of identifying social structures (socio-demographic characteristics such as age, gender, socioeconomic status and ethnic background, etc.), as well as when and where homicides are most likely to occur in terms of variations in time and location. In other words it can be used to identify both social and situational crime preventive strategies.

National policy responses will need to take into account nation-specific homicide characteristics. It is not until comparisons are made with other countries that unique characteristics of national homicide can be highlighted. National differences are key to identifying and prioritizing areas that can be targeted in homicide prevention work. The structural differences that have been found in the three project countries indicate that different homicide prevention strategies are required for different countries. Homicides related to organized crime cannot be fought with the same methods as those used against crimes committed by alcoholic men in private homes. For effective crime prevention, it is important to know these differences as well as their possible causes.

As national homicide prevention policies are shaped or changed, the EHM will be an important source during the evaluation process, as well as for the evaluation of other policies. Chang- 
es in criminal justice policies and alcohol policies, among others, may also be studied with the help of the EHM. The impact of policies can be studied by monitoring changes over time, and the EHM provides a control measure to make sure that national or local changes are not incorrectly attributed to other causes, such as being part of a general international trend. Furthermore, the EHM can help determine whether some specific national policies are more successful than others, and whether certain preventive measures that are intended to protect specific victim groups are successful.

For all of the reasons stated above, the project group hopes that the EU will find it valuable to encourage other member states to collect data according to the EHM codebook, in order to create comparable homicide data on an EU level. One suggestion as to how this could be done is by the EU commission setting up a fund from which EU member states can apply for means for gathering national data according to the EHM. Parts of these funds could then be set aside for the steering group, which would function as an advisory council, as well as for quality controls. These are questions that must be resolved before the EHM can reach its full potential. 


\section{List of references}

Aebi et al. (2006). European sourcebook of Crime and Criminal Justice Statistics - 2006, $3^{\text {rd }}$ edition. http://www.europeansourcebook.org/esb3_Full.pdf (Information was retrieved: 2/1/2011).

van Beek, D. J. (1999). De delictscenarioprocedure bij seksueel agressieve delinquenten. [The crime scenario procedure among sexually aggressive delinquents]. Arnhem: Gouda Quint.

Bijleveld \& Smit (2006). Homicide in the Netherlands; on the structuring of homicide typologies. Homicide studies, vol. 10, 2006, nr. 3, pp. 195-219.

de Boer, A. P. (1990). Partnerdoding. Een empirisch forensischpsychiatrisch onderzoek. [Intimate partner homicide. An empirical forensic-psychiatric study]. Arnhem: Gouda Quint.

Brants, C. H. \& Koenraadt, F. (1998). "Criminaliteit en mediahype. Een terugblik op de publieke beeldvorming rond kindermoord. [Criminal behaviour and media-hype. A reflection on the public discourse surrounding child homicide]". Delict en Delinquent 28 (6): 542-564.

Brookman, F. \& Nolan, J. (2005). “The Dark Figure of Infanticide in England and Wales: Complexities of Diagnosis" J Interpers Violence July 2006 21: 869-889.

Bye, K. Elin. (2008). Alcohol and Homicide in Eastern Europe. A Time Series Analysis of Six Countries. Homicide studies. February 2008, 12(1): 7-27.

Centers for Disease Control and Prevention (2003). National Violent Death Reporting System (NVDRS) coding manual [Online]. National Center for Injury Prevention and Control, Centers for Disease Control and Prevention (producer). Available from: URL: www.cdc.gov/injury.

Chon, D.S., (2002). The relationship between national homicide rates and medical care: a cross-national assessment. El Paso: LFB Scholarly Publishing LLC.

CIA (2010). https://www.cia.gov/library/publications/the-worldfactbook/fields/2103.html? countryName $=\&$ countryCode $=x x \&$ regionCode $=\mathrm{t}$ ? countryCode $=\mathrm{xx} \# \mathrm{xx}$ (Information was retrieved: 2/1/2011).

de Farias, F. R. (2009). The homicide, the pervert act and paternity. US-China Education Review Feb. 2009, Volume 6, No.2 (Serial No.51), 48-57. 
van Dijk, J. \& van Kesteren, J. \& Smit, P. (2007). Criminal Victimisation in International Perspective. Key findings from the 2004-2005 ICVS and EU ICS. Den Haag: WODC.

van Doorslaer E., Wagstaff, A. \& Bleichrodt, H. (1997). Incomerelated inequalities in health: Some international comparisons. Journal of Health economies, 16: 93-112.

van Eck, C. (2001). Door bloed gezuivert. Eerwraak bij Turken in Nederland. [Purified by blood. Honour Killings among Turks in the Netherlands]. Amsterdam: Bert Bakker.

Eisner, M. (2008). "Modernity Strikes Back? A Historical Perspective on the Latest Increase in Interpersonal Violence (19601990)." International Journal of Conflict and Violence, Vol. 2 (2) 2008: 288-316.

Ervasti, K. (1995). "Barnamordsbrotten i Finland under 1800-talet. [The infanticide debate in Finland during the $19^{\text {th }}$ century]". Historisk Tidskrift för Finland 80: 64-84.

Eurostat (2007).

http://pxweb2.stat.fi/Dialog/varval.asp?ma=tps00131_fi\&ti=De ath+due+to+chronic+liver+disease $\% 2 \mathrm{C}+$ by+gender $\&$ path $=. . /$ Database/Eurostat/ter/\&lang=3\&multilang=fi (Information was retrieved: 2/1/2011).

Eurostat (2009).

http://pxweb2.stat.fi/Dialog/varval.asp?ma=tsdph100_fi\&ti=Hea lthy+life+years+and+life+expectancy+at+birth $\% 2 \mathrm{C}+$ by+gender \&path=../Database/Eurostat/ter/\&lang=3\&multilang=fi (Information was retrieved: $2 / 1 / 2011$ ).

Eurostat (2010).

http://pxweb2.stat.fi/Dialog/varval.asp? ma=tps00001_ fi\&ti $=$ Total + population $\&$ path $=. . /$ Database/Eurostat $/$ $\mathrm{vrm} /$ \&lang=3\&multilang=fi (Information was retrieved: $2 / 1 / 2011$ ).

Fuldauer, A. (1994). Fatalie liefde. Mannen en vrouwen de bun partner doodden of daartoe en poging deden. [Fatal love. Men and women who killed or attempted to kill their intimate partner]. Amsterdam: De Arbeiderspers.

Franke, H. (1994). "Violent crime in the Netherlands. A historicalsociological analysis." Crime, Law \& Social Change 21/1994: 73-100.

van Gemert, F. (1994a). "Chicken kills hawk: Gay murders during the eighties in Amsterdam" Journal of Homosexuality 26 (4): 149-174.

van Gemert, F. (1994b). Fatale fantasie. Een onderzoek naar moorden op prostituees. [Fatal fantasy. A study on homicides of prostitutes']. Den Haag: WODC.

Ganpat, S.M. \& Liem, M. (2011) 'Homicide in the Netherlands', In: Handbook of European Homicide Research. Liem, M. \& Pridemore, W. (eds.). New York: Springer (forthcoming). 
Granath, S. (2007). Rättsliga reaktioner på ungdomsbrott 19802005: Påfölidsval, uppsåtsbedömningar och kriminalpolitik. En kriminologisk analys. [The justice System's response to youth crime 1980-2005]. Avhandlingsserie 25. Stockholm: Kriminologiska Institutionen, Stockholms universitet.

Granath, S. (2008). Bättre akutsjukvård - färre dödsoffer? [Improvements in emergency health care - less causalities?]. Apropå nr. 1/2008. Stockholm: Swedish National Council for Crime Prevention (Brå).

Granath, S. (2011). "Homicide in Sweden.” In: Handbook in European Homicide Research. Liem, M. \& Pridemore, W. (eds.). New York: Springer. (forthcoming).

Grönfors, M. (1981). Suomen mustalaiskansa [The Finnish Roma]. Juva: WSOY.

Haapasalo, J. \& Petäjä, S. (1999). "Mother Who Killed or Attempted to Kill Their Child: Life Circumstances, Childhood Abuse, and Types of Killing." Violence and Victims 14: 219-239.

Hagelstam, C. \& Häkkänen, H. (2006). "Adolescent homicides in Finland: Offence and offender characteristics.” Forensic Science International 164: 110-115.

Hakko, H. (2000). Seasonal Variation of Suicides and Homicides in Finland - with special attention to statistical techniques used in seasonality studies. Acta Universitatis Ouluensis D 583. Oulu: Oulun yliopisto.

Harris, A., Thomas, S.H., Fischer, G. A., \& Hirsch, D.J., (2002). Murder and Medicine: The Lethality of Criminal Assault 19601999. Homicide Studies nr. 6, 128-166.

von Hofer, H. (1990). "Homicide in Swedish Statistics, 17501988" In: Criminal Violence in Scandinavia. Scandinavian Studies in Criminology 11. Oslo: Norwegian University Press.

von Hofer, H. (2008). Brott och straff i Sverige. Historisk kriminalstatistik 1750-2005 [Crime and Punishment in Sweden. Historical Criminal Justice Statistics 1750-2005]. Stockholm: Kriminologiska institutionen, Stockholms universitet.

Human Development Reports (2010).

http://hdrstats.undp.org/en/countries/profiles/COUNTRY.html (Information was retrieved: 2/1/2011).

International Homicide Statistics (2004). UNODC.

http://www.unodc.org/unodc/en/data-and-analysis/ihs.html (Information was retrieved: 23/12/2010).

Johnson, B. \& Wingerden, S.G.C., van \& Nieuwbeerta, P. (2010) Sentencing of homicide offenders in the Netherlands. Criminology, vol. 48, issue 4, pp. 981-1018.

Kaipainen, M. (1996). Nuorten vakava väkivalta. Vertaileva 15-22-vuotiaita mielentilatutkimuksessa olleita ja psykiatriseen avohoitoon hakeutuneita nuoria miehiä koskeva tutkimus. Vankeinhoidon koulutuskeskuksen julkaisu 8/96. [Aggravated 
violent crimes of juveniles]. Vammala: HYKS psykiatrian klinikka, oikeuspsykiatrian yksikkö.

Killias, M. \& Aebi, M. F. (2000). "Crime Trends in Europe from 1990 to 1996: How Europe Illustrates the Limits of the American Experience" European Journal on Criminal Policy and Research, 8: 43-63.

Kivivuori, J. (1999). Suomalainen henkirikos. Teonpiirteet ja tekojen olosubteet vuosina 1988 ja 1996. [The Finnish Homicide. Main Characteristics of Homicides in 1988 and 1996]. Oikeuspoliittisen tutkimuslaitoksen julkaisuja 159. Helsinki: Oikeuspoliittinen tutkimuslaitos.

Kivivuori, J. (2002). "Sudden Increase of Homicide in Early 1970s Finland." Journal of Scandinavian Studies in Criminology and Crime Prevention 3 (1): 6-21.

Kivivuori, J. \& Lehti, M. (2003). "Homicide Followed by Suicide in Finland: Trend and Social Locus." Journal of Scandinavian Studies in Criminology and Crime Prevention, Vol. 4: 223-236.

Kivivuori, J. \& Lehti, M. (2006). The Social Composition of Homicide in Finland, 1960-2000. Acta Sociologica, 49(1), 67-82.

Kivivuori, J. \& Lehti, M. (2010). "Homicide in the Nordic Area: Finland and Sweden compared." Unpublished manuscript for the Nordic volume in the Crime and Justice -series.

Kivivuori, Janne \& Savolainen, Jukka \& Danielsson, Petri (2011). Theory and Explanation in Contemporary European Homicide Research. In: European Sourcebook of Homicide Research. Liem, M. \& Pridemore, W. (eds.). New York: Springer. (forthcoming).

Koenraadt, F. (1996). Ouderdoding als ultiem delict. [Parricide. The ultimate offence]. Deventer: Gouda Quint.

Landberg, J. (2010). Alcohol-Related Problems in Eastern Europe - A Comparative Perspective. Centre for Social Research on Alcohol and Drugs. Stockholm University: Department of Sociology.

Lehti, M. (1997). Viron henkirikollisuus 1990-luvulla. [Homicides in Estonia in the 1990s]. Oikeuspoliittisen tutkimuslaitoksen julkaisuja 148. Helsinki: Oikeuspoliittinen tutkimuslaitos.

Lehti, M. (2001). Väkivallan hyökyaalto. 1900-luvun alkuvuosikymmenten henkirikollisuus Suomessa ja Luoteis-Virossa. [Homicides in Finland and north-western Estonia during the first decades of the 20th century]. Oikeuspoliittisen tutkimuslaitoksen julkaisuja 178, Helsinki: Oikeuspoliittinen tutkimuslaitos.

Lehti, M. (2002). Henkirikokset 1998-2000. Tutkimus poliisin tietoon vuosina 1998-2000 tulleista henkirikoksista. [Homicides in 1998-2000]. Oikeus 2002:14. Helsinki: Tilastokeskus.

Lehti, M. (2007). Nuoret ja henkirikollisuus 1980-2004. [Homicides by juveniles in 1980-2004]. Oikeuspoliittisen tutkimus- 
laitoksen tutkimustiedonantoja 78, Helsinki: Oikeuspoliittinen tutkimuslaitos.

Lehti, M. \& Kivivuori, J. (2005). Alcohol-related violence as an explanation for the difference between homicide rates in Finland and the other Nordic Countries. Nordisk alkohol- \& narkotikatidskrift, 22 (English supplement), 5-18.

Lehti, M. \& Kivivouri, J. (2011). 'Homicide in Finland'. In: Handbook of European Homicide Research, Liem, M. \& Pridemore, W. (eds.). New York: Springer (forthcoming).

Leistra, G. \& Nieuwbeerta, P. (2003). Moord en doodslag in Nederland. [Murder and manslaughter in the Netherlands]. Amsterdam: Prometheus.

Lenke, L. (1990). Alcohol and Criminal Violence. Time Series Analyses in a Comparative Perspective. Stockholm: Almqvist \& Wiksell.

Lenke, L. (2009a). "Alkohol och våldsbrottslighet. Tidsserieanalyser i komparativ perspektiv" In: Leif Lenke in memoriam, edited by Hans von Hofer. Stockholm: Kriminologiska institutionen.

Lenke, L. (2009b). "Totalkonsumptionens betydelse för alkoholskadeutvecklingen i Sverige" In: Leif Lenke in memoriam, edited by Hans von Hofer. Stockholm: Kriminologiska institutionen.

Lenke, L. (2009c). "Våldsbrottsligheten i teoretisk belysning. Mot en politisk teori" In: Leif Lenke in memoriam, edited by Hans von Hofer. Stockholm: Kriminologiska institutionen.

Liem, M. (2010). Homicide followed by Suicide: An Empirical Analysis. Utrecht: Utrecht University.

Liem, M. \& Ganpat, S. (2011). "Homicide in the Netherlands" In: Handbook in European Homicide Research. Liem, M. \& Pridemore, W. (eds.). New York: Springer (forthcoming).

Liem, M. \& Koenraadt, F. (2007). "Homicide-Suicide in the Netherlands: A Newspaper Surveillance Study" Journal of Forensic Psychiatry and Psychology, 18, 482-493.

Liem, M. \& Koenraadt, F. (2008a). "Familicide: A Comparison with Spousal and Child Homicide". Criminal Behaviour and Mental Health, 18, 306-318.

Liem, M. \& Koenraadt, F. (2008b). "Filicide - A Comparative Study of Maternal versus Paternal Child Homicide". Criminal Behaviour and Mental Health, 18, 166-176.

Liem, M. \& Nieuwbeerta, P. (2010). "Homicide followed by Suicide: A Comparison with Homicide and Suicide". Suicide and Life-Threatening Behavior, 40, 133-145.

Liem, M. \& Postulart, M. \& Nieuwbeerta, P. (2009). "HomicideSuicide in the Netherlands: An Epidemiology". Homicide Studies, 13, 99-123.

Liem, M. \& Pridemore, W. (2011). Handbook in European Homicide Research. New York: Springer (forthcoming). 
Loeber, R. \& Slot, W. (2007). "Serious and Violent Juvenile Delinquency." In Crime and Justice in the Netherlands, edited by Michael Tonry and Catrien Bijlevend. Crime and Justice 35. Chicago: The University of Chicago Press.

McCall, P. L. \& Nieuwbeerta, P. (2007). Structural Covariates of Homicide Rates. A European City Cross-National Comparative Analysis. Homicide Studies 11: 167-188.

Nadanovsky P., Celeste, R., Wilson, M., \& Daly, M. (2009). Homicide and impunity: an ecological analysis at state level in Brazil. Rev Saúde Pública 2009;43(5). 733-742.

Nauta, A. \& Werdmölder, H. (2002). "Onderzoek naar kenmerken van eerwraak. [A study on the characteristics of honour killings]." Tijdschrift voor Criminologie 44: 367-373.

Nieuwbeerta, P. \& Leistra, G. (2007). Dodelijk geweld. Moord en doodslag in Nederland. [Fatal violence. Murder and manslaughter in the Netherlands]. Amsterdam: Uitgeverij Balans.

Nikunen, M. (2005). Surman jälkeen itsemurha. Kulttuuriset luokitukset rikosuutisissa. [Homicide-suicides in the press]. Tampere: Tampereen yliopisto.

OECD Health Data (2010). www.ecosante.org/oecd.ht (Information was retrieved: 2/1/2011).

Paanila, J. (2004). Vaarallisten rikoksenuusijoiden uusimisriskiin vaikuttavat tekijät Suomessa 1971-1995. [Violent crime recidivists in Finland in 1971-1995]. Kuopion yliopiston julkaisuja D 337. Kuopio: Kuopion yliopisto.

Pajuoja, J. (1987). Suomalaisen väkivallanaallon huippu 1920- ja 1930-luvulla. [The climax of the Finnish homicide wave in the 1920s and 1930s]. In: Oikeutta ja historiaa. Heikki Ylikankaan 50-vuotisjublakirja. Juva: WSOY.

Pajuoja, J. (1995). Väkivalta ja mielentila [Violent Crime and Mental Disorders]. Suomalaisen lakimiesyhdistyksen julkaisuja A 201. Jyväskylä: Suomalainen lakimiesyhdistys.

Pajuoja, J. \& Salminen, M. (1996). Kadonneet henkilöt. [Missing persons]. Helsinki: Keskusrikospoliisi.

van de Port, M. (2001). Geliquideerd. Criminele afrekeningen in Nederland. [Asssassinated. Criminal Homicide in the Netherlands]. Amsterdam: Meulenhoff.

Pridemore, W. A. (2002). "Vodka and Violence: Alcohol Consumption and Homicide Rates in Russia." American Journal of Public Health, Vol. 92, No. 12: 1921-1930.

Pridemore, W. A. (2003). Demographic, temporal, and spatial patterns of homicide rates in Russia. European Sociological Review, 19, 41-59.

Pridemore, W.A. (2004). Weekend effects on binge drinking and homicide mortality: Preliminary evidence for the social connection between alcohol and violence in Russia. Addiction, 99, 1034-1041. 
Putkonen, A. (2008). Mental Disorders and Violent Crime. Epidemiological Study on Factors Associated with severe Violent Offending. Kuopion yliopiston julkaisuja D 422. Kuopio: Kuopion yliopisto.

Putkonen, H. (2003). Homicidal Women in Finland 1982-1992. Publications of the National Public Health Institute KTL A5/2003. Helsinki: KTL.

Rajala, J. (2004). Kurittajia ja puukkosankareita. Väkivalta ja sen kontrollointi Kannaksen rajaseudulla 1885-1917 [Violent Crime and Control in the Karelian Isthmus in 1885-1917]. Bibliotheca Historica 87. Helsinki:SKS.

Rossow, I. (2001). "Alcohol and homicide: a cross-cultural comparison of the relationship in 14 European countries." Addiction (2001) 96 (Supplement 1): S77-S92.

Rying, M. (2000). Dödligt våld i Sverige 1990-96. [Lethal violence in Sweden 1990-96]. Stockholm: Institute of Criminology, University of Stockholm.

Rying, M. (2001). Dödligt våld i nära relationer. [Lethal violence in intimate relationships]. Brå-rapport 2001:11. Stockholm: Brå.

Rying, M. (2007). Utvecklingen av dödligt våld $i$ nära relationer [Trends in Intimate-partner Homicides against Women]. Brårapport 2007:6. Stockholm: Brå.

Rying, M. (2008). "Dödligt våld" [Lethal violence]. In: Brottsutvecklingen i Sverige fram till àr 2007. Brå-rapport 2008:23. Stockholm: Brå.

Säävälä, H. (2001). Isänsä surmannut poika - psykiatrinen tutkimus. [Male patricides - a psychiatric study]. Acta Universitas Ouluensis D 657. Oulu: Oulun yliopisto.

Savolainen, J. (2000). Inequality, welfare state, and homicide: further support for the institutional anomie theory. Criminology 38: 1021-1042.

Savolainen, J. \& Lehti, M. \& Kivivuori, J. (2008). Historical Origins of a Cross-national Puzzle: Homicide in Finland, 1750 to 2000. Homicide Studies, 12: 67-89.

Savolainen, J. \& Messner, S. \& Kivivuori, J. (2000). Crime is Part of the Problem: Contexts of Lethal Violence in Finland and the USA. Journal of Scandinavian Studies in Criminology, Vol. 1, No. 1: 41-55.

Sethi, D. \& Hughes, K. \& Bellis, M. \& Mitis, F. \& Racioppi, F. (2010). European Report on Preventing Violence and Knife Crime among Young People. Copenhagen: WHO Europe.

Sirén, R. (2000). Pahoinpitelyrikollisuus 1950-1997. Kehityspiirteitä ja kehitystä selittäviä tekijöitä [Assault criminality in 1950-1997]. Oikeuspoliittisen tutkimuslaitoksen julkaisuja 169. Helsinki: Oikeuspoliittinen tutkimuslaitos.

Skog, O.-J. \& Björk E. (1988). "Alkohol og voldskriminalitet. En analyse av utviklingen i Norge 1931-82 [Alcohol and Crimi- 
nal Violence in Norway in 1931-82]." Nordisk Tidsskrift for Kriminalvidenskab, Vol. 75, No. 1: 1-23.

Smit, P. \& Biileveld, C. \& van der Zee, S. (2001). "Homicide in the Netherlands: an exploratory study of the 1998 cases." Homicide Studies 5 (4): 293-310.

Smit, P. \& Nieuwbeerta, P. (2007). Moord en doodslag in Nederland, 1998 en 2002-2004. [Murder and homicide in the Netherlands, 1998 and 2002-2004]. Den Haag: WODC.

Smit, P . \& de Jong, R. \& Bijleveld, C. (2011). "Homicide data in Europe. Definitions, sources and statistics." In: Handbook in European Homicide Research. Liem, M. \& Pridemore, W. (eds.). New York: Springer (forthcoming).

Stickley, A., \& Pridemore, W. A. (2007). The Social-Structural Correlates of Homicide in Late-Tsarist Russia. The British Journal of Criminology, (January 2007) 47, 80-99.

Titterington, V. B. \& Grundies, V. (2007). An Exploratory Analysis of German and U.S. Youthful Homicide Offending. Homicide Studies 11: 189-212.

Vanamo, T. \& Kauppi, A. \& Karkola, K. \& Merikanto, J. \& Räsänen, E. (2001). "Intra-Familial Child Homicide in Finland 1970-1994: Incidence, Causes of Death and Demographic Characteristics." Forensic Science International 117: 199-204.

Verheugt, A.J. (2007) Moordouders - Kinderdoding in Nederland. Een klinisch en forensisch psychologische studie naar de persoon van de kinderdoders [Homicidal Parents - Child homicide in the Netherlands. A clinical and forensic psychological study into the person of child murderers]. Assen: Van Gorcum.

Verkko, V. (1931a). Henki- ja pahoinpitelyrikollisunden kehityssuunnan ja tason määräämisestä I. Suomi ja sen naapurimaat. [A statistical analysis on homicides and assault crimes I]. Tilastollis-metodologinen tutkimus. Helsinki.

Verkko, V. (1931b). Henki- ja pahoinpitelyrikollisunden kehityssuunnan ja tason määräämisestä II. Muut maat. [A statistical analysis on homicides and assault crimes II]. Tilastollis-metodologinen tutkimus. Helsinki.

Verkko, V. (1948). Maailman vanhin väkivaltatilasto. [The oldest bomicide statistics in the world]. Taulustolaitoksen 200-vuotismuiston johdosta. Tilastokatsauksia 11-12/1948.

Verkko, V. (1951). Homicides and suicides in Finland and their dependence on national character. Scandinavian studies in sociology 3. Köbenhavn.

Viljanen, T. (1983). Henkirikokset Suomessa vuosina 1970-79. [Homicides in Finland in 1970-79]. Oikeuspoliittisen tutkimuslaitoksen julkaisuja 60. Helsinki: Oikeuspoliittinen tutkimuslaitos.

de Vries, P. R. \& Liem, M. \& Nieuwbeerta, P. (2010). "Recidive van jongeren betrokken bij moord en doodslag [Recidivism 
of Juvenile Homicide Offenders]." Mens \& Maatschappij (85, 2010, 213-241).

Weizmann-Henelius, G. (2004). Violent Female Perpetrators in Finland. Personality and Life Events. Vaasa: Vanhan Vaasan sairaala.

Wikström, P.-O. (1991). "Cross-National Comparisons and Context-specific Trends in Criminal Homicide". Journal of Crime and Justice, Vol XIV, No. 2: 71-95.

Wikström, P.-O. (1992). "Context-specific Trends in Criminal Homicide in Stockholm 1951-1987." Studies on Crime Prevention 1 (1): 88-105.

World Bank (2010). http://data.worldbank.org/indicator. (Information was retrieved: 3/5/2011).

World Drug Report 2010 (2010).

http://www.unodc.org/unodc/en/data-and-analysis/WDR-2010. $\mathrm{html}$ (Information was retrieved: 23/12/2010).

WHO (2004). WHO Global Status Report on Alcohol 2004. Geneva: WHO.

Yecilgöz, Y. (1995). Allah, Satan en het recht. Communicatie met Turkse verdachten. [Allah, Satan and the law. Communication with Turkish defendants]. Arnhem: Gouda Quint.

Ylikangas, H. (1976). "Major Fluctuations in Crimes of Violence in Finland." Journal of Scandinavian History 1: 81-103.

Ylikangas, H. (1990). A Historical Review of Violent Crime in Finland. In: Criminal Violence in Scandinavia. Scandinavian Studies in Criminology 11. Annika Snare (ed.). Oslo: Norwegian University Press.

Ylikangas, H. (1998a). About Violence. Rikollisuuden historia -projektin julkaisuja 1. Helsinki: Rikollisuuden historia projekti.

Ylikangas, H. (1998b). The Knife Fighters. Violent Crime in Southern Ostrobothnia 1790-1825. Humaniora 293. Helsinki: The Finnish Academy of Science and Letters. 


\section{Appendix}

\section{Appendix A. Description of national homicide data in Finland, the Netherlands and Sweden}

\section{Finland}

The National Research Institute of Legal Policy (NRILP) collected the Finnish contribution of data towards the EHM. The NRILP provided information about all cases of lethal violence that occurred in Finland in 2003-2006 and that were known to the Finnish police by the end of the year 2010 .

The data cover the crimes investigated by the police under the legal definitions of murder (murha), voluntary manslaughter (tappo), voluntary manslaughter under mitigating circumstances (surma), infanticide (lapsensurma) and assault resulting in death (pahoinpitely ja kuolemantuottamus). Attempted homicides are not included.

The data, including information about most variables concerning the crimes, the victims and the perpetrators are part of the Finnish Homicide Monitoring System (FHMS).

The FHMS is maintained jointly by the NRILP, the Finnish Police College and the Police Department of the Ministry of the Interior. It includes all intentional homicides reported to the Finnish police after May, 2002. The FHMS is based on information produced during preliminary investigations. The data are collected directly by the chief investigator of each individual homicide on a compulsory standard electronic form. The national crime reporting system of the police is used as a control measure to make sure that all cases are included and that all the data are acquired. Information is registered after the preliminary investigation is closed. For crimes that are not cleared within a reasonable amount of time, the available data are registered about one year after the initiation of the investigation, provided that the case is still being investigated as a probable homicide. 
The database contains information on the main characteristics of the crime, the victims and the main perpetrator. It also contains information related to the investigation of the crime and information on the behaviour of the suspects after the crime and during the investigation. The number of internal variables for each case is about 90 .

In addition, the NRILP inserts external data on the prior criminal court convictions of the perpetrators and the victims, and also on the punishments received by the perpetrators. These data are collected from the crime records and criminal conviction registers of the Legal Register Centre, using the personal identity numbers of the victims and the perpetrators registered in the FHMS.

\section{Data quality}

A number of quality control strategies are used to ensure that as few cases as possible are missing from the data, that the data are correct and do not have internal inconsistencies and that the analyses conducted using the data will yield valid results.

A central issue is to make sure that there are as many cases as there are actual events of lethal violence on a yearly basis. It is possible that the method of collection used might result in cases being included twice and that cases might be missed. In order to prevent this from happening, comparisons are made with other sources (see figure AA1). In Finland, two such sources exist; the national cause-of-death statistics that are collected annually by Statistics Finland and the electronic crime report system of the Finnish Police (PATJA). The cases recorded in the FHMS are compared annually with those of the cause-of-death statistics and on a monthly basis with those registered in the PATJA by the NRILP.

The comparisons show that the sources are in agreement with one another. All the cases registered in the PATJA as homicides

Figure AA1. The number of cases of lethal violence in Finland in 2003-2009 according to the Finnish Homicide Monitoring System, police statistics and cause-of-death statistics.

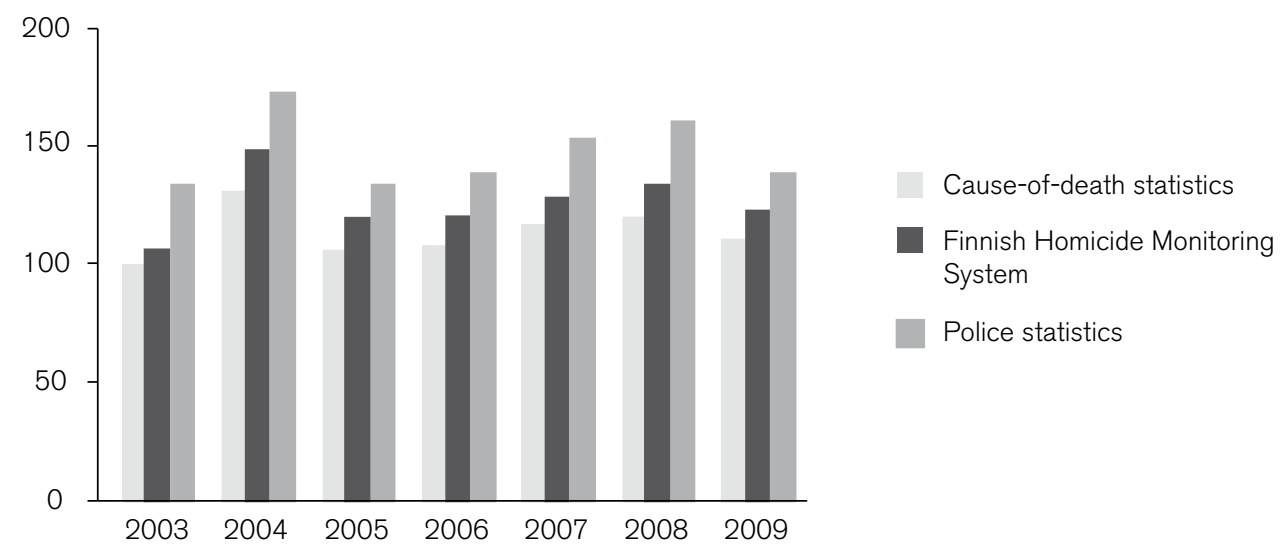


after the investigation were also registered in the FHMS, during the period outlined above. The annual number of cases registered in the FHMS is about 10 per cent higher than in the cause-ofdeath statistics, although the trends are similar. The numbers in the FHMS are, on the other hand, about 10 per cent lower than those in the official crime statistics (based on PATJA). The discrepancy between the cause-of-death statistics and the FHMS is caused mainly by the fact that the cause-of-death statistics are populationbased while the FHMS is country-based, i.e. cause-of-death statistics include all deaths of persons with a permanent residence in Finland, regardless of in which country they were killed, while the FHMS includes all homicides committed in Finland regardless of where the victim have his/her residence.

The discrepancy between the official crime statistics and the FHMS is caused by the fact that the official crime statistics are not based on cases where the investigation has been concluded, but on cases registered as homicides in the PATJA on a certain day of the year. Because of this, they include a considerable number of suspicious deaths that will later prove to be suicides, accidents, or natural deaths.

Double recordings are eliminated from the FHMS by comparing the personal identity numbers of the victims of each new case with those of the victims in cases already recorded in the system.

In order to control that the variable values are correct, each new case recorded in the FHMS is checked to make sure that the relationship between the victim and the perpetrator corresponds both to their gender and age (e.g., that a husband is male and a wife is female; that a daughter is younger than her mother).

Controls of the reasonability of the results are made throughout the report by comparing the results with those from previously conducted analyses.

\section{The Netherlands}

In order to provide data for the EHM for the period 2003-2006, the Dutch Homicide Monitor was used. The Dutch Homicide Monitor is an on-going monitoring system that includes all homicides in the Netherlands that took place between 1992 and 2009. The Monitor is based on national data and provides information about the characteristics of the incidents, perpetrators and victims of homicide. The Dutch Homicide Monitor includes all lethal offences that have been categorized as either murder (art. 289 and 291 Dutch Code of Criminal Law) or manslaughter ${ }^{24}$ (art. 287,

24 According to the Dutch Criminal Law, homicide comprises two offences: murder and manslaughter. Murder refers to crimes where a person kills someone deliberately and with premeditation. Manslaughter refers to crimes where a person has deliberately killed some-one else. 
288 and 290 Dutch Code of Criminal Law), together comprising the category homicide. This implies that - in contrast to Finland and Sweden - cases of assaults resulting in death are not included in the Dutch data (this includes robberies with lethal outcomes). However, as in the other countries, abortion, euthanasia and assisted suicide are also excluded.

To determine whether an incident should be classified as a homicide, the data are based primarily on the qualification of the crime given by the Public Prosecutor. Cases where the Public Prosecutor prosecuted at least one perpetrator are included in the database. This means that if the perpetrator was prosecuted, but eventually convicted for another offence, acquitted by the judge or release from all charges, then this person is still included in the database. However, not all cases are solved (meaning that no suspects were known to the police). In cases were the crime was unsolved or when the prosecution has not (yet) taken place, the data are based on the police assessment of the case.

\section{Data sources used}

The Dutch Homicide Monitor is based on six sources, which partially overlap but also complement one another:

- All homicide-related newspaper articles generated by the Netherlands National News Agency (ANP). These articles have a lot of information on the characteristics of the homicides, the perpetrators and victims.

- The Elsevier Annual Report. Elsevier is a weekly magazine that publishes an annual report on all homicides that have taken place. This report is based on both ANP articles and police files.

- Data stemming from police registration from the 25 Police regions in the Netherlands. Several police regions supply (additional) data from their own documentation, which is incorporated in the database.

- Files from the National Bureau of Investigation (NRI) ${ }^{25}$. Information on homicides in the Netherlands is collected by the NRI as part of the National Police Force (KLPD). The information available in these files concerns the date and location of the homicide, weapon use as well as basic demographic characteristics of both victim and perpetrator.

- Files from the Public Prosecution Service of the Ministry of Justice. This database includes the judicial procedures of prosecuted homicide perpetrators.

25 At midyear 2005, the National Bureau of Investigation stopped registering homicide incidents on the national level. 
- Files from the Criminal Justice Knowledge Centre (WODC). In addition to files from the KLPD and the Public Prosecution Service, these files contain detailed information stemming from interviews with relevant investigators who were in charge of the homicide investigation. ${ }^{26}$

\section{Data quality}

Statistics Netherlands produces annual cause-of-death statistics. There are, however, several limitations in using these statistics for describing the size and nature of the homicide phenomenon. First of all, cause-of-death statistics only include information on the victim, without linking the victim information to event information and perpetrator information. In addition, cause-of-death statistics only include the causes of death for Dutch citizens. Those who die as a result of homicide whilst in the Netherlands, but without being a Dutch national, are not included in the statistics.

The use of multiple sources in the Dutch Homicide Monitor allows for a complete and reliable overview of all homicides that have taken place in the Netherlands during the years 2003-2006. Multiple sources made it possible to examine both overlap and missing information. Through a constant process of verification, an up-to-date overview of homicide in the Netherlands has been made possible. In cases where there exist doubts or where it was unclear whether a homicide had actually taken place - and not, for example, an accident or suicide - the relevant authorities were contacted directly in order to receive more information and clarification about the specific incident. In addition, missing information or contradictory information was verified by contacting the authorities involved in the case. Furthermore, due to the intensive collaboration with all institutions involved, rather than relying on one source of information, the Dutch Homicide Monitor is able to give the most reliable overview on homicide in the Netherlands.

26 Smit, P.R. \& Nieuwbeerta, P. (2007) Moord en doodslag in Nederland, 1998 en 2002-2004 [Murder and manslaughter in the Netherlands, 1998 and 20022004]. The Hague: WODC. 
Figure AA2. The number of cases of lethal violence in the Netherlands in 20032009 according to cause-of-death statistics and the Dutch Homicide Monitor.

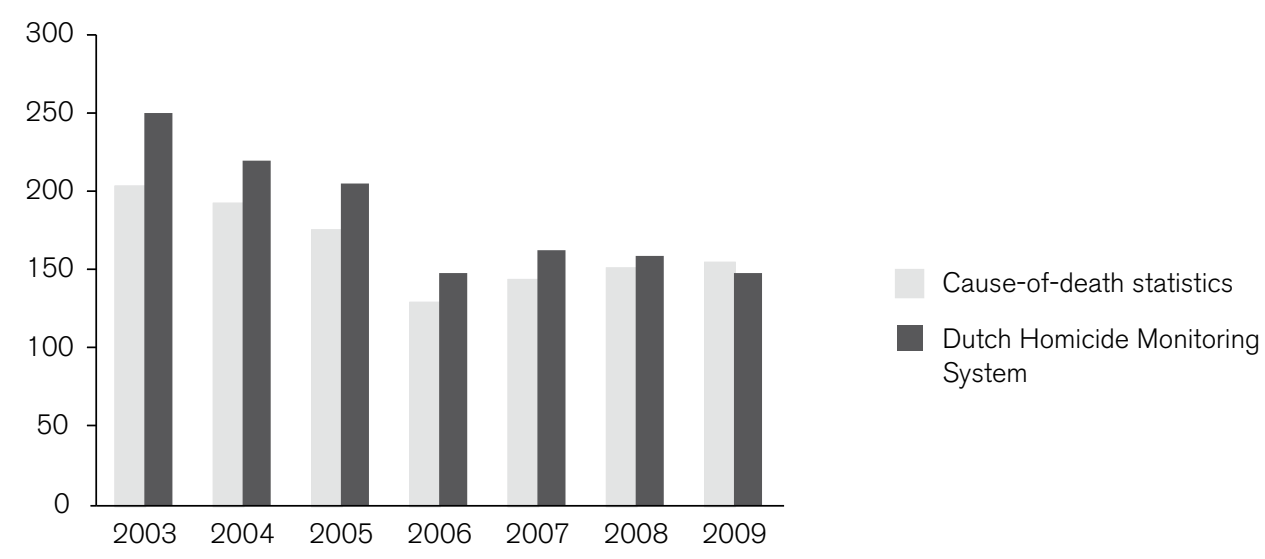

Although all possible sources were used in striving to create a complete database containing all homicides committed in the Netherlands, it is possible that some cases were missed. These incidents most likely include undiscovered cases or cases that were misclassified as suicides or accidents by the police. The Dutch Homicide Monitor includes all homicides that have been registered by at least one institution or agency involved in the case.

It should be mentioned, however, that due to capacity problems in some police regions the verification process for the homicide cases committed in 2005-2006 was not completely finished during the time of the project. However, for 12 of the 25 police regions the verification process was completed. Therefore, for 13 of 25 the police regions the information is based on data stemming from the ANP articles and The Elsevier Annual Report.

Furthermore, during the time of the report, the data collection from the Public Prosecution Service had not yet been completed. Therefore, the information from the Public Prosecution Service covers cases of homicide that were committed in the years 20032004. For the years 2005 and 2006, the information is based on data stemming from police registrations, ANP articles and The Elsevier Annual Report.

\section{Sweden}

The Swedish data included in the EHM stem from a larger dataset produced by the National Council for Crime Prevention, including all cases of lethal violence committed in Sweden during the years 1990-2008. The data collected covers the legal definitions of murder, manslaughter and assault resulting in death. 


\section{Data sources used}

The Swedish data are primarily based on three different sources.

- All cases that have been reported to the police under the criminal codes regarding lethal violence (murder, manslaughter and assault resulting in death). The reports were located with the help of the police case management system (RAR). Information from the public prosecutor was then added to see what was decided in each individual case (if the prosecution has been withdrawn or not). This information was located with the help of the prosecution service's case management system (CÅBRA).

- All cases which the courts have ruled to be murder, manslaughter or assault resulting in death. The judgments were collected from the district courts through the use of criminal statistics collected by the National Council for Crime Prevention.

- Preliminary investigations concerning lethal violence in cases where there are no indications in the data from the public prosecutor that the initial police report led to anyone being sentenced ${ }^{27}$. The preliminary investigations were collected from each of the 21 regional police authorities in Sweden.

By connecting these three types of documents - police reports, preliminary investigations and judgments - in-depth information was obtained for all registered cases of lethal violence. Since the cases were monitored through the judicial system, cases that were initially reported as lethal violence but later found to be something else could be distinguished from cases that actually involved murder, manslaughter or assault resulting in death. Conversely, cases that were initially not reported as lethal violence but were later found to be cases of lethal violence are included.

\section{Data quality}

To ensure that all cases of lethal violence have been included ${ }^{28}$, comparisons have been made with Swedish national cause-ofdeath statistics that are collected by The National Board of Health and Welfare every year as well as with official criminal statistics produced by The National Council for Crime Prevention.

The comparisons show that the different sources are in agreement with one another, as indicated in figure AA3. There are a number of explanations as to why the three different sources do

27 A substantial number of these cases are found to be something other than lethal violence (e.g., suicide, accident, death from natural causes, etc). Around 300 cases of lethal violence are reported each year and the annual systematic review of these shows that around 200 are something other than lethal violence.

28 All methods possible have been used to ensure that no registered cases have been missed. However, it is of course always possible that some cases are missing due to unregistered cases, and cases that have been misclassified as something other than a case of lethal violence. 
Figure AA3. The number of cases of lethal violence in Sweden in 2002-2008 according to cause-of-death statistics, Criminal Statistics and data included in the EHM.

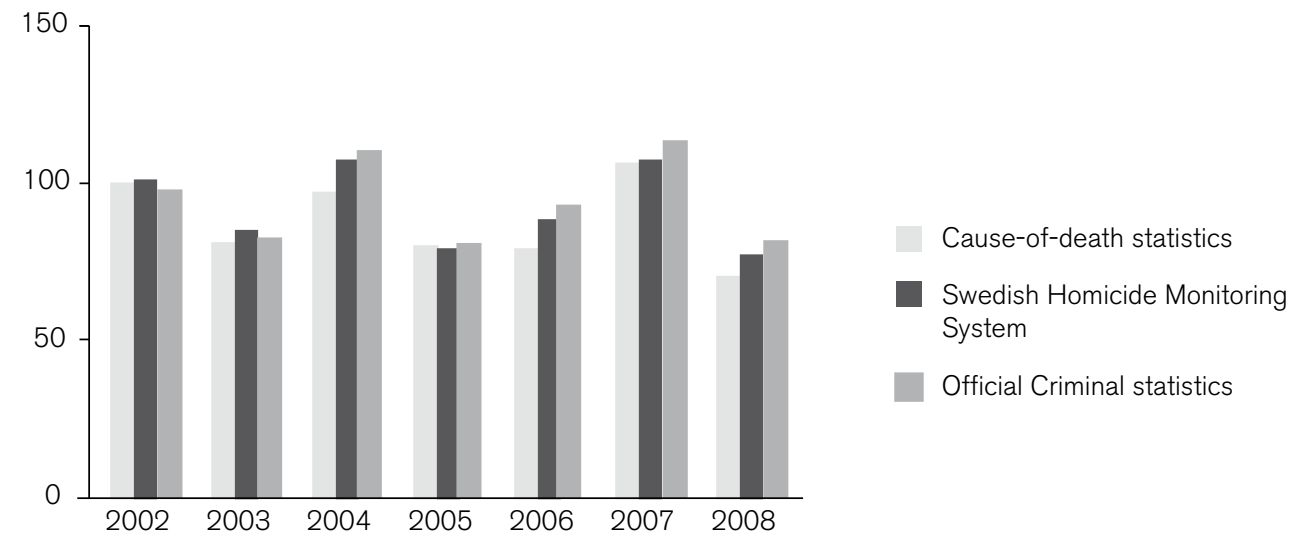

not display identical numbers. First of all, the national cause-ofdeath statistics include all persons registered as residents in Sweden regardless of where the homicide took place, while the official criminal statistics and the Swedish lethal violence data are based on cases that occurred within the country, regardless of the victim's country of residence. This means that the national cause-of-death statistics show a somewhat lower level of lethal violence than criminal statistics for most Western European countries, because they usually have more asylum seekers or temporary residents within the country than they have citizens abroad who become victims of lethal violence (Spierenburg, 2008). In addition, there will be a number of established cases of lethal violence included in the official criminal statistics based on preliminary investigations or even court judgments where the body of the victim has not been found, meaning that the case is not entered into the national causeof-death statistics.

There are also a small number of cases of self-defence and accidents that are included in the national cause-of-death statistics, but which are not included in the official criminal statistics or the Swedish lethal violence data.

As official criminal statistics are compiled and concluded for each year, some cases defined as lethal violence may since then have been redefined as accidents or other events in the courts of appeal or the Supreme Court.

Regional comparisons were made to make sure that there were no cases of lethal violence missing. The comparisons were made on the county level for each of Sweden's 21 counties. The data produced in the in-depth studies of the official criminal statistics meant that each individual case (linked by the police case number) could be identified. If a case was found to be missing, then it was 
collected from police and prosecutor files and, if found to be a case of lethal violence, entered into the database.

When quantitative research is based on registered information from many different authorities and is coded by more than one person, there is always a risk that cases are entered into the database twice. Earlier studies of the quality of Sweden's criminal statistics and police reports have shown that the same case of lethal violence may exist as two separate reports with different case identifications numbers. Cases that are reported more than once may cause the results of an analysis to be biased, and can also, by adding to the total number of cases, hide the fact that there may be other unique cases missing.

To check for cases that have been coded twice, variables that generally show a unique value for each case, such as date of the crime and police case identification numbers, were aggregated. When such a value occurred more than once on different rows, the case was checked to make sure that two events have actually occurred on the same day or that they are cases with multiple victims or perpetrators. Cases that had been entered twice were removed.

In order to check for errors that occurred when merging files, during coding or in the compilation process, tests were made to make sure that the values concerning one unique case correspond logically. The dataset allows for certain combinations of values for the different variables. (If the perpetrator committed suicide at the time of the crime, then there should be no entered values regarding court judgment and sentence; if the victim is single, then the relationship between the victim and the perpetrator should not have the value for husband or wife, etc.). When the tests revealed that a mistake had been made, the cases were looked over and corrected.

The value counts of some key variables were compared with previous studies of lethal violence based on the same or similar data, in order to check for possible coding errors and general validity. For the Swedish data, variables where comparisons with previous studies can be easily done include geographic distribution, relationship, crime location, methods of violence (modus operandi), age structures and others. The distributions of the variables are in line with those in previous studies. 


\section{Appendix B. The European Homicide Monitor Guidebook and Coding Manual 2011}

\section{Background}

Crimes that lead to lethal violence through murder, manslaughter or assault resulting in death involve the most severe types of violence. Cases of lethal violence are assigned substantial resources in connection to criminal investigations, court cases and the implementation of penal sanctions, which involve long custodial sentences. They also constitute offences that receive a lot of media attention and that have great effect on perceptions of insecurity in society at large. Systematic knowledge about lethal violence is necessary for the assessment of national trends, factors that foster lethal violence, preventive measures, sentencing policy and the treatment of perpetrators.

Lethal violence is a crime category with a very small dark figure, which makes it particularly suitable for international comparisons. Within the EU there have been no homogenous comparisons regarding lethal violence. It is unknown how many countries have national data on the occurrence of homicide, and the data that does exist is not always comparable with other national data due to definitional differences. Although homicide rates and trends have been compared, the similarities and differences in homicide event, victim, and offender characteristics within EU member states have not yet been compared.

In order to enable comparisons of lethal violence within EU countries, the National Council for Crime Prevention in Sweden, the National Research Institute of Legal Policy in Finland and the Institute of Criminal Law and Criminology of Leiden University in the Netherlands received funding from the EU for a three-year project to be conducted in the years 2009-2011. During this time, the three countries combined their national homicide data, thereby laying the foundation for a joint database on lethal violence among all EU member states. This provides new opportunities for detailed comparisons and analyses. A first comparative analysis was also been carried out, comparing the rates and characteristics of lethal violence in the three member states.

It is the hope and expectation of the three project members that the database can and will be used by other EU member states by adding national data to the international dataset as well as using 
the data for analyses on lethal violence in Europe. This will be possible under the assumption that necessary resources are provided to ensure that the work on the European homicide monitor will continue.

Finland, the Netherlands and Sweden have national datasets that are updated continuously. For the purpose of the analysis, the variables in the European Homicide Monitor were chosen with regard to the information already available in the three countries national data. Before the end of the project, a final set of variables should be decided on, consisting of ideal variables rather than already existing ones. The variables from each national dataset have been compared and 85 variables have been chosen to form the international dataset. Some variables have been chosen even though only two of three countries had them in their national data. Some variables required recoding, others did not.

This manual is intended to be used by those wanting to collect data in the European Homicide Monitor format. The Guidebook and Coding Manual can be kept at hand during coding and will hopefully answer questions that may arise during the coding process.

The content in this Guidebook and Coding Manual reflects the current state of the European Homicide Monitor in the year 2011. The content may be subject to change after its printing.

\section{Introduction}

Homicide is defined in the European Homicide Monitor as an intentional criminal act of violence by one or more human beings resulting in the death of one or more other human beings. The terms homicide and lethal violence are used interchangeably in this guidebook and coding manual. Homicide attempts, suicides, accidents, abortions, euthanasia and legal police interventions are not included.

The European Homicide Monitor includes all cases of homicide committed during the years 2003-2006 in Finland, the Netherlands and Sweden that are known to the judicial system. Cases where foreigners staying in the country become victims of homicide are included, but not cases where citizens of Sweden, Finland or the Netherlands became victims of lethal violence abroad.

Each homicide case was monitored from the initial police report until a judgement was made in a court of first instance.

\section{Data sources}

A number of different data sources were used in order to collect the national data from the three countries currently included in the European Homicide Monitor. Different data are available depend- 
ing on the source and the country of origin. The different sources are:

- Official crime statistics

- Police reports

- Police investigations

- Autopsy reports

- Judgements

- Psychiatric evaluations

- The media

There is no set list of priority between the different sources, although the information from two sources may be contradictory. It is up to each country to decide on a hierarchy which best fits the goal of having the highest quality data possible, based on which types of documents are considered the most reliable. Different types of documents may be accessible and valued differently depending on their source.

\section{The dataset}

The dataset is designed so that each unit (row) consists of data belonging to one person. In other words, one homicide event involving one victim and two perpetrators will have three rows in the dataset. Apart from each person having a unique serial number, each case (with one or more victims and perpetrators) is connected through the use of a case number variable.

The dataset consists of 85 variables, each in its own column. Some variables are open answer variables; others have a number of alternatives of which one must be chosen. Clarifying instructions are presented in the coding manual, which give additional information about how the variable and the variable labels should be used and interpreted.

\section{The variables}

The first variables in the dataset are technical and describe the serial number, case number, the country where the homicide took place and the legal status of the case. The subsequent variables describe when and where the homicide has taken place and how it has been carried out. The type of homicide and motives are described next, and after that the questions regarding the personal characteristics of the victim and perpetrator. Towards the end of the variable set there are a few questions about the case in terms of prosecution and sentencing, followed by variables concerning the prior criminal record of the perpetrator. Lastly, there is a vari- 
able to indicate so-called corresponding cases (i.e., cases that are of serial character or have some other connection to each other).

There are variables with open answers and labelled answers in the code manual. The general pattern for answering the variables with labelled answers is 0 for no and 1 for yes. The value 999 or 9999 is used when the answer is unknown (if the variable can assume the positive value of 999 or 9999 , then the numbers -999 or -9999 are used instead). The value 99 is usually used to indicate that the information is missing due to the perpetrator in the case being unknown.

There are both case-bound and individual-bound variables in the dataset. Information about the variable types and how they are entered into the dataset can be found in the table below.

Table AB1. Variable types, numbers and instructions for the EHM dataset.

\begin{tabular}{lll}
\hline Variable type & Variable numbers & Instruction \\
\hline Case-bound & $\begin{array}{l}1-14,19-23 \\
18,24-28,33-46,\end{array}$ & Values should be the same for both victim/-s and perpetrator/-s. \\
Individual-bound & Values should differ for each involved individual. \\
Victim-bound & $15-16,29$ and 47 & $\begin{array}{l}\text { Values should differ if there are multiple victims. Fill in the value } \\
\text { for the principal victim on the perpetrator row (for a definition of } \\
\text { principal victim see below). }\end{array}$ \\
Perpetrator-bound $17,30-32,72-83$ & $\begin{array}{l}\text { Values should differ if there are multiple perpetrators. Fill in the } \\
\text { value for the principal perpetrator on the victim row (for a defini- } \\
\text { tion of principal perpetrator see below). } \\
\text { Variables } 72-83 \text { should only be filled in on the row of the perpe- } \\
\text { trator. }\end{array}$ \\
\hline
\end{tabular}

\section{Definitions}

Below is a list of definitions of some terms used in the dataset.

\section{Homicide}

A homicide is defined as an intentional criminal act of violence by one or more human beings resulting in the death of one or more other human beings.

\section{Homicide case}

A homicide case is defined as when a homicide act has taken place between one or more unique victim/-s and perpetrator/-s. Should two or more homicides take place involving the same perpetrator/$\mathrm{s}$, then the difference between one homicide case with two victims and two separate homicide cases is the amount of time that has gone by between the two homicides. Homicides that have been committed by the same perpetrator and have taken place within 
24 hours are considered to be one case with two victims. Homicides that have been committed by the same perpetrator and have taken place with more than 24 hours between them are considered to be two separate cases.

\section{Principal victim}

The principal victim is defined as the victim with the closest relationship to the perpetrator. If the victim and perpetrator are equally as close, choose the victim that died first. If this information is not available, choose randomly.

\section{Principal perpetrator}

The principal perpetrator is defined as the perpetrator that has been prosecuted (see variable 72). If more than one perpetrator is prosecuted, then the principal perpetrator is the one with the most severe sentence (see variable 73). If two or more of the perpetrators have equal sentences, then choose the one with the most severe sanction (see variable 74). If the sanctions are equal, then the person with the closest relationship to the victim is the principal perpetrator (see variable 47). If this is information is not available, or if the perpetrators are equally as close to the victims, then you should choose at random.

\section{Mental illness}

Mental illness is defined as there being documented evidence from one or more sources that the individual has been the recipient of psychiatric care or has been diagnosed with a mental disorder at the time of the crime.

\section{Separation}

Separation is defined as the temporary or permanent splitting up of persons who have been in a romantic relationship.

\section{Child killing}

Child killing is defined as the killing of a person between the age of 1 and 18 .

\section{Infanticide}

An infant is defined as a child up to the age of one year. Infanticide refers to when a child is killed within a year after his/her birth.

\section{Eye witness}

An eye witness is any person other than a suspect or perpetrator who was present and observed the incident that resulted in the homicide or lethal violence. The actual act of homicide must have been seen by the witness, i.e. having been present at the scene or having heard the crime take place is not enough. 


\section{Definitions used from other sources}

Some variables in the dataset have been defined with the help of other sources. These are:

- variable 20, where the middle-sized geographical unit of where the crime took place has been classified according to the country's NUTS 2 regions (Nomenclature of Territorial Units for Statistics),

- variable 21 , where the small geographical unit of where the crime took place has been classified according to the country's NUTS 3 regions (Nomenclature of Territorial Units for Statistics),

- variable 24 , where the modus of the crime has been classified according to the ICD-10 (International Classification of Diseases version 10),

- variable 28 concerning firearm categories, originally from the Harvard (US) NVDRS (National Violent Death Reporting System) Coding Manual from 2003,

- variable 32 , where the method of suicide used by the perpetrator (if suicide was committed during or after the crime) has been classified according to the ICD-10 (International Classification of Diseases version 10) and

- variable 62 , where the professional status of the victim or perpetrator has been classified according to the European SocioEconomic Classification.

Furthermore, five variables have been left undefined in the dataset. The reason for leaving some variables undefined is because some terms are better decided on in accordance with national standards or practices. Therefore, it is left to each country that submits data to decide on a definition that best suits their national circumstances. These variables are:

- variable 7 , concerning the definition of when the crime is considered solved,

- variable 19 , concerning the definition of a rural and urban area in which the crime took place,

- variable 58 , concerning whether the mother's or father's birth country should be entered for parents' country of birth,

- variable 60 , concerning the definition of when a victim or perpetrator should be considered to have children (legal definitions of adopted children etc. may vary) and

- variable 71 , concerning choosing a suitable geographical unit to define whether the crime took place in the individual's area of residence or outside said area. 


\section{The coding manual}

\begin{tabular}{|c|c|c|c|c|}
\hline $\begin{array}{l}\text { Variable } \\
\text { number }\end{array}$ & $\begin{array}{l}\text { Variable name in } \\
\text { SPSS }\end{array}$ & $\begin{array}{l}\text { Complete } \\
\text { variable name }\end{array}$ & Label & Clarifying instructions \\
\hline 1 & SERNR & Serial number & Open variable (numeric) & $\begin{array}{l}\text { The serial number starts off with the } \\
\text { submitting countries' country code times } \\
10,000 \text {. Add one for every new row. Each } \\
\text { number must be unique (only appear on } \\
\text { one single row in the dataset) and by the } \\
\text { first digits indicate the country of origin by } \\
\text { country code (see Appendix B for a com- } \\
\text { plete list). }\end{array}$ \\
\hline 2 & CASENR & Case number & Open variable (numeric) & $\begin{array}{l}\text { The serial number starts off with the } \\
\text { submitting countries' country code times } \\
10,000 \text {. Add one for every new case. Each } \\
\text { case number must be unique (only appear } \\
\text { on the rows that belong to the same case } \\
\text { in the dataset) and by the first digits indi- } \\
\text { cate the country of origin by country code } \\
\text { (see Appendix B for a complete list). }\end{array}$ \\
\hline 3 & COUNTR & Country & $\begin{array}{l}30=\text { Greece } \\
31=\text { Netherlands } \\
32=\text { Belgium } \\
33=\text { France } \\
34=\text { Spain } \\
36=\text { Hungary } \\
39=\text { Italy } \\
40=\text { Romania } \\
43=\text { Austria } \\
44=\text { United Kingdom } \\
45=\text { Denmark } \\
46=\text { Sweden } \\
48=\text { Poland } \\
49=\text { Germany } \\
351=\text { Portugal } \\
352=\text { Luxembourg } \\
353=\text { Ireland } \\
356=\text { Malta } \\
357=\text { Cyprus } \\
358=\text { Finland } \\
359=\text { Bulgaria } \\
370=\text { Lithuania } \\
371=\text { Latvia } \\
372=\text { Estonia } \\
386=\text { Slovenia } \\
420=\text { Czech republic } \\
421=\text { Slovakia }\end{array}$ & $\begin{array}{l}\text { Choose the country that has submitted the } \\
\text { data (should be the same as the country in } \\
\text { which the homicide occurred). The value is } \\
\text { the same as the country code (see Appen- } \\
\text { dix B for a complete list). }\end{array}$ \\
\hline 4 & NRVIC & Number of victims & $\begin{array}{l}\text { Open variable (numeric) } \\
999=\text { Unknown }\end{array}$ & $\begin{array}{l}\text { State the number of victims involved in the } \\
\text { case. A victim is defined as any person } \\
\text { who is a victim of lethal violence. Murder } \\
\text { attempts, other forms of violence and other } \\
\text { crimes committed against others in the } \\
\text { same incident are not to be included. }\end{array}$ \\
\hline
\end{tabular}




\begin{tabular}{|c|c|c|c|c|}
\hline $\begin{array}{l}\text { Variable } \\
\text { number }\end{array}$ & $\begin{array}{l}\text { Variable name in } \\
\text { SPSS }\end{array}$ & $\begin{array}{l}\text { Complete } \\
\text { variable name }\end{array}$ & Label & Clarifying instructions \\
\hline 5 & NRPERP & $\begin{array}{l}\text { Number of perpe- } \\
\text { trators }\end{array}$ & $\begin{array}{l}\text { Open variable (numeric) } \\
999=\text { Unknown }\end{array}$ & $\begin{array}{l}\text { State the number of perpetrators involved } \\
\text { in the case. A perpetrator is defined as any } \\
\text { person who is suspected of and/or charged } \\
\text { with homicide. Perpetrators that have been } \\
\text { found not guilty are therefore included in } \\
\text { the data. }\end{array}$ \\
\hline 6 & CRIME & $\begin{array}{l}\text { Legal type of } \\
\text { Homicide }\end{array}$ & $\begin{array}{l}1=\text { Murder } \\
2=\text { Manslaughter (cases with miti- } \\
\text { gating circumstances) } \\
3=\text { Assault resulting in death } \\
4=\text { Infanticide } \\
999=\text { Unknown }\end{array}$ & $\begin{array}{l}\text { Indicate the type of homicide that has been } \\
\text { reported to/is being investigated by the } \\
\text { police. "Manslaughter" also refers to "aggra- } \\
\text { vated manslaughter", and "Assault resulting } \\
\text { in death" also refers to "Aggravated assault } \\
\text { resulting in death". Infanticide is defined as } \\
\text { the deliberate killing of an infant under the } \\
\text { age of one. } \\
\text { If there are multiple perpetrators charged } \\
\text { with different legal types of homicide, } \\
\text { choose the most severe. See the definition } \\
\text { of principal perpetrator. }\end{array}$ \\
\hline 7 & SOLVED & $\begin{array}{l}\text { Has the crime } \\
\text { been solved? }\end{array}$ & $\begin{array}{l}0=\text { No } \\
1=\text { Yes } \\
999=\text { Unknown }\end{array}$ & $\begin{array}{l}\text { This means that cases that are cleared or } \\
\text { "exceptionally cleared" by the police are } \\
\text { considered solved. However, there might } \\
\text { exist slight national variations in the defini- } \\
\text { tion of when a case are considered solved. }\end{array}$ \\
\hline 8 & YEARREP & $\begin{array}{l}\text { Year the crime was } \\
\text { reported }\end{array}$ & $\begin{array}{l}\text { Open variable (numeric) } \\
999=\text { Unknown }\end{array}$ & $\begin{array}{l}\text { State the year the crime became known to } \\
\text { the police (four digit number, e.g. 2008). }\end{array}$ \\
\hline 9 & YEARCOM & $\begin{array}{l}\text { Year the crime was } \\
\text { committed }\end{array}$ & $\begin{array}{l}\text { Open variable (numeric) } \\
999=\text { Unknown }\end{array}$ & $\begin{array}{l}\text { State the year the crime was committed } \\
\text { (four digit number, e.g. 2008). }\end{array}$ \\
\hline 10 & MONTH & $\begin{array}{l}\text { Month the crime } \\
\text { was committed }\end{array}$ & $\begin{array}{l}1=\text { January } \\
2=\text { February } \\
3=\text { March } \\
4=\text { April } \\
5=\text { May } \\
6=\text { June } \\
7=\text { July } \\
8=\text { August } \\
9=\text { September } \\
10=\text { October } \\
11=\text { November } \\
12=\text { December } \\
999=\text { Unknown }\end{array}$ & State the month the crime was committed. \\
\hline 11 & WDAY & $\begin{array}{l}\text { Day the crime was } \\
\text { committed }\end{array}$ & $\begin{array}{l}1=\text { Monday } \\
2=\text { Tuesday } \\
3=\text { Wednesday } \\
4=\text { Thursday } \\
5=\text { Friday } \\
6=\text { Saturday } \\
7=\text { Sunday } \\
8=\text { Day unknown, Mon-Thu } \\
9=\text { Day unknown, Fri-Sun } \\
999=\text { Unknown }\end{array}$ & $\begin{array}{l}\text { State the day of the week that the crime } \\
\text { was committed. }\end{array}$ \\
\hline 12 & PUBHOL & $\begin{array}{l}\text { Crime committed } \\
\text { during a public } \\
\text { holiday }\end{array}$ & $\begin{array}{l}0=\text { No } \\
1=\text { Yes } \\
999=\text { Unknown }\end{array}$ & $\begin{array}{l}\text { Indicate whether the crime was commit- } \\
\text { ted during a public or national holiday (e.g. } \\
\text { Christmas Eve). This does not include } \\
\text { School Holidays (e.g. summer holidays). }\end{array}$ \\
\hline 13 & TIME & $\begin{array}{l}\text { Time the crime } \\
\text { was committed }\end{array}$ & $\begin{array}{l}1=\text { Morning }(6.00 \text { to } 12.00) \\
2=\text { Afternoon }(12.00 \text { to } 18.00) \\
3=\text { Evening }(18.00 \text { to } 24.00) \\
4=\text { Night }(00.00 \text { to } 6.00) \\
999=\text { Unknown }\end{array}$ & $\begin{array}{l}\text { The time of day that the crime was com- } \\
\text { mitted. }\end{array}$ \\
\hline
\end{tabular}




\begin{tabular}{|c|c|c|c|c|}
\hline $\begin{array}{l}\text { Variable } \\
\text { number }\end{array}$ & $\begin{array}{l}\text { Variable name in } \\
\text { SPSS }\end{array}$ & $\begin{array}{l}\text { Complete } \\
\text { variable name }\end{array}$ & Label & Clarifying instructions \\
\hline 14 & TIMEDISC & $\begin{array}{l}\text { Days between } \\
\text { crime was commit- } \\
\text { ted and the crime } \\
\text { was revealed or } \\
\text { the body discov- } \\
\text { ered }\end{array}$ & $\begin{array}{l}\text { Open variable (numeric) } \\
9999=\text { Unknown }\end{array}$ & $\begin{array}{l}\text { Indicate the number of days that have gone } \\
\text { by from the time the crime was committed } \\
\text { until it was discovered. } \\
\text { Value } 0=\text { the crime was discovered within } \\
\text { the same calendar day or, if the calendar } \\
\text { day has changed, within } 12 \text { hours after it } \\
\text { was committed. Value } 1=\text { the crime was } \\
\text { discovered one day (with at least } 12 \text { hours } \\
\text { marginal) after the crime was committed. } \\
\text { (For example, a crime committed late at } \\
\text { night, } 11.30 \text { PM, and discovered (or first } \\
\text { reported) at } 2.30 \text { AM, is considered dis- } \\
\text { covered within the same day (as well as a } \\
\text { crime committed } 5.30 \text { AM and discovered } \\
19.00 \text { PM). A crime committed } 11.30 \text { PM } \\
\text { and discovered } 12.30 \text { PM the next day, on } \\
\text { the other hand, is considered discovered } 1 \\
\text { day after it was committed.) }\end{array}$ \\
\hline 15 & TIMDEATH & $\begin{array}{l}\text { Hours between } \\
\text { committed crime } \\
\text { and time of death }\end{array}$ & $\begin{array}{l}\text { Open variable (numeric) } \\
999=\text { Unknown }\end{array}$ & $\begin{array}{l}\text { The number of hours that went by from } \\
\text { the time the crime was committed until } \\
\text { the victim died. ( } 0=\text { the victim died within } \\
\text { the first hour, } 1=\text { the victim died after one } \\
\text { hour etc.). }\end{array}$ \\
\hline 16 & VICDECEASED & $\begin{array}{l}\text { Victim deceased } \\
\text { before, during or } \\
\text { after professional } \\
\text { medical care? }\end{array}$ & $\begin{array}{l}1=\text { Deceased before professional } \\
\text { medical care } \\
2=\text { Deceased during professional } \\
\text { medical care } \\
3=\text { Deceased after professional } \\
\text { medical care } \\
999=\text { Unknown }\end{array}$ & $\begin{array}{l}\text { Indicate whether the victim died before, } \\
\text { during or after professional medical care, } \\
\text { e.g. in an ambulance or at the hospital. }\end{array}$ \\
\hline 17 & TIMEARRESTED & $\begin{array}{l}\text { Days between } \\
\text { crime was commit- } \\
\text { ted and the prin- } \\
\text { cipal perpetrator } \\
\text { was arrested }\end{array}$ & $\begin{array}{l}\text { Open variable } \\
9997=\text { Perpetrator committed } \\
\text { suicide before arrest } \\
9998=\text { Perpetrator unknown } \\
9999=\text { Unknown }\end{array}$ & $\begin{array}{l}\text { The number of days that have gone by } \\
\text { from the time the crime was committed } \\
\text { and the principal perpetrator was arrested } \\
\text { by the police. Code according to the same } \\
\text { principal as in variable } 14 \text {. If the perpetrator } \\
\text { was arrested within the first day or within } \\
12 \text { hours after the crime, then choose value } \\
0 . \text { If the perpetrator was arrested after the } \\
\text { first day (with at least } 12 \text { hours marginal) } \\
\text { choose value } 1 \text {. Enter the value for the prin- } \\
\text { cipal perpetrator on the row of the victim. }\end{array}$ \\
\hline
\end{tabular}




\begin{tabular}{|c|c|c|c|c|}
\hline $\begin{array}{l}\text { Variable } \\
\text { number }\end{array}$ & $\begin{array}{l}\text { Variable name in } \\
\text { SPSS }\end{array}$ & $\begin{array}{l}\text { Complete } \\
\text { variable name }\end{array}$ & Label & Clarifying instructions \\
\hline 18 & CRIMESCENE & Crime scene & $\begin{array}{l}-4=\text { Private home, resident un- } \\
\text { known } \\
1=\text { Private home of victim and } \\
\text { perpetrator } \\
2=\text { Private home of perpetrator } \\
3=\text { Private home of victim } \\
4=\text { Private home of other person } \\
\text { (not victim or perpetrator) } \\
5=\text { Institution, dormitory } \\
6=\text { Hotel or motel } \\
7=\text { Inside a car or other private } \\
\text { vehicle } \\
8=\text { Park, forest or recreational area } \\
9=\text { Shop, restaurant or other place } \\
\text { of entertainment and amusement } \\
\text { (coffee shop, bar, amusement park, } \\
\text { etc.) } \\
10=\text { Street, road, public transporta- } \\
\text { tion or other public place } \\
11=\text { Workplace } \\
12=\text { Other } \\
999=\text { Unknown }\end{array}$ & $\begin{array}{l}\text { Indicate where the act of lethal violence } \\
\text { took place. This refers to where the crime } \\
\text { was committed, not to the place where the } \\
\text { body was found. } \\
\text { Private home (values }-4,1,2,3,4 \text { ) means } \\
\text { in or around the home, including the at- } \\
\text { tic, basement, staircase, garden etc. If the } \\
\text { homicide has taken place in a private home, } \\
\text { but it is unclear which of the values } 1-3 \text { you } \\
\text { should choose, then you should choose - } 4 \text {. } \\
\text { Institution, Dormitory (value } 5 \text { ) includes. } \\
\text { hospitals, prisons, dormitories and homeless } \\
\text { shelters } \\
\text { Value } 10 \text { also applies to queues, parking } \\
\text { lots, on a train or in a school. }\end{array}$ \\
\hline 19 & URBANRURAL & $\begin{array}{l}\text { Was the crime } \\
\text { committed in an } \\
\text { urban or rural } \\
\text { area? }\end{array}$ & $\begin{array}{l}1=\text { Urban } \\
2=\text { Rural } \\
999=\text { Unknown }\end{array}$ & $\begin{array}{l}\text { Indicate whether the crime was committed } \\
\text { in an urban or rural area. Each country is } \\
\text { free to use a definition that best describes } \\
\text { the division between urban and rural na- } \\
\text { tionally. }\end{array}$ \\
\hline 20 & NUTS2 & $\begin{array}{l}\text { NUTS } 2 \text { code for } \\
\text { area where crime } \\
\text { was committed }\end{array}$ & Open variable (string) & $\begin{array}{l}\text { Indicate in which NUTS } 2 \text { region (Nomen- } \\
\text { clature of Territorial Units for Statistics) the } \\
\text { crime was committed. If unknown, leave } \\
\text { blank. } \\
\text { Se appendix A for a list of NUTS } 2 \text { regions } \\
\text { in SE, FI and NL. See the following website } \\
\text { for a full list and further details: } \\
\text { http://epp.eurostat.ec.europa.eu/portal/ } \\
\text { page/portal/nuts_nomenclature/introduc- } \\
\text { tion }\end{array}$ \\
\hline 21 & NUTS3 & $\begin{array}{l}\text { NUTS } 3 \text { code for } \\
\text { area where crime } \\
\text { was committed }\end{array}$ & Open variable (string) & $\begin{array}{l}\text { Indicate in which NUTS } 3 \text { region the crime } \\
\text { was committed. If unknown, leave blank. } \\
\text { Se appendix A for a list of NUTS } 3 \text { regions } \\
\text { in SE, Fi and NL. See the following website } \\
\text { for a full list and further details: } \\
\text { http://epp.eurostat.ec.europa.eu/portal/ } \\
\text { page/portal/nuts nomenclature/introduc- } \\
\text { tion }\end{array}$ \\
\hline
\end{tabular}




\begin{tabular}{|c|c|c|c|c|}
\hline $\begin{array}{l}\text { Variable } \\
\text { number }\end{array}$ & $\begin{array}{l}\text { Variable name in } \\
\text { SPSS }\end{array}$ & $\begin{array}{l}\text { Complete } \\
\text { variable name }\end{array}$ & Label & Clarifying instructions \\
\hline 22 & POLICEREP & $\begin{array}{l}\text { By whom was the } \\
\text { crime made known } \\
\text { to the police? }\end{array}$ & $\begin{array}{l}1=\text { The victim or someone asked } \\
\text { by the victim } \\
2=\text { The perpetrator or someone } \\
\text { asked by the perpetrator } \\
3=\text { A relative or friend of the victim } \\
\text { or perpetrator } \\
4=\text { Other private person (witness, } \\
\text { bystander, neighbour, etc.) } \\
5=\text { The police themselves discov- } \\
\text { ered the crime } \\
6=\text { Other person on duty (e.g. } \\
\text { medical staff, fire brigade, superin- } \\
\text { tendent, janitor) } \\
7=\text { Other } \\
999=\text { Unknown }\end{array}$ & $\begin{array}{l}\text { Indicate who first reported or made the } \\
\text { crime known to the police or the authorities. }\end{array}$ \\
\hline 23 & WITNESS & $\begin{array}{l}\text { Were there any } \\
\text { eyewitnesses? }\end{array}$ & $\begin{array}{l}0=\text { No } \\
1=\text { Yes } \\
999=\text { Unknown }\end{array}$ & $\begin{array}{l}\text { Indicate if there were any eyewitnesses to } \\
\text { the homicide. Witness(es) are any person(s) } \\
\text { other than a suspect or perpetrator who } \\
\text { was present and observed the incident that } \\
\text { led to the homicide or lethal violence. Be- } \\
\text { ing at the crime scene or hearing the crime } \\
\text { does not qualify. }\end{array}$ \\
\hline 24 & MODUS & $\begin{array}{l}\text { Indicate the modus } \\
\text { operandi of the } \\
\text { homicide }\end{array}$ & $\begin{array}{l}1=\text { Poisoning } \\
2=\text { Exposure to corrosive or hot } \\
\text { substances } \\
3=\text { Hanging/Strangulation/Suf- } \\
\text { focation } \\
4=\text { Drowning } \\
5=\text { Firearm } \\
6=\text { Bomb/explosive } \\
7=\text { Smoke or fire } \\
8=\text { Knife or other sharp object/ } \\
\text { weapon } \\
9=\text { Blunt object/weapon } \\
10=\text { Axe } \\
11=\text { Push or shove (from/in front } \\
\text { of something) } \\
12=\text { Motor Vehicle } \\
13=\text { Hitting, kicking or other similar } \\
\text { physical violence without weapon } \\
14=\text { Other } \\
999=\text { Unknown }\end{array}$ & $\begin{array}{l}\text { The labels are loosely based on the ICD } 10 \\
\text { list of } \text { Assault under the chapter External } \\
\text { causes of morbidity and mortality (World } \\
\text { Health Organisation, International Classifi- } \\
\text { cation of Diseases, } 1990 \text { ). Changes have } \\
\text { been made to better suit the data. } \\
1=I C D 10: X 85, X 88 \\
2=I C D 10: X 86, X 87, X 89, X 90, X 98 \\
3=I C D 10: X 91 \\
4=I C D 10: X 92 \\
5=I C D 10: X 93, X 94, X 95 \\
6=I C D 10: X 96 \\
7=I C D 10: X 97 \\
8=I C D 10: X 99 \\
9=I C D 10: Y 00 \\
11=I C D 10: Y 01, Y 02 \\
12=I C D 10: Y 03 \\
13=I C D 10: Y 04, Y 07 \\
14=I C D 10: Y 08, Y 09 \\
\text { The methods are listed in the same order } \\
\text { as they are mentioned in the ICD 10. If } \\
\text { multiple methods have been used, choose } \\
\text { the method highest up on the list. For ex- } \\
\text { ample, if the victim has been stabbed (value } \\
8 \text { ) and kicked (value 13), choose value } 8 . \\
\\
\text { When multiple sources indicate that differ- } \\
\text { ent types of violence have caused death, } \\
\text { submit the type given in the autopsy first. } \\
\text { If there is no autopsy, then you should use } \\
\text { in the following order: medical statement, } \\
\text { police statement, media statement, your } \\
\text { own assessment. }\end{array}$ \\
\hline
\end{tabular}




\begin{tabular}{|c|c|c|c|c|}
\hline $\begin{array}{l}\text { Variable } \\
\text { number }\end{array}$ & $\begin{array}{l}\text { Variable name in } \\
\text { SPSS }\end{array}$ & $\begin{array}{l}\text { Complete } \\
\text { variable name }\end{array}$ & Label & Clarifying instructions \\
\hline 25 & KNIFE & $\begin{array}{l}\text { Placement of } \\
\text { knife-related vio- } \\
\text { lence on body }\end{array}$ & $\begin{array}{l}0=\text { Knife not used } \\
1=\text { Left chest } \\
2=\text { Throat } \\
3=\text { Abdomen/stomach } \\
4=\text { Back } \\
5=\text { Right chest } \\
6=\text { Other body parts } \\
7=\text { Knife was used but did not } \\
\text { enter the victim's body } \\
999=\text { Unknown } \\
9999=\text { Unknown if knife was used } \\
\text { or not }\end{array}$ & $\begin{array}{l}\text { If the violence leading to the victim's death } \\
\text { was knife-related, indicate were the stabs } \\
\text { were positioned on the body of the victim. } \\
\text { The labels are listed from most ( } 1=\text { Left } \\
\text { chest) to least severe ( } 6=\text { Other body } \\
\text { parts). Indicate the most severe violence. } \\
\text { If a knife has been used and it is unclear } \\
\text { where the stabs were positioned, use value } \\
999 .\end{array}$ \\
\hline 26 & NRSTABS & Number of stabs & $\begin{array}{l}\text { Open variable (numeric) } \\
-999=\text { Unknown } \\
-9999=\text { Unknown if there were } \\
\text { any stabs }\end{array}$ & $\begin{array}{l}\text { Indicate the number of stabs in the victim's } \\
\text { body. }\end{array}$ \\
\hline 27 & FIREARM & $\begin{array}{l}\text { License circum- } \\
\text { stances when } \\
\text { firearm used }\end{array}$ & $\begin{array}{l}0=\text { Firearm not used } \\
1=\text { Legal firearm } \\
2=\text { Illegal firearm } \\
999=\text { Unknown } \\
9999=\text { Unknown if firearm was } \\
\text { used or not }\end{array}$ & $\begin{array}{l}\text { If a firearm has been used, then you should } \\
\text { indicate its legality. } \\
\text { Legal = The perpetrator had a license for it } \\
\text { Illegal = The firearm was illegal and/or the } \\
\text { perpetrator had no license to use it }\end{array}$ \\
\hline 28 & TYPEFIREARM & $\begin{array}{l}\text { Type of firearm } \\
\text { used to cause } \\
\text { victims death }\end{array}$ & $\begin{array}{l}0=\text { Firearm not used } \\
1=\text { Pistol, revolver or other hand- } \\
\text { gun } \\
2=\text { Rifle, shotgun or other long gun } \\
3=\text { Machine gun } \\
999=\text { Unknown } \\
9999=\text { Unknown if firearm was } \\
\text { used or not }\end{array}$ & $\begin{array}{l}\text { Indicate the type of firearm that was used } \\
\text { in the homicide. If multiple type of firearms } \\
\text { where used, indicate the type from which } \\
\text { the killing bullets were fired. } \\
\text { Pistols, revolvers and other handguns (1) } \\
\text { are firearms designed to be held and op- } \\
\text { erated by one hand, with the other hand } \\
\text { optionally supporting the shooting hand. } \\
\text { Rifles, shotguns or other long guns (2) } \\
\text { are firearms designed to be fired from the } \\
\text { shoulder or held in both hands. Machine } \\
\text { guns (3) are firearms designed to fire nu- } \\
\text { merous bullets in quick succession from an } \\
\text { ammunition belt or large-capacity magazine. } \\
\text { The three categories of firearms are, in } \\
\text { order of appearance, based on the catego- } \\
\text { ries } 2-7,8-24 \text { and } 1 \text { in the Harvard (US) } \\
\text { NVDRS Coding manual (2003). }\end{array}$ \\
\hline 29 & VICVIOL & $\begin{array}{l}\text { Victim's violence } \\
\text { against perpetrator }\end{array}$ & $\begin{array}{l}0=\text { Victim did not use any violence } \\
1=\text { Victim used violence in self- } \\
\text { defence } \\
2=\text { Victim used violence first or in a } \\
\text { non-self-defence manner } \\
999=\text { Unknown }\end{array}$ & $\begin{array}{l}\text { Indicate if the victim used any violence } \\
\text { against the perpetrator when the crime was } \\
\text { committed. }\end{array}$ \\
\hline 30 & SUICIDE & $\begin{array}{l}\text { Perpetrator's } \\
\text { suicide }\end{array}$ & $\begin{array}{l}0=\text { No } \\
1=\text { Yes } \\
2=\text { Suicide attempt only } \\
99=\text { Perpetrator unknown } \\
999=\text { Unknown }\end{array}$ & $\begin{array}{l}\text { Indicate if the perpetrator tried to/did } \\
\text { commit suicide after having committed } \\
\text { the crime. Earlier attempts are not to be } \\
\text { included. } \\
\text { In cases with multiple perpetrators, enter } \\
\text { the value for each perpetrator on each row. } \\
\text { On the row of the victim you should indicate } \\
\text { the answer for the principal perpetrator. }\end{array}$ \\
\hline
\end{tabular}




\begin{tabular}{|c|c|c|c|c|}
\hline $\begin{array}{l}\text { Variable } \\
\text { number }\end{array}$ & $\begin{array}{l}\text { Variable name in } \\
\text { SPSS }\end{array}$ & $\begin{array}{l}\text { Complete } \\
\text { variable name }\end{array}$ & Label & Clarifying instructions \\
\hline 31 & SUICIDETIME & $\begin{array}{l}\text { Time of committed } \\
\text { suicide }\end{array}$ & $\begin{array}{l}0=\text { Perpetrator did not commit } \\
\text { suicide } \\
1=0-1 \text { hours after the homicide } \\
2=1-24 \text { hours after the homicide } \\
3=24 \text { hours to one week after the } \\
\text { homicide } \\
4=\text { More than one week after the } \\
\text { homicide } \\
99=\text { Perpetrator unknown } \\
999=\text { Unknown }\end{array}$ & $\begin{array}{l}\text { Indicate when the perpetrator committed } \\
\text { suicide. Suicide attempts are not to be } \\
\text { included (value 0). } \\
\text { In cases with multiple perpetrators, enter } \\
\text { the value for each perpetrator on each row. } \\
\text { On the row of the victim you should indicate } \\
\text { the answer for the principal perpetrator. }\end{array}$ \\
\hline 32 & SUICIDEMETHOD & Method of suicide & $\begin{array}{l}0=\text { The perpetrator did not commit } \\
\text { suicide } \\
1=\text { Overdose, legal substance } \\
2=\text { Overdose, illegal substance } \\
3=\text { Hanging, suffocation, stran- } \\
\text { gulation } \\
4=\text { Drowning } \\
5=\text { Firearm } \\
6=\text { Explosives } \\
7=\text { Smoke or fire } \\
8=\text { Knife/cutting } \\
9=\text { Blunt object } \\
10=\text { Jumping in front of or from } \\
\text { something } \\
11=\text { Motor vehicle } \\
12=\text { Other } \\
99=\text { Perpetrator unknown } \\
999=\text { Unknown }\end{array}$ & $\begin{array}{l}\text { Indicate the method of the suicide. } \\
\text { The labels are loosely based on the ICD } 10 \\
\text { list of Assault under the chapter External } \\
\text { causes of morbidity and mortality (World } \\
\text { Health Organisation, International Classifi- } \\
\text { cation of Diseases, 1990). Changes have } \\
\text { been made to better suit the data. } \\
1=\text { ICD 10: X60, X61, X63, X64, X65, } \\
\text { X66, X67, X68, X69 } \\
2=I C D 10: X 62, X 64, X 67, X 68, X 69 \\
3=I C D 10: X 70 \\
4=I C D 10: X 71 \\
5=I C D 10: X 72, X 73, X 74 \\
6=I C D 10: X 75 \\
7=I C D 10: X 76 \\
8=I C D 10: X 78 \\
9=I C D 10: X 79 \\
10=I C D 10: X 80, X 8 \\
11=I C D 10: X 82 \\
12=I C D 10: X 77, X 83, X 84 \\
\text { The methods are listed in the same order } \\
\text { as they are mentioned in the ICD 10. If } \\
\text { multiple methods have been used, choose } \\
\text { the method highest up on the list. } \\
\text { Suicide attempts not included (value } 0 \text { ). }\end{array}$ \\
\hline
\end{tabular}




\begin{tabular}{|c|c|c|c|c|}
\hline $\begin{array}{l}\text { Variable } \\
\text { number }\end{array}$ & $\begin{array}{l}\text { Variable name in } \\
\text { SPSS }\end{array}$ & $\begin{array}{l}\text { Complete } \\
\text { variable name }\end{array}$ & Label & Clarifying instructions \\
\hline 33 & TYPEHOM & $\begin{array}{l}\text { Type of homicide } \\
\text { (in broad terms) }\end{array}$ & $\begin{array}{l}1=\text { Partner killing } \\
2=\text { Child killing within family } \\
3=\text { Infanticide } \\
4=\text { Other familial killing } \\
5=\text { Criminal milieu (rip deals, nar- } \\
\text { cotics affairs etc.) } \\
6=\text { Robbery killing: commercial } \\
\text { business (shop, bank, taxi etc.) } \\
7=\text { Robbery killing: private home } \\
8=\text { Robbery killing: street robbery } \\
\text { (civilian victim) } \\
9=\text { Nightlife violence } \\
10=\text { Killing by mentally disturbed } \\
\text { person (Non-family) } \\
11=\text { Other in non-criminal milieu } \\
12=\text { Killing by children, not family- } \\
\text { related } \\
13=\text { Child killed by adult, not } \\
\text { family-related } \\
14=\text { Sexual } \\
15=\text { Other } \\
999=\text { Unknown }\end{array}$ & 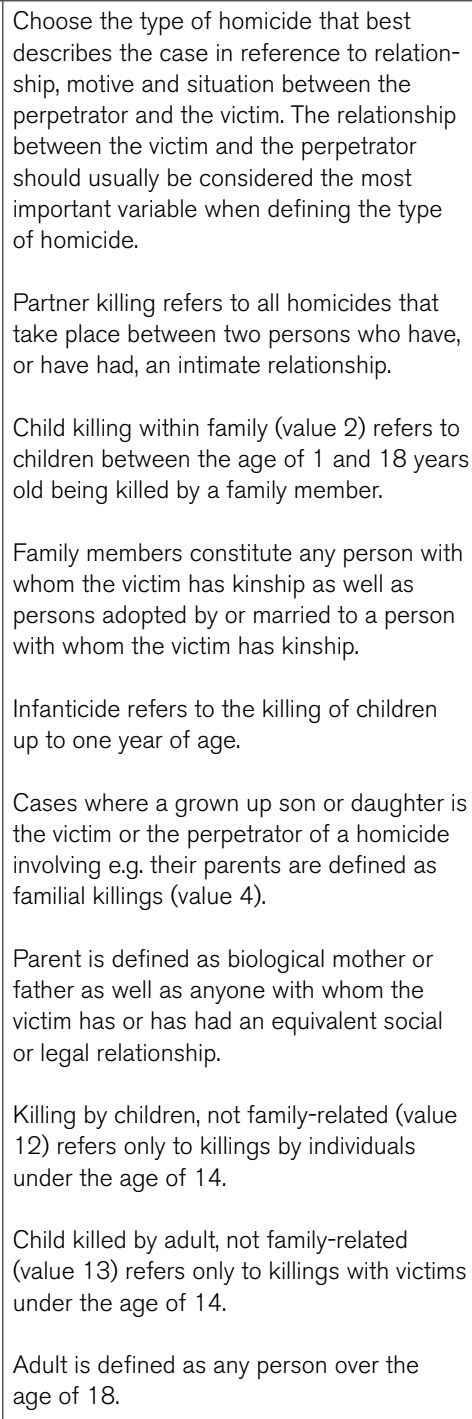 \\
\hline 34 & MREVENGE & Motive revenge & $\begin{array}{l}0=\text { No, other motive } \\
1=\text { Yes } \\
999=\text { Unknown }\end{array}$ & $\begin{array}{l}\text { Indicate whether revenge was a motive. } \\
\text { In variables, } 34-46 \text { multiple answers may } \\
\text { be given if there is more than one motive. } \\
\text { In the case of multiple perpetrators, indicate } \\
\text { the motives for each of them on their row. } \\
\text { Indicate the motive of the principal perpe- } \\
\text { trator on the row of the victim. }\end{array}$ \\
\hline 35 & MJEALOUSY & Motive jealousy & $\begin{array}{l}0=\text { No, other motive } \\
1=\text { Yes } \\
999=\text { Unknown }\end{array}$ & Indicate whether jealousy was a motive. \\
\hline 36 & MSEPARATION & Separation motive & $\begin{array}{l}0=\text { No, other motive } \\
1=\text { Yes } \\
999=\text { Unknown }\end{array}$ & Indicate whether separation was a motive. \\
\hline
\end{tabular}




\begin{tabular}{|c|c|c|c|c|}
\hline $\begin{array}{l}\text { Variable } \\
\text { number }\end{array}$ & $\begin{array}{l}\text { Variable name in } \\
\text { SPSS }\end{array}$ & $\begin{array}{l}\text { Complete } \\
\text { variable name }\end{array}$ & Label & Clarifying instructions \\
\hline 37 & MTRIVIALITY & Triviality motive & $\begin{array}{l}0=\text { No, other motive } \\
1=\text { Yes } \\
999=\text { Unknown }\end{array}$ & $\begin{array}{l}\text { Indicate whether a triviality caused the } \\
\text { homicide. }\end{array}$ \\
\hline 38 & MOTHAT & Hate crime motive & $\begin{array}{l}0=\text { No, other motive } \\
1=\text { Yes } \\
999=\text { Unknown }\end{array}$ & $\begin{array}{l}\text { Indicate whether the homicide was a hate } \\
\text { crime. }\end{array}$ \\
\hline 39 & MOTTHR & $\begin{array}{l}\text { Perpetrator threat- } \\
\text { ened motive }\end{array}$ & $\begin{array}{l}0=\text { No, other motive } \\
1=\text { Yes } \\
999=\text { Unknown }\end{array}$ & $\begin{array}{l}\text { Indicate whether a motive was the perpe- } \\
\text { trator being threatened. }\end{array}$ \\
\hline 40 & MOTMEN & $\begin{array}{l}\text { Mental illness/psy- } \\
\text { chological disorder }\end{array}$ & $\begin{array}{l}0=\text { No, other motive } \\
1=\text { Yes } \\
999=\text { Unknown }\end{array}$ & $\begin{array}{l}\text { Indicate whether mental illness or psycho- } \\
\text { logical disorder was a motive. }\end{array}$ \\
\hline 41 & MOTALT & Motive altruism & $\begin{array}{l}0=\text { No, other motive } \\
1=\text { Yes } \\
999=\text { Unknown }\end{array}$ & $\begin{array}{l}\text { Indicate whether altruism was a motive (e. } \\
\text { g. a man killing his mother who is suffer- } \\
\text { ing from a severe and very painful chronic } \\
\text { disease). }\end{array}$ \\
\hline 42 & MOTNCEC & $\begin{array}{l}\text { Was the motive } \\
\text { financial, but not in } \\
\text { itself criminal? }\end{array}$ & $\begin{array}{l}0=\text { No, other motive } \\
1=\text { Yes } \\
999=\text { Unknown }\end{array}$ & $\begin{array}{l}\text { Indicate whether the motive was financial } \\
\text { but in itself non-criminal, e.g. the homicide } \\
\text { is a result of an action to get some bor- } \\
\text { rowed object back. }\end{array}$ \\
\hline 43 & MOTCEC & $\begin{array}{l}\text { Was the motive } \\
\text { criminal for a fi- } \\
\text { nancial purpose? }\end{array}$ & $\begin{array}{l}0=\text { No, other motive } \\
1=\text { Yes } \\
999=\text { Unknown }\end{array}$ & $\begin{array}{l}\text { Indicate whether the motive was financial } \\
\text { and criminal e.g. the homicide was the } \\
\text { result of a robbery or burglary. }\end{array}$ \\
\hline 44 & MOTSEX & $\begin{array}{l}\text { Was the motive } \\
\text { rape or other } \\
\text { sexual offence? }\end{array}$ & $\begin{array}{l}0=\text { No, other motive } \\
1=\text { Yes } \\
999=\text { Unknown }\end{array}$ & $\begin{array}{l}\text { Indicate whether the motive was of sexual } \\
\text { nature. }\end{array}$ \\
\hline 45 & MOTCRIM & $\begin{array}{l}\text { Was the motive } \\
\text { of other criminal } \\
\text { nature? }\end{array}$ & $\begin{array}{l}0=\text { No, other motive } \\
1=\text { Yes } \\
999=\text { Unknown }\end{array}$ & $\begin{array}{l}\text { Indicate whether the motive was of other } \\
\text { criminal nature. }\end{array}$ \\
\hline 46 & МОТОТН & $\begin{array}{l}\text { Was the motive } \\
\text { any other than the } \\
\text { above? }\end{array}$ & $\begin{array}{l}0=\text { No } \\
1=\text { Yes } \\
999=\text { Unknown }\end{array}$ & $\begin{array}{l}\text { Indicate whether the motive was another } \\
\text { than those stated above in variables } 34-45 \text {. }\end{array}$ \\
\hline
\end{tabular}




\begin{tabular}{|c|c|c|c|c|}
\hline $\begin{array}{l}\text { Variable } \\
\text { number }\end{array}$ & $\begin{array}{l}\text { Variable name in } \\
\text { SPSS }\end{array}$ & $\begin{array}{l}\text { Complete } \\
\text { variable name }\end{array}$ & Label & Clarifying instructions \\
\hline 47 & RELAT & $\begin{array}{l}\text { Relationship be- } \\
\text { tween victim and } \\
\text { perpetrator. }\end{array}$ & $\begin{array}{l}0=\text { Perpetrator and victim do not } \\
\text { know each other } \\
1=\text { Husband } \\
2=\text { Ex-husband } \\
3=\text { Boyfriend } \\
4=\text { Ex-boyfriend } \\
5=\text { Wife } \\
6=\text { Ex-wife } \\
7=\text { Girlfriend } \\
8=\text { Ex-girlfriend } \\
9=\text { Father } \\
10=\text { Stepfather } \\
11=\text { Mother } \\
12=\text { Stepmother } \\
13=\text { Child } \\
14=\text { Stepchild } \\
15=\text { Sibling } \\
16=\text { Grandparent or great grand- } \\
\text { parent } \\
17=\text { Other relative } \\
18=\text { Housemate or flatmate (previ- } \\
\text { ous or present) } \\
19=\text { Co-worker (previous or pre- } \\
\text { sent) } \\
20=\text { Classmate (previous or pre- } \\
\text { sent) } \\
21=\text { Teacher (previous or present) } \\
22=\text { Schoolmate (previous or } \\
\text { present) } \\
23=\text { Patient (previous or present) } \\
24=\text { Therapist (previous or pre- } \\
\text { sent) } \\
25=\text { Prostitute (previous or pre- } \\
\text { sent) } \\
26=\text { Purchaser of sexual services } \\
\text { (previous or present) } \\
27=\text { Neighbour } \\
28=\text { Friend or long-time acquaint- } \\
\text { same sex; martes (marital or en- } \\
\text { ance } \\
29=\text { The perpetrator and victim are } \\
\text { slightly known to each other (not } \\
\text { friends) } \\
30=\text { New acquaintance (met in the } \\
\text { last } 24 \text { hours) }\end{array}$ & $\begin{array}{l}\text { Enter the value for the relationship that the } \\
\text { victim has to the perpetrator (i.e. the victim } \\
\text { is the (variable value) of the perpetrator). } \\
\text { In cases of "overlapping" relations e. g. } \\
\text { when the victim is a neighbour as well as a } \\
\text { friend of the perpetrator, use the value that } \\
\text { describes the principal (first and/or most } \\
\text { important) status of the relationship. If this } \\
\text { is not possible, use the value that indicates } \\
\text { the most objective circumstance in the } \\
\text { relationship. In the case of neighbour and } \\
\text { friend, this means that the code for neigh- } \\
\text { bour (value } 27 \text { ) should be used if the victim } \\
\text { and perpetrators were neighbours before } \\
\text { they were friends and/or because being } \\
\text { neighbours is factual while the extent of } \\
\text { their friendship is harder to determine. } \\
\text { If the victim is a mistress or lover of the } \\
\text { perpetrator, code girlfriend (value } 7 \text { ) or } \\
\text { boyfriend (value 3). If the victim is the child } \\
\text { of the perpetrator's unmarried partner, code } \\
\text { stepchild (value } 14 \text { ). If victim is the parent } \\
\text { of the perpetrator's partner, code other rela- } \\
\text { tive (value 17). } \\
\text { In cases of partner-relations of the same } \\
\text { sex, use the values } 1-4 \text { if it is a female- } \\
\text { female relationship, and the values } 5-8 \text { if it } \\
\text { is a male-male relationship. E.g. if a woman } \\
\text { is killed by a woman she is married to, the } \\
\text { relationship is coded as a } 1 \text {, and if a man is } \\
\text { killed by his ex-boyfriend, the relationship } \\
\text { is coded as an } 8 \text {. In same-sex-relations } \\
\text { where the martial or engagement status is } \\
\text { unknown, use value } 32 \text { or } 33 \text {. }\end{array}$ \\
\hline 48 & $\begin{array}{l}\text { PRETHREATSBY- } \\
\text { PERP }\end{array}$ & $\begin{array}{l}\text { Previous unlawful } \\
\text { threats by per- } \\
\text { petrator towards } \\
\text { victim? }\end{array}$ & $\begin{array}{l}0=\text { No } \\
1=\text { Yes, but without it being re- } \\
\text { ported to the police } \\
2=\text { Yes, and it has been reported } \\
\text { to the police } \\
999=\text { Unknown }\end{array}$ & $\begin{array}{l}\text { Indicate if the perpetrator has threatened } \\
\text { the victim in an unlawful way prior to the } \\
\text { crime. } \\
\text { If threats have occurred but it is uncertain } \\
\text { if they have been reported to the police, } \\
\text { choose value } 1 .\end{array}$ \\
\hline
\end{tabular}




\begin{tabular}{|c|c|c|c|c|}
\hline $\begin{array}{l}\text { Variable } \\
\text { number }\end{array}$ & $\begin{array}{l}\text { Variable name in } \\
\text { SPSS }\end{array}$ & $\begin{array}{l}\text { Complete } \\
\text { variable name }\end{array}$ & Label & Clarifying instructions \\
\hline 49 & $\begin{array}{l}\text { PRETHREATSBY- } \\
\text { VIC }\end{array}$ & $\begin{array}{l}\text { Previous unlawful } \\
\text { threats by victim } \\
\text { towards perpetra- } \\
\text { tor? }\end{array}$ & $\begin{array}{l}0=\text { No } \\
1=\text { Yes, but without it being re- } \\
\text { ported to the police } \\
2=\text { Yes, and it has been reported } \\
\text { to the police } \\
999=\text { Unknown }\end{array}$ & $\begin{array}{l}\text { Indicate if the victim has threatened the } \\
\text { perpetrator in an unlawful way prior to the } \\
\text { crime. } \\
\text { If threats have occurred but it is uncertain } \\
\text { if they have been reported to the police, } \\
\text { choose value } 1 .\end{array}$ \\
\hline 50 & $\begin{array}{l}\text { PREVIOLENCEBY- } \\
\text { PERP }\end{array}$ & $\begin{array}{l}\text { Previous violence } \\
\text { by perpetrator } \\
\text { towards the victim? }\end{array}$ & $\begin{array}{l}0=\text { No } \\
1=\text { Yes, but without it being re- } \\
\text { ported to the police } \\
2=\text { Yes, and it has been reported } \\
\text { to the police } \\
999=\text { Unknown }\end{array}$ & $\begin{array}{l}\text { Indicate if the perpetrator has used violence } \\
\text { against the victim prior to the crime. } \\
\text { If violence has occurred but it is uncertain } \\
\text { if it has been reported to the police, choose } \\
\text { value } 1 .\end{array}$ \\
\hline 51 & $\begin{array}{l}\text { PREVIOLENCE- } \\
\text { BYVIC }\end{array}$ & $\begin{array}{l}\text { Previous violence } \\
\text { by victim towards } \\
\text { the perpetrator }\end{array}$ & $\begin{array}{l}0=\text { No } \\
1=\text { Yes, but without it being re- } \\
\text { ported to the police } \\
2=\text { Yes, and it has been reported } \\
\text { to the police } \\
999=\text { Unknown }\end{array}$ & $\begin{array}{l}\text { Indicate if the victim has used violence } \\
\text { against the perpetrator prior to the crime. } \\
\text { If violence has occurred but it is uncertain } \\
\text { if it has been reported to the police, choose } \\
\text { value } 1 .\end{array}$ \\
\hline 52 & TYPE & $\begin{array}{l}\text { Is the individual a } \\
\text { victim or perpetra- } \\
\text { tor? }\end{array}$ & $\begin{array}{l}0=\text { Victim } \\
1=\text { Perpetrator }\end{array}$ & $\begin{array}{l}\text { Indicate whether the case row concerns a } \\
\text { victim or a perpetrator. }\end{array}$ \\
\hline 53 & PRINCIPAL & $\begin{array}{l}\text { Is the individual a } \\
\text { principal victim or a } \\
\text { principal perpetra- } \\
\text { tor in the homicide } \\
\text { case? }\end{array}$ & $\begin{array}{l}0=\text { No } \\
1=\text { Yes, principal perpetrator } \\
2=\text { Yes, principal victim } \\
999=\text { Unknown }\end{array}$ & $\begin{array}{l}\text { Indicate whether the row concerns a victim } \\
\text { or a perpetrator that can be considered to } \\
\text { be a principal individual in the case. } \\
\text { The Principal Victim = The victim with the } \\
\text { closest relationship to the perpetrator. If the } \\
\text { victim and perpetrator are equally as close, } \\
\text { or the relationship is unknown, choose the } \\
\text { victim that died first. If the relationship is } \\
\text { equal or unknown, choose the oldest victim } \\
\text { as the principal victim. If all victims are of } \\
\text { the same age or if their age is unknown, } \\
\text { choose randomly. } \\
\text { The principal perpetrator = The perpetrator } \\
\text { that has been prosecuted (see variable } 72 \text { ). } \\
\text { If more than one perpetrator is prosecuted, } \\
\text { then the principal is the one with the most } \\
\text { severe sentence (see variable } 73 \text { ). If two } \\
\text { or more of the perpetrators have equal } \\
\text { sentences, then choose the one with the } \\
\text { most severe sanction (see variable } 74 \text { ). If } \\
\text { that also is equal, then it is the one with } \\
\text { the closest relationship to the victim (see } \\
\text { variable } 47 \text { ). If that also is equal, choose } \\
\text { randomly. }\end{array}$ \\
\hline 54 & GENDER & $\begin{array}{l}\text { Gender of the } \\
\text { individual }\end{array}$ & $\begin{array}{l}1=\text { Male } \\
2=\text { Female } \\
999=\text { Unknown }\end{array}$ & State the gender of the individual. \\
\hline 55 & AGE & $\begin{array}{l}\text { Age of the indi- } \\
\text { vidual }\end{array}$ & $\begin{array}{l}\text { Open variable (numeric) } \\
150=\text { Unknown, } 15 \text { years or over } \\
151=\text { Unknown, under } 15 \text { years } \\
999=\text { Unknown }\end{array}$ & $\begin{array}{l}\text { State the age of the individual (at the time } \\
\text { of the crime). }\end{array}$ \\
\hline
\end{tabular}




\begin{tabular}{|c|c|c|c|c|}
\hline $\begin{array}{l}\text { Variable } \\
\text { number }\end{array}$ & $\begin{array}{l}\text { Variable name in } \\
\text { SPSS }\end{array}$ & $\begin{array}{l}\text { Complete } \\
\text { variable name }\end{array}$ & Label & Clarifying instructions \\
\hline 56 & BIRTHCOUNTRY & $\begin{array}{l}\text { Birth country of } \\
\text { the individual }\end{array}$ & $\begin{array}{l}0=\text { Same country the crime took } \\
\text { place in } \\
1=\text { Canada } \\
2=\text { Unites states } \\
3=\text { Puerto Rico } \\
-999=\text { Unknown } \\
-998=\text { Unknown foreign country } \\
-997=\text { Unknown Europe } \\
-996=\text { Unknown North America } \\
-995=\text { Unknown South America } \\
-994=\text { Unknown Africa } \\
-993=\text { Unknown Asia (west parts) } \\
-992=\text { Unknown Asia (east parts) } \\
-991=\text { Unknown Oceania } \\
-990=\text { Other }\end{array}$ & $\begin{array}{l}\text { Choose the birth country of the individual. } \\
\text { Use the official country code for the nation } \\
\text { (see appendix B for a full list of country } \\
\text { codes). } \\
\text { The United States and Puerto Rico have } \\
\text { the same country code as Canada (value } \\
\text { 1). Therefore, use value } 2 \text { for the United } \\
\text { States and value } 3 \text { for Puerto Rico. } \\
\text { Note the different "unknown" values at the } \\
\text { bottom of the list. } \\
\text { If individuals are born in countries that } \\
\text { no longer exist, e.g. former Yugoslavia or } \\
\text { USSR, and it is unknown in which part they } \\
\text { were born according to new values (e.g. } \\
\text { Serbia, Bosnia, Belarus, etc.), code them as } \\
\text { being born in the biggest new country by } \\
\text { population. At present ( } 2011 \text { ): Yugoslavia= } \\
\text { Serbia and USSR = Russia. }\end{array}$ \\
\hline 57 & CITIZ & $\begin{array}{l}\text { Citizenship of the } \\
\text { individual }\end{array}$ & $\begin{array}{l}0=\text { Same country the crime took } \\
\text { place in } \\
1=\text { Canada } \\
2=\text { Unites states } \\
3=\text { Puerto Rico } \\
-999=\text { Unknown } \\
-998=\text { Unknown foreign country } \\
-997=\text { Unknown Europe } \\
-996=\text { Unknown North America } \\
-995=\text { Unknown South America } \\
-994=\text { Unknown Africa } \\
-993=\text { Unknown Asia (west parts) } \\
-992=\text { Unknown Asia (east parts) } \\
-991=\text { Unknown Oceania } \\
-990=\text { Other }\end{array}$ & $\begin{array}{l}\text { Indicate the citizenship of the individual. } \\
\text { In cases of double citizenship, choose the } \\
\text { country of residence first and the country of } \\
\text { birth second. Use the official country code } \\
\text { for the nation (see appendix B for a full list } \\
\text { of country codes). } \\
\text { The United States and Puerto Rico have } \\
\text { the same country code as Canada (value } \\
\text { 1). Therefore, use value } 2 \text { for the United } \\
\text { States and value } 3 \text { for Puerto Rico. } \\
\text { Note the different "unknown" values at the } \\
\text { bottom of the list. } \\
\text { If individuals are born in countries that } \\
\text { no longer exist, e.g. former Yugoslavia or } \\
\text { USSR, and it is unknown in which part they } \\
\text { were born according to new values (e.g. } \\
\text { Serbia, Bosnia, Belarus, etc.), code them as } \\
\text { being born in the biggest new country by } \\
\text { population. At present ( } 2011 \text { ): Yugoslavia = } \\
\text { Serbia and USSR = Russia. }\end{array}$ \\
\hline
\end{tabular}




\begin{tabular}{|c|c|c|c|c|}
\hline $\begin{array}{l}\text { Variable } \\
\text { number }\end{array}$ & $\begin{array}{l}\text { Variable name in } \\
\text { SPSS }\end{array}$ & $\begin{array}{l}\text { Complete } \\
\text { variable name }\end{array}$ & Label & Clarifying instructions \\
\hline 58 & PARENTS & $\begin{array}{l}\text { Birth country of } \\
\text { the individual's } \\
\text { parents }\end{array}$ & $\begin{array}{l}0=\text { Same country the crime took } \\
\text { place in } \\
1=\text { Canada } \\
2=\text { Unites states } \\
3=\text { Puerto Rico } \\
-999=\text { Unknown } \\
-998=\text { Unknown foreign country } \\
-997=\text { Unknown Europe } \\
-996=\text { Unknown North America } \\
-995=\text { Unknown South America } \\
-994=\text { Unknown Africa } \\
-993=\text { Unknown Asia (west parts) } \\
-992=\text { Unknown Asia (east parts) } \\
-991=\text { Unknown Oceania } \\
-990=\text { Other }\end{array}$ & $\begin{array}{l}\text { Indicate the country of birth for one parent } \\
\text { if only one parent was born abroad, and } \\
\text { the country of birth for both parents if they } \\
\text { are from the same country. If the parents } \\
\text { were both born abroad, but born in different } \\
\text { countries, it is up to the submitting country } \\
\text { to choose the birth country of the father or } \\
\text { the mother of the individual. Use the official } \\
\text { country code for the nation (see appendix } \\
\text { B for a full list of country codes). } \\
\text { The United States and Puerto Rico have } \\
\text { the same country code as Canada (value } \\
\text { 1). Therefore, use value } 2 \text { for the United } \\
\text { States and value } 3 \text { for Puerto Rico. } \\
\text { Note the different "unknown" values at the } \\
\text { bottom of the list. } \\
\text { If individuals are born in countries that } \\
\text { no longer exist, e.g. former Yugoslavia or } \\
\text { USSR, and it is unknown in which part they } \\
\text { were born according to new values (e.g. } \\
\text { Serbia, Bosnia, Belarus, etc.), code them as } \\
\text { being born in the biggest new country by } \\
\text { population. At present ( } 2011 \text { ): Yugoslavia = } \\
\text { Serbia and USSR = Russia. }\end{array}$ \\
\hline 59 & CIVIL & Civil status & $\begin{array}{l}1=\text { Married } \\
2=\text { Cohabitants } \\
3=\text { In a boyfriend/girlfriend rela- } \\
\text { tionship } \\
4=\text { Single } \\
5=\text { Divorced } \\
6=\text { Widowed } \\
999=\text { Unknown } \\
\end{array}$ & State the civil status of the individual. \\
\hline 60 & CHILD & $\begin{array}{l}\text { Does the individual } \\
\text { have children? }\end{array}$ & $\begin{array}{l}0=\text { No } \\
1=\text { Yes } \\
999=\text { Unknown }\end{array}$ & $\begin{array}{l}\text { Indicate whether the individual has children } \\
\text { or not. Having children means that the indi- } \\
\text { vidual is a parent according to the national } \\
\text { legal definition in the country where the } \\
\text { homicide was committed. }\end{array}$ \\
\hline 61 & HOUSESIT & $\begin{array}{l}\text { Housing situation } \\
\text { of the individual }\end{array}$ & $\begin{array}{l}0=\text { Cohabiting with partner } \\
1=\text { Cohabiting with both parents or } \\
\text { stepparents } \\
2=\text { Cohabiting with one parent or } \\
\text { stepparent } \\
3=\text { Living alone (with or without } \\
\text { children) } \\
4=\text { Cohabiting with friend } \\
5=\text { Temporarily living with someone } \\
6=\text { Homeless } \\
7=\text { Closed institution } \\
8=\text { Other } \\
999=\text { Unknown }\end{array}$ & $\begin{array}{l}\text { Indicate the housing situation of the indi- } \\
\text { vidual. } \\
\text { 'Cohabiting with friend' also means cohabit- } \\
\text { ing with relatives other than parents, step- } \\
\text { parents or children (e.g. siblings, cousins } \\
\text { etc.) } \\
\text { Partners who live together on and off are } \\
\text { regarded as cohabiting with partner (value } \\
\text { 0). } \\
\text { Closed institution (value } 7 \text { ) applies to pris- } \\
\text { ons, psychiatric wards etc. }\end{array}$ \\
\hline
\end{tabular}




\begin{tabular}{|c|c|c|c|c|}
\hline $\begin{array}{l}\text { Variable } \\
\text { number }\end{array}$ & $\begin{array}{l}\text { Variable name in } \\
\text { SPSS }\end{array}$ & $\begin{array}{l}\text { Complete } \\
\text { variable name }\end{array}$ & Label & Clarifying instructions \\
\hline 62 & PROF & $\begin{array}{l}\text { Professional status } \\
\text { of the individual }\end{array}$ & $\begin{array}{l}0=\text { Working class } \\
1=\text { Intermediate } \\
2=\text { Managers and professionals } \\
3=\text { Retired } \\
4=\text { Unemployed } \\
5=\text { Sick-listed or disabled } \\
6=\text { Not yet of school age } \\
7=\text { Student } \\
8=\text { Military service } \\
9=\text { Housewife/-husband/stay-at- } \\
\text { home parent } \\
10=\text { Asylum seeker } \\
11=\text { Imprisoned or in a similar } \\
\text { institution } \\
12=\text { Other } \\
999=\text { Unknown }\end{array}$ & $\begin{array}{l}\text { Labels } 1-3 \text { are based on the European } \\
\text { Socio-economic Classification. Se the fol- } \\
\text { lowing webpage for more details of which } \\
\text { professions are included in the three } \\
\text { categories: http://www.iser.essex.ac.uk/re- } \\
\text { search/esec/user-guide/detailed-category- } \\
\text { descriptions-and-operational-issues. }\end{array}$ \\
\hline 63 & EDUC & $\begin{array}{l}\text { Level of completed } \\
\text { education of the } \\
\text { individual }\end{array}$ & $\begin{array}{l}0=\text { Not completed compulsory } \\
\text { school } \\
1=\text { Compulsory school } \\
2=\text { Higher education } \\
3=\text { Occupational education } \\
4=\text { Not started school } \\
5=\text { Enrolled in compulsory school } \\
6=\text { Enrolled in higher education } \\
7=\text { Enrolled in occupational edu- } \\
\text { cation } \\
999=\text { Unknown }\end{array}$ & $\begin{array}{l}\text { Indicate the highest completed level of } \\
\text { education of the individual. } \\
\text { Compulsory school (value 2) is defined ac- } \\
\text { cording to the national legal definition in the } \\
\text { country where the homicide was committed. }\end{array}$ \\
\hline 64 & DRINK & $\begin{array}{l}\text { Had the individual } \\
\text { been drinking } \\
\text { alcohol at the time } \\
\text { of the crime? }\end{array}$ & $\begin{array}{l}0=\text { No, nothing in the case indi- } \\
\text { cates this } \\
1=\text { Yes, some indications exist } \\
2=\text { Yes, there are sure indications } \\
999=\text { Unknown }\end{array}$ & $\begin{array}{l}\text { Indicate if the individual had been drinking } \\
\text { alcohol at the time of the crime. } \\
\text { Some indications mean that there are cir- } \\
\text { cumstances in the case that indicate that } \\
\text { the individual had been drinking alcohol at } \\
\text { the time of the crime, e.g. empty bottles or } \\
\text { cans or other paraphernalia, the presence } \\
\text { of other persons who have been drinking } \\
\text { alcohol or a recent history of alcoholism. } \\
\text { Sure indications mean that there is explicit } \\
\text { information about the individual having } \\
\text { been drinking alcohol at the time of the } \\
\text { crime. }\end{array}$ \\
\hline
\end{tabular}




\begin{tabular}{|c|c|c|c|c|}
\hline $\begin{array}{l}\text { Variable } \\
\text { number }\end{array}$ & $\begin{array}{l}\text { Variable name in } \\
\text { SPSS }\end{array}$ & $\begin{array}{l}\text { Complete } \\
\text { variable name }\end{array}$ & Label & Clarifying instructions \\
\hline 65 & DRUG & $\begin{array}{l}\text { Had the individual } \\
\text { taken drugs at the } \\
\text { time of the crime? }\end{array}$ & $\begin{array}{l}0=\text { No, nothing in the case indi- } \\
\text { cates this } \\
1=\text { Yes, some indications exist } \\
2=\text { Yes, there are sure indications } \\
999=\text { Unknown }\end{array}$ & $\begin{array}{l}\text { Indicate if the individual had taken any } \\
\text { drugs at the time of the crime. } \\
\text { Some indications mean that there are cir- } \\
\text { cumstances in the case that indicate that } \\
\text { the individual had taken drugs at the time } \\
\text { of the crime, e.g. drug paraphernalia, the } \\
\text { presence of other persons who have been } \\
\text { taking drugs or a recent history of drug } \\
\text { abuse. } \\
\text { Sure indications mean that there is explicit } \\
\text { information about the individual having } \\
\text { been taking drugs at the time of the crime. } \\
\text { Drugs refer to the use of "narcotics" (heroin, } \\
\text { morphine etc.) as well as stimulants (co- } \\
\text { caine, amphetamine etc.) and hallucinogens } \\
\text { (ecstasy, hashish etc.). Excessive use (i.e. } \\
\text { more than prescribed) of legally prescribed } \\
\text { drugs is also included in the definition. }\end{array}$ \\
\hline 66 & ALCOHOLIC & $\begin{array}{l}\text { Is the individual an } \\
\text { alcoholic? }\end{array}$ & $\begin{array}{l}0=\text { No, nothing in the case indi- } \\
\text { cates this } \\
1=\text { Yes, some indications exist } \\
2=\text { Yes, there are sure indications } \\
999=\text { Unknown }\end{array}$ & $\begin{array}{l}\text { Indicate whether the individual is known to } \\
\text { be an alcoholic. } \\
\text { Some indications mean that there are cir- } \\
\text { cumstances in the case that indicate that } \\
\text { the individual has excessive drinking pat- } \\
\text { terns, such as consuming large amounts of } \\
\text { alcohol over a period of several days. } \\
\text { Sure indications mean that the individual } \\
\text { has been diagnosed and/or treated clini- } \\
\text { cally. }\end{array}$ \\
\hline 67 & DRUGADD & $\begin{array}{l}\text { Is the individual a } \\
\text { drug addict? }\end{array}$ & $\begin{array}{l}0=\text { No, nothing in the case indi- } \\
\text { cates this } \\
1=\text { Yes, some indications exist } \\
2=\text { Yes, there are sure indications } \\
999=\text { Unknown }\end{array}$ & $\begin{array}{l}\text { Indicate whether the individual is known to } \\
\text { be a drug addict. } \\
\text { Some indications mean that there are } \\
\text { circumstances in the case that indicate } \\
\text { that the individual has excessive drug use } \\
\text { patterns at the time of the crime, such as } \\
\text { consuming "hard" or large amounts of drugs } \\
\text { over a period of several days. } \\
\text { Sure indications mean that the individual } \\
\text { has been diagnosed and/or treated clini- } \\
\text { cally. } \\
\text { Drug dependence refers to the use of } \\
\text { "narcotics" (heroin, morphine etc.) as well } \\
\text { as stimulants (cocaine, amphetamine etc.) } \\
\text { and hallucinogens (ecstasy, hashish etc.) } \\
\text { Excessive use (i.e. more than prescribed) of } \\
\text { legally prescribed drugs is also included in } \\
\text { the definition. }\end{array}$ \\
\hline
\end{tabular}




\begin{tabular}{|c|c|c|c|c|}
\hline $\begin{array}{l}\text { Variable } \\
\text { number }\end{array}$ & $\begin{array}{l}\text { Variable name in } \\
\text { SPSS }\end{array}$ & $\begin{array}{l}\text { Complete } \\
\text { variable name }\end{array}$ & Label & Clarifying instructions \\
\hline 68 & $\mathrm{PSYCH}$ & $\begin{array}{l}\text { Does the individual } \\
\text { have a history of } \\
\text { mental illness } \\
\text { or suffer from } \\
\text { a psychological } \\
\text { disorder? }\end{array}$ & $\begin{array}{l}0=\text { No, nothing in the case indi- } \\
\text { cates this } \\
1=\text { Yes, some indications exist } \\
2=\text { Yes, there are sure indications } \\
999=\text { Unknown }\end{array}$ & $\begin{array}{l}\text { Indicate whether the individual has a history } \\
\text { of mental illness or is suffering from a psy- } \\
\text { chological disorder. } \\
\text { Some indications mean that there is in- } \\
\text { formation about or circumstances in the } \\
\text { case that indicate that the individual has } \\
\text { a history of mental illness, e.g. distressed } \\
\text { psychological or behavioural patterns or } \\
\text { self-expressed concern over mental health. } \\
\text { Sure indications mean that the person has } \\
\text { been diagnosed and/or treated clinically. }\end{array}$ \\
\hline 69 & VIOLENTHISTORY & $\begin{array}{l}\text { Does the individual } \\
\text { have a history of } \\
\text { violence? }\end{array}$ & $\begin{array}{l}0=\text { No } \\
1=\text { Yes } \\
999=\text { Unknown }\end{array}$ & $\begin{array}{l}\text { Indicate if the individual has a history of } \\
\text { violence. History of violence is defined } \\
\text { as having been reported to the police for } \\
\text { violent crimes previous to the homicide } \\
\text { occasion. }\end{array}$ \\
\hline 70 & OTHCRIM & $\begin{array}{l}\text { Were any other } \\
\text { crimes committed } \\
\text { against the individ- } \\
\text { ual in the homicide } \\
\text { event? }\end{array}$ & $\begin{array}{l}0=\text { No, no other crimes were com- } \\
\text { mitted against the individual in the } \\
\text { homicide event } \\
1=\text { Sexual assault against the } \\
\text { individual } \\
2=\text { Other crime against the indi- } \\
\text { vidual } \\
3=\text { The individual was the witness } \\
\text { of a crime } \\
999=\text { Unknown }\end{array}$ & $\begin{array}{l}\text { Indicate whether there were any other } \\
\text { crimes committed against the individual in } \\
\text { the situation of the homicide. The data in } \\
\text { this variable refers to the specific individual } \\
\text { on each row, not the case overall. So, if } \\
\text { the perpetrator was robbed by the victim, } \\
\text { for example, then code no (value 0) on the } \\
\text { row of the victim and other crime against } \\
\text { the individual (value 2) on the row for the } \\
\text { perpetrator. } \\
\text { If more than one value is applicable for one } \\
\text { individual, choose the value highest up on } \\
\text { the list, e.g. sexual assault (value 1) before } \\
\text { other crimes (value2). }\end{array}$ \\
\hline 71 & AREA & $\begin{array}{l}\text { The individual's re- } \\
\text { lation to the region } \\
\text { or area where the } \\
\text { crime was com- } \\
\text { mitted }\end{array}$ & $\begin{array}{l}0=\text { Living in another region/area/ } \\
\text { city } \\
1=\text { Living in the same region/ } \\
\text { area/city } \\
999=\text { Unknown }\end{array}$ & $\begin{array}{l}\text { Indicate whether the individual lives in the } \\
\text { same or in a different region/area/city than } \\
\text { the one where the homicide took place. It is } \\
\text { up to each submitting country to choose a } \\
\text { suitable geographical unit to best describe } \\
\text { the individuals relation to the place where } \\
\text { the homicide was committed. }\end{array}$ \\
\hline 72 & PROSECUTED & $\begin{array}{l}\text { Has the suspect } \\
\text { been prosecuted } \\
\text { of homicide? }\end{array}$ & $\begin{array}{l}0=\text { No, there is no suspect } \\
1=\text { No, the suspect has not yet } \\
\text { been arrested } \\
2=\text { No, the suspect is too young to } \\
\text { be prosecuted } \\
3=\text { No, the suspect is deceased } \\
4=\text { No, other reason } \\
5=\text { Yes } \\
6=\text { Yes, but only of other crime/-s } \\
999=\text { Unknown }\end{array}$ & $\begin{array}{l}\text { Indicate whether the suspect has been } \\
\text { prosecuted or charged with the homicide. } \\
\text { In case of appeal, enter the details from the } \\
\text { court of first instance. }\end{array}$ \\
\hline
\end{tabular}




\begin{tabular}{|c|c|c|c|c|}
\hline $\begin{array}{l}\text { Variable } \\
\text { number }\end{array}$ & $\begin{array}{l}\text { Variable name in } \\
\text { SPSS }\end{array}$ & $\begin{array}{l}\text { Complete } \\
\text { variable name }\end{array}$ & Label & Clarifying instructions \\
\hline 73 & SENTENCED & $\begin{array}{l}\text { Has the perpetra- } \\
\text { tor been sen- } \\
\text { tenced? }\end{array}$ & $\begin{array}{l}0=\text { No, perpetrator found not guilty } \\
1=\text { No, the perpetrator was not } \\
\text { held accountable for his/her ac- } \\
\text { tions due to mental illness } \\
2=\text { No, perpetrator deceased } \\
3=\text { No, not sentenced for other } \\
\text { reasons } \\
4=\text { Yes, of homicide } \\
5=\text { Yes, of other crime/-s } \\
99=\text { Perpetrator unknown } \\
999=\text { Unknown }\end{array}$ & $\begin{array}{l}\text { Indicate whether the perpetrator has been } \\
\text { sanctioned. } \\
\text { For variables } 72-74 \text {, in case of appeal, enter } \\
\text { the details from the court of first instance. } \\
\text { The label 'perpetrator convicted of other } \\
\text { crime' refers to other crimes committed at } \\
\text { the same time as the homicide, not crimes } \\
\text { committed at another time but for which the } \\
\text { perpetrator is sentenced at the same trial. } \\
\text { If the perpetrator has not yet been sen- } \\
\text { tenced but is going to be, choose value } 3 \text {. } \\
\text { In case of a combination of homicide (value } \\
4 \text { ) and other crime/-s (value 5) choose } \\
\text { value } 4 .\end{array}$ \\
\hline 74 & SANCTIONED & $\begin{array}{l}\text { What was the } \\
\text { perpetrator sanc- } \\
\text { tioned to? }\end{array}$ & $\begin{array}{l}0=\text { Perpetrator not sanctioned } \\
1=\text { Prison } \\
2=\text { Acute Psychiatric care } \\
3=\text { Long term psychiatric care } \\
4=\text { Prison and psychiatric care } \\
\text { (acute or long term) } \\
5=\text { Youth prison } \\
6=\text { Youth prison and psychiatric } \\
\text { care } \\
7=\text { Youth institutional treatment } \\
8=\text { Youth prison and youth institu- } \\
\text { tional treatment } \\
9=\text { Other } \\
999=\text { Unknown }\end{array}$ & $\begin{array}{l}\text { Indicate what sanction the perpetrator has } \\
\text { been given. } \\
\text { The term sanctioned is used to avoid ex- } \\
\text { clusion of sanctions that do not follow a } \\
\text { sentence. } \\
\text { Long term psychiatric care (value } 3 \text { ) refers } \\
\text { to a sanction of acute psychiatric care + } \\
\text { long term psychiatric care. } \\
\text { Enter not sanctioned (value 0) for all known } \\
\text { perpetrators who have not been sanctioned } \\
\text { whatever the reason (perpetrator dead, } \\
\text { found not guilty etc.) }\end{array}$ \\
\hline 75 & $\begin{array}{l}\text { LENGTHSEN- } \\
\text { TENCE }\end{array}$ & $\begin{array}{l}\text { Length of sen- } \\
\text { tence }\end{array}$ & $\begin{array}{l}\text { Open variable (numeric) } \\
-9998=\text { Lifetime } \\
-9999=\text { Unknown }\end{array}$ & $\begin{array}{l}\text { Indicate the length of the sentence in } \\
\text { number of days ( } 30 \text { days in one month, } \\
365 \text { days in one year). Sentence reduction } \\
\text { is not included. Code } 9999 \text { if perpetrator is } \\
\text { sentenced to a time-restricted sanction but } \\
\text { it is unknown for how long. } \\
\text { If the perpetrator has not been sentenced, } \\
\text { leave blank. Leave blank if the perpetrator } \\
\text { has only been sanctioned for other crimes. }\end{array}$ \\
\hline 76 & PREHOM & $\begin{array}{l}\text { Has the perpetra- } \\
\text { tor previously been } \\
\text { sentenced for } \\
\text { homicide? }\end{array}$ & $\begin{array}{l}0=\text { No } \\
1=\text { Yes } \\
999=\text { Unknown }\end{array}$ & $\begin{array}{l}\text { Indicate whether the perpetrator has been } \\
\text { found guilty of homicide prior to this homi- } \\
\text { cide event. }\end{array}$ \\
\hline 77 & PREVIO & $\begin{array}{l}\text { Has the perpetra- } \\
\text { tor previously } \\
\text { been sentenced } \\
\text { for other violent } \\
\text { crimes? }\end{array}$ & $\begin{array}{l}0=\text { No } \\
1=\text { Yes } \\
999=\text { Unknown }\end{array}$ & $\begin{array}{l}\text { Indicate whether the perpetrator has been } \\
\text { found guilty of other violent crime prior to } \\
\text { the crime. Violent crime refers to all assault } \\
\text { crimes excluding those already covered by } \\
\text { variables } 75,77 \text { and } 78 \text {. }\end{array}$ \\
\hline 78 & PRESEX & $\begin{array}{l}\text { Has the perpetra- } \\
\text { tor previously been } \\
\text { sentenced for } \\
\text { sexual crimes? }\end{array}$ & $\begin{array}{l}0=\text { No } \\
1=\text { Yes } \\
999=\text { Unknown }\end{array}$ & $\begin{array}{l}\text { Indicate whether the perpetrator been } \\
\text { found guilty of sex crimes prior to the } \\
\text { homicide. }\end{array}$ \\
\hline
\end{tabular}




\begin{tabular}{|c|c|c|c|c|}
\hline $\begin{array}{l}\text { Variable } \\
\text { number }\end{array}$ & $\begin{array}{l}\text { Variable name in } \\
\text { SPSS }\end{array}$ & $\begin{array}{l}\text { Complete } \\
\text { variable name }\end{array}$ & Label & Clarifying instructions \\
\hline 79 & PREROB & $\begin{array}{l}\text { Has the perpetra- } \\
\text { tor previously been } \\
\text { sentenced for } \\
\text { robbery? }\end{array}$ & $\begin{array}{l}0=\text { No } \\
1=\text { Yes } \\
999=\text { Unknown }\end{array}$ & $\begin{array}{l}\text { Indicate whether the perpetrator has been } \\
\text { found guilty of robbery prior to the homi- } \\
\text { cide. }\end{array}$ \\
\hline 80 & PREPROP & $\begin{array}{l}\text { Has the perpetra- } \\
\text { tor previously } \\
\text { been sentenced } \\
\text { for crimes against } \\
\text { property? }\end{array}$ & $\begin{array}{l}0=\text { No } \\
1=\text { Yes } \\
999=\text { Unknown }\end{array}$ & $\begin{array}{l}\text { Indicate whether the perpetrator has been } \\
\text { found guilty of property crime prior to the } \\
\text { homicide. }\end{array}$ \\
\hline 81 & PREDRUG & $\begin{array}{l}\text { Has the perpetra- } \\
\text { tor previously been } \\
\text { sentenced for drug } \\
\text { crimes? }\end{array}$ & $\begin{array}{l}0=\text { No } \\
1=\text { Yes } \\
999=\text { Unknown }\end{array}$ & $\begin{array}{l}\text { Indicate whether the perpetrator has been } \\
\text { found guilty of drug crime prior to the } \\
\text { homicide. }\end{array}$ \\
\hline 82 & PRETRAF & $\begin{array}{l}\text { Has the perpetra- } \\
\text { tor previously been } \\
\text { sentenced for } \\
\text { traffic violations? }\end{array}$ & $\begin{array}{l}0=\text { No } \\
1=\text { Yes } \\
999=\text { Unknown }\end{array}$ & $\begin{array}{l}\text { Indicate whether the perpetrator has been } \\
\text { found guilty of traffic violations prior to the } \\
\text { homicide. }\end{array}$ \\
\hline 83 & PREOTH & $\begin{array}{l}\text { Has the perpetra- } \\
\text { tor previously } \\
\text { been sentenced } \\
\text { for other crimes } \\
\text { than those stated } \\
\text { above? }\end{array}$ & $\begin{array}{l}0=\text { No } \\
1=\text { Yes } \\
999=\text { Unknown }\end{array}$ & $\begin{array}{l}\text { Indicate whether the perpetrator been } \\
\text { found guilty of other crime prior to the } \\
\text { homicide than those stated above in vari- } \\
\text { ables } 74-81 .\end{array}$ \\
\hline 84 & PRECON & $\begin{array}{l}\text { Number of previ- } \\
\text { ous convictions }\end{array}$ & $\begin{array}{l}\text { Open variable (numeric) } \\
999=\text { Unknown }\end{array}$ & $\begin{array}{l}\text { Indicate the perpetrator's number of previ- } \\
\text { ous convictions (not the number of crimes). } \\
\text { All convictions count (independent of which } \\
\text { sanction is given). In case of appeal, enter } \\
\text { the details from the court of first instance. }\end{array}$ \\
\hline 85 & CORR & $\begin{array}{l}\text { Corresponding } \\
\text { cases }\end{array}$ & $\begin{array}{l}\text { Open variable (numeric) } \\
99=\text { No corresponding cases } \\
999=\text { Unknown }\end{array}$ & $\begin{array}{l}\text { If a perpetrator or victim in the case is } \\
\text { connected to any other case (for example } \\
\text { when the perpetrator of one homicide is } \\
\text { the victim of another or when one person } \\
\text { commits multiple homicides at different } \\
\text { times) this is indicated by entering the } \\
\text { corresponding serial number. When there } \\
\text { are no indications of corresponding cases, } \\
\text { choose value } 99 . \\
\text { Victims and perpetrators in the same case, } \\
\text { as well as cases with multiple victims or } \\
\text { perpetrators are not indicated here. Instead, } \\
\text { they are connected through the case } \\
\text { number variable (variable number } 2 \text { ). }\end{array}$ \\
\hline
\end{tabular}




\section{Guidebook and coding manual - Appendix A}

\begin{tabular}{|c|c|c|}
\hline Sweden & & \\
\hline NUTS region & Name & Code \\
\hline 2 & Stockholm & SE01 \\
\hline 2 & East middle Sweden & SE02 \\
\hline 2 & South Sweden & SE03 \\
\hline 2 & North middle Sweden & SE04 \\
\hline 2 & Middle Norrland & SE05 \\
\hline 2 & Upper Norrland & SE06 \\
\hline 2 & Småland and the islands & SE07 \\
\hline 2 & West Sweden & SE08 \\
\hline 3 & Stockholm & SE010 \\
\hline 3 & Uppsala & SE021 \\
\hline 3 & Södermanland & SE022 \\
\hline 3 & Östergötland & SE023 \\
\hline 3 & Örebro & SE024 \\
\hline 3 & Västmanland & SE025 \\
\hline 3 & Blekinge & SE041 \\
\hline 3 & Skåne & SE044 \\
\hline 3 & Värmland & SE061 \\
\hline 3 & Dalarna & SE062 \\
\hline 3 & Gävleborg & SE063 \\
\hline 3 & Västernorrland & SE071 \\
\hline 3 & Jämtland & SE072 \\
\hline 3 & Västerbotten & SE081 \\
\hline 3 & Norrbotten & SE082 \\
\hline 3 & Jönköping & SE091 \\
\hline 3 & Kronoberg & SE092 \\
\hline 3 & Kalmar & SE093 \\
\hline 3 & Gotland & SE094 \\
\hline 3 & Halland & SEOA 1 \\
\hline 3 & Västra Götaland & SEOA2 \\
\hline
\end{tabular}

\begin{tabular}{|l|l|l|}
\hline Finland & & \\
\hline NUTS region & Name & Code \\
\hline 2 & East Finland & Fl13 \\
\hline 2 & South Finland & Fl18 \\
\hline 2 & West Finland & Fl19 \\
\hline 2 & North Finland & Fl1A \\
\hline
\end{tabular}




\begin{tabular}{|c|c|c|}
\hline 2 & Åland & $\mathrm{F} / 20$ \\
\hline 3 & Etelä-Savo & $\mathrm{Fl} 131$ \\
\hline 3 & Pohjois-Savo & $\mathrm{Fl} 132$ \\
\hline 3 & Pohjois-Karjala & Fl133 \\
\hline 3 & Kainuu & Fl134 \\
\hline 3 & Uusimaa & Fl181 \\
\hline 3 & Itä-Uusimaa & Fl182 \\
\hline 3 & Varsinais-Suomi & $\mathrm{F} 1183$ \\
\hline 3 & Kanta-Häme & Fl184 \\
\hline 3 & Päijät-Häme & Fl185 \\
\hline 3 & Kymenlaakso & Fl186 \\
\hline 3 & Etelä-Karjala & $\mathrm{F} 1187$ \\
\hline 3 & Keski-Suomi & Fl193 \\
\hline 3 & Etelä-Pohjanmaa & Fl194 \\
\hline 3 & Pohjanmaa & Fl195 \\
\hline 3 & Satakunta & Fl196 \\
\hline 3 & Pirkanmaa & Fl197 \\
\hline 3 & Keski-Pohjanmaa & Fl1A1 \\
\hline 3 & Pohjois-Pohjanmaa & FI1A2 \\
\hline 3 & Lappi & FI1A3 \\
\hline 3 & Åland & FI200 \\
\hline
\end{tabular}

\begin{tabular}{|l|l|l|}
\hline The Netherlands & & \\
\hline NUTS region & Name & Code \\
\hline 2 & Groningen & NL11 \\
\hline 2 & Friesland & NL12 \\
\hline 2 & Drenthe & NL13 \\
\hline 2 & Overijssel & NL21 \\
\hline 2 & Gelderland & NL22 \\
\hline 2 & Flevoland & NL23 \\
\hline 2 & Utrecht & NL31 \\
\hline 2 & North Holland & NL32 \\
\hline 2 & South Holland & NL33 \\
\hline 2 & Zeeland & NL34 \\
\hline 2 & North Brabant & NL41 \\
\hline 2 & Limburg & NL42 \\
\hline & & \\
\hline 3 & East Groningen & NL111 \\
\hline 3 & Delfzijl en omgeving & NL112 \\
\hline 3 & Overig Groningen & NL113 \\
\hline
\end{tabular}




\begin{tabular}{|c|c|c|}
\hline 3 & North Friesland & NL121 \\
\hline 3 & South West Friesland & NL122 \\
\hline 3 & South East Friesland & NL123 \\
\hline 3 & North Drenthe & NL131 \\
\hline 3 & South East Drenthe & NL132 \\
\hline 3 & South West Drenthe & NL133 \\
\hline 3 & North Overijssel & NL211 \\
\hline 3 & South West Overijssel & NL212 \\
\hline 3 & Twente & NL213 \\
\hline 3 & Veluwe & NL221 \\
\hline 3 & South West Gelderland & NL224 \\
\hline 3 & Achterhoek & NL225 \\
\hline 3 & Arnhem \& Nijmegen & NL226 \\
\hline 3 & Flevoland & NL230 \\
\hline 3 & Utrecht & NL310 \\
\hline 3 & Kop van North Holland & NL321 \\
\hline 3 & Alkmaar en omgeving & NL322 \\
\hline 3 & IJmond & NL323 \\
\hline 3 & Agglomeratie Haarlem & NL324 \\
\hline 3 & Zaanstreek & NL325 \\
\hline 3 & Greater Amsterdam & NL326 \\
\hline 3 & Het Gooi and Vechtstreek & NL327 \\
\hline 3 & Leiden and Bollenstreek & NL331 \\
\hline 3 & The Hague & NL332 \\
\hline 3 & Delft and Westland & NL333 \\
\hline 3 & East South Holland & NL334 \\
\hline 3 & Rijnmond & NL335 \\
\hline 3 & South South Holland & NL336 \\
\hline 3 & Zeeuws-Vlaanderen & NL341 \\
\hline 3 & Overig Zeeland & NL342 \\
\hline 3 & West North Brabant & NL411 \\
\hline 3 & Mid North Brabant & NL412 \\
\hline 3 & North-East North Brabant & NL413 \\
\hline 3 & South-East Morth Brabant & NL414 \\
\hline 3 & North Limburg & NL421 \\
\hline 3 & Mid Limburg & NL422 \\
\hline 3 & South Limburg & NL423 \\
\hline
\end{tabular}




\section{Guidebook and coding manual - Appendix B}

\begin{tabular}{|c|c|}
\hline Afghanistan & 93 \\
\hline Albania & 355 \\
\hline Algeria & 213 \\
\hline American Samoa & 1684 \\
\hline Andorra & 376 \\
\hline Angola & 244 \\
\hline Anguilla & 1264 \\
\hline Antarctica & 672 \\
\hline Antigua and Barbuda & 1268 \\
\hline Argentina & 54 \\
\hline Armenia & 374 \\
\hline Aruba & 297 \\
\hline Australia & 61 \\
\hline Austria & 43 \\
\hline Azerbaijan & 994 \\
\hline Bahamas & 1242 \\
\hline Bahrain & 973 \\
\hline Bangladesh & 880 \\
\hline Barbados & 1246 \\
\hline Belarus & 375 \\
\hline Belgium & 32 \\
\hline Belize & 501 \\
\hline Benin & 229 \\
\hline Bermuda & 1441 \\
\hline Bhutan & 975 \\
\hline Bolivia & 591 \\
\hline Bosnia and Herzegovina & 387 \\
\hline Botswana & 267 \\
\hline Brazil & 55 \\
\hline British Indian Ocean Territory & 44 \\
\hline British Virgin Islands & 1284 \\
\hline Brunei & 673 \\
\hline Bulgaria & 359 \\
\hline Burkina Faso & 226 \\
\hline Burma (Myanmar) & 95 \\
\hline Burundi & 257 \\
\hline Cambodia & 855 \\
\hline Cameroon & 237 \\
\hline
\end{tabular}

\begin{tabular}{|c|c|}
\hline Canada * & 1 \\
\hline Cape Verde & 238 \\
\hline Cayman Islands & 1345 \\
\hline Central African Republic & 236 \\
\hline Chad & 235 \\
\hline Chile & 56 \\
\hline China & 86 \\
\hline Christmas Island & 61 \\
\hline Cocos (Keeling) Islands & 61 \\
\hline Colombia & 57 \\
\hline Comoros & 269 \\
\hline Cook Islands & 682 \\
\hline Costa Rica & 506 \\
\hline Croatia & 385 \\
\hline Cuba & 53 \\
\hline Cyprus & 357 \\
\hline Czech Republic & 420 \\
\hline Democratic Republic of the Congo & 243 \\
\hline Denmark & 45 \\
\hline Djibouti & 253 \\
\hline Dominica & 1767 \\
\hline Dominican Republic & 1809 \\
\hline Ecuador & 593 \\
\hline Egypt & 20 \\
\hline El Salvador & 503 \\
\hline Equatorial Guinea & 240 \\
\hline Eritrea & 291 \\
\hline Estonia & 372 \\
\hline Ethiopia & 251 \\
\hline Falkland Islands & 500 \\
\hline Faroe Islands & 298 \\
\hline Fiji & 679 \\
\hline Finland & 358 \\
\hline France & 33 \\
\hline French Polynesia & 689 \\
\hline Gabon & 241 \\
\hline Gambia & 220 \\
\hline Gaza Strip & 970 \\
\hline
\end{tabular}




\begin{tabular}{|c|c|}
\hline Georgia & 995 \\
\hline Germany & 49 \\
\hline Ghana & 233 \\
\hline Gibraltar & 350 \\
\hline Greece & 30 \\
\hline Greenland & 299 \\
\hline Grenada & 1473 \\
\hline Guam & 1671 \\
\hline Guatemala & 502 \\
\hline Guinea & 224 \\
\hline Guinea-Bissau & 245 \\
\hline Guyana & 592 \\
\hline Haiti & 509 \\
\hline Holy See (Vatican City) & 39 \\
\hline Honduras & 504 \\
\hline Hong Kong & 852 \\
\hline Hungary & 36 \\
\hline Iceland & 354 \\
\hline India & 91 \\
\hline Indonesia & 62 \\
\hline Iran & 98 \\
\hline Iraq & 964 \\
\hline Ireland & 353 \\
\hline Isle of Man & 44 \\
\hline Israel & 972 \\
\hline Italy & 39 \\
\hline Ivory Coast & 225 \\
\hline Jamaica & 1876 \\
\hline Japan & 81 \\
\hline Jersey & 44 \\
\hline Jordan & 962 \\
\hline Kazakhstan & 7 \\
\hline Kenya & 254 \\
\hline Kiribati & 686 \\
\hline Kosovo & 381 \\
\hline Kuwait & 965 \\
\hline Kyrgyzstan & 996 \\
\hline Laos & 856 \\
\hline Latvia & 371 \\
\hline Lebanon & 961 \\
\hline Lesotho & 266 \\
\hline
\end{tabular}

\begin{tabular}{|c|c|}
\hline Liberia & 231 \\
\hline Libya & 218 \\
\hline Liechtenstein & 423 \\
\hline Lithuania & 370 \\
\hline Luxembourg & 352 \\
\hline Macau & 853 \\
\hline Macedonia & 389 \\
\hline Madagascar & 261 \\
\hline Malawi & 265 \\
\hline Malaysia & 60 \\
\hline Maldives & 960 \\
\hline Mali & 223 \\
\hline Malta & 356 \\
\hline Marshall Islands & 692 \\
\hline Mauritania & 222 \\
\hline Mauritius & 230 \\
\hline Mayotte & 262 \\
\hline Mexico & 52 \\
\hline Micronesia & 691 \\
\hline Moldova & 373 \\
\hline Monaco & 377 \\
\hline Mongolia & 976 \\
\hline Montenegro & 382 \\
\hline Montserrat & 1664 \\
\hline Morocco & 212 \\
\hline Mozambique & 258 \\
\hline Namibia & 264 \\
\hline Nauru & 674 \\
\hline Nepal & 977 \\
\hline Netherlands & 31 \\
\hline Netherlands Antilles & 599 \\
\hline New Caledonia & 687 \\
\hline New Zealand & 64 \\
\hline Nicaragua & 505 \\
\hline Niger & 227 \\
\hline Nigeria & 234 \\
\hline Niue & 683 \\
\hline Norfolk Island & 672 \\
\hline North Korea & 850 \\
\hline Northern Mariana Islands & 1670 \\
\hline Norway & 47 \\
\hline
\end{tabular}




\begin{tabular}{|c|c|}
\hline Oman & 968 \\
\hline Pakistan & 92 \\
\hline Palau & 680 \\
\hline Panama & 507 \\
\hline Papua New Guinea & 675 \\
\hline Paraguay & 595 \\
\hline Peru & 51 \\
\hline Philippines & 63 \\
\hline Pitcairn Islands & 870 \\
\hline Poland & 48 \\
\hline Portugal & 351 \\
\hline Puerto Rico * & $3(1)$ \\
\hline Qatar & 974 \\
\hline Republic of the Congo & 242 \\
\hline Romania & 40 \\
\hline Russia & 7 \\
\hline Rwanda & 250 \\
\hline Saint Barthelemy & 590 \\
\hline Saint Helena & 290 \\
\hline Saint Kitts and Nevis & 1869 \\
\hline Saint Lucia & 1758 \\
\hline Saint Martin & 1599 \\
\hline Saint Pierre and Miquelon & 508 \\
\hline Saint Vincent and the Grenadines & 1784 \\
\hline Samoa & 685 \\
\hline San Marino & 378 \\
\hline Sao Tome and Principe & 239 \\
\hline Saudi Arabia & 966 \\
\hline Senegal & 221 \\
\hline Serbia & 381 \\
\hline Seychelles & 248 \\
\hline Sierra Leone & 232 \\
\hline Singapore & 65 \\
\hline Slovakia & 421 \\
\hline Slovenia & 386 \\
\hline Solomon Islands & 677 \\
\hline Somalia & 252 \\
\hline South Africa & 27 \\
\hline South Korea & 82 \\
\hline Spain & 34 \\
\hline Sri Lanka & 94 \\
\hline
\end{tabular}

\begin{tabular}{|c|c|}
\hline Sudan & 249 \\
\hline Suriname & 597 \\
\hline Svalbard & 47 \\
\hline Swaziland & 268 \\
\hline Sweden & 46 \\
\hline Switzerland & 41 \\
\hline Syria & 963 \\
\hline Taiwan & 886 \\
\hline Tajikistan & 992 \\
\hline Tanzania & 255 \\
\hline Thailand & 66 \\
\hline Timor-Leste & 670 \\
\hline Togo & 228 \\
\hline Tokelau & 690 \\
\hline Tonga & 676 \\
\hline Trinidad and Tobago & 1868 \\
\hline Tunisia & 216 \\
\hline Turkey & 90 \\
\hline Turkmenistan & 993 \\
\hline Turks and Caicos Islands & 1649 \\
\hline Tuvalu & 688 \\
\hline Uganda & 256 \\
\hline Ukraine & 380 \\
\hline United Arab Emirates & 971 \\
\hline United Kingdom & 44 \\
\hline United States * & $2(1)$ \\
\hline Uruguay & 598 \\
\hline US Virgin Islands & 1340 \\
\hline Uzbekistan & 998 \\
\hline Vanuatu & 678 \\
\hline Venezuela & 58 \\
\hline Vietnam & 84 \\
\hline Wallis and Futuna & 681 \\
\hline West Bank & 970 \\
\hline Western Sahara & 212 \\
\hline Yemen & 967 \\
\hline Zambia & 260 \\
\hline Zimbabwe & 263 \\
\hline
\end{tabular}

* The United States and Puerto Rico have the same country code as Canada (1). Therefore, use 2 for the United States and 3 for Puerto Rico. 
This report contains a comparative, descriptive analysis of the 1577 homicide cases committed in Finland, Sweden and the Netherlands during the years 2003-2006. Differences and similarities have been studied with regards to rates and structural characteristics, giving answers to the questions of where, when and how homicide takes place as well as who the victims and perpetrators are.

Comparisons have been made possible due to the creation of a joint database on lethal violence among the three countries containing information about each case on both incident and individual level. By combining these data, the foundations for a joint database on lethal violence among multiple European countries, here termed the European Homicide Monitor (EHM), has been created. The EHM provides a unique data source for research and could help both policy targeting and evaluating what works in homicide prevention.

The project is financed by the EU and is a collaboration between the National Research Institute of Legal policy in Finland, the Institute of Criminology and Criminal Law of Leiden University in the Netherlands and the National Council for Crime Prevention in Sweden (lead partner). 